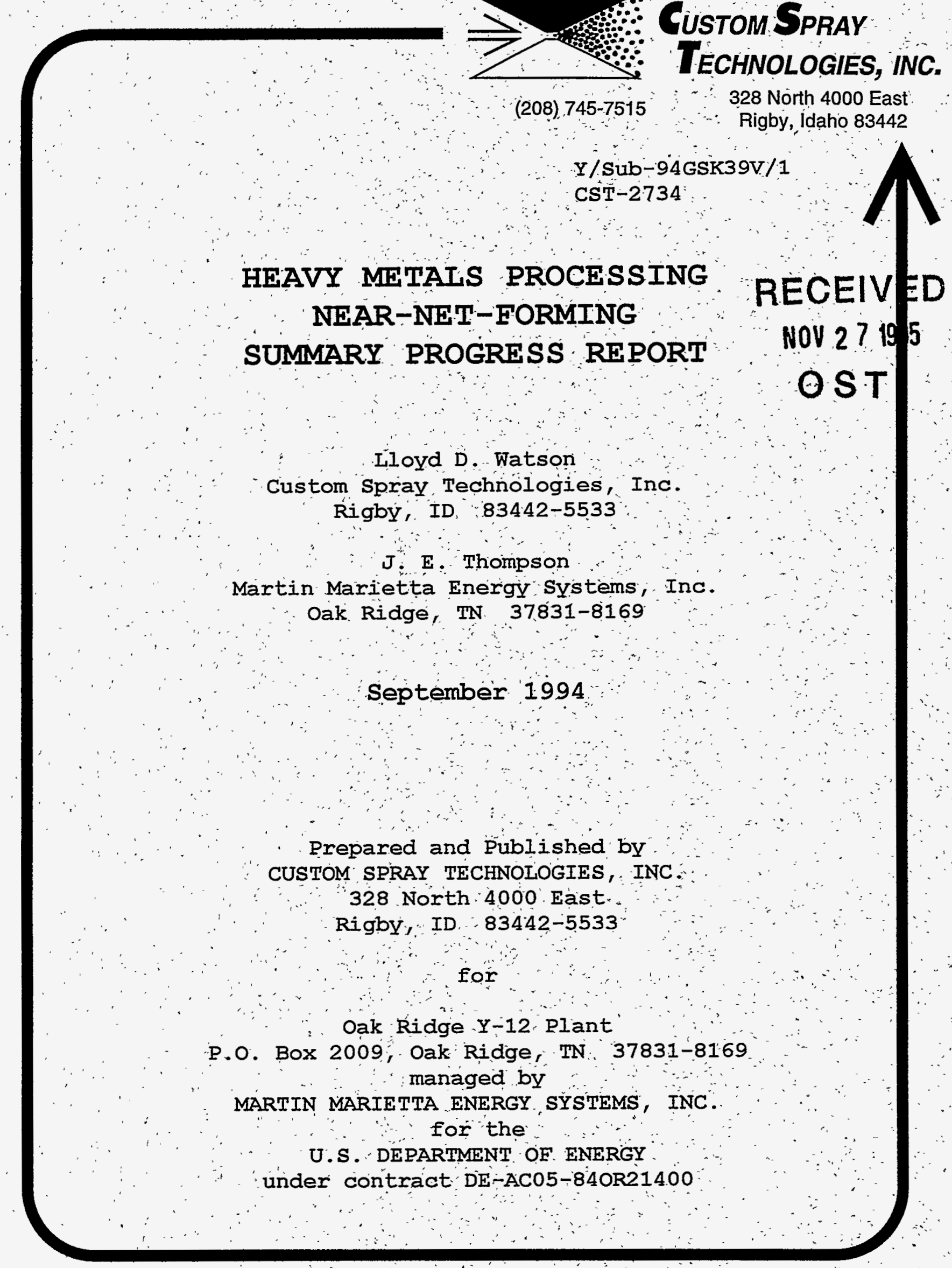


This report was prepared as an account of work sponsored by an ajency of the united states Government: Neither the United states Government nor any agency thereof no any of their èmployes, makes any wanranty express or implied, or ássumes ary legal liability or. responsibility ifor the ácuracy completeness, "or usefulness of any information, apparatus, product, or process disclosed, or represents that its use would hot infringe privately owned rights " Reference herên to any specitic commercial product, pracess or service by trade name, trademark manufacturér or otherwise, does not necessarily constitute or imply its endorsement recommendation, "or favoring by the united states Government or any agency theréf. The views ahdopinions of authors expressed herein do not necessarily, state or reflect those of the united states Government or any agency thereof. 
Y/Sub-94GSK39V/I

CST-2734

\title{
HEAVY METALS PROCESSING NEAR-NET-FORMING SUMMARY PROGRESS REPORT
}

\author{
Lloyd D. Watson \\ Custom Spray Technologies, Inc. \\ Rigby, ID 83442-5533 \\ J. E. Thompson \\ Martin Marietta Energy Systems, Inc. \\ Oak Ridge, TN 37831-8169
}

September 1994

\footnotetext{
Prepared and Published by CUSTOM SPRAY TECHNOLOGIES, INC.

328 North 4000 East

Rigby, ID 83442-5533

for

Oak Ridge Y-12 Plant

P.O. Box 2009, Oak Ridge, TN 37831-8169

managed by

MARTIN MARIETTA ENERGY SYSTEMS, INC.

for the

U.S. DEPARTMENT OF ENERGY

under contract DE-AC05-84OR21400
}

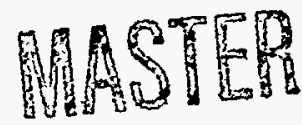

OISTRLUTION OF TIIIS DOCUMENT IS LAULATED 
EXECUTIVE SUMMARY $\ldots \ldots \ldots \ldots \ldots \ldots \ldots \ldots \ldots \ldots \ldots \ldots \ldots \ldots$

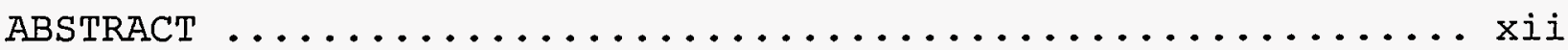

1. INTRODUCTION $\ldots \ldots \ldots \ldots \ldots \ldots \ldots \ldots \ldots \ldots \ldots \ldots \ldots \ldots \ldots$

1.1 OBJECTIVES $\ldots \ldots \ldots \ldots \ldots \ldots \ldots \ldots \ldots \ldots \ldots \ldots \ldots \ldots \ldots \ldots \ldots \ldots$

1.2 BACKGROUND $\ldots \ldots \ldots \ldots \ldots \ldots \ldots \ldots \ldots \ldots \ldots \ldots \ldots \ldots \ldots \ldots \ldots$

1.3 WORK SCOPE $\ldots \ldots \ldots \ldots \ldots \ldots \ldots \ldots \ldots \ldots \ldots \ldots \ldots \ldots \ldots \ldots \ldots$

1.3.1 Phase I: High-Density Experiments ........ 6

1.3.2 Phase I-Addendum I: Reactivity Experiments . 6

1.3.3 Extended Surrogate Alloy Experiments ...... 7

1.4 TASK DESCRIPTION $\ldots \ldots \ldots \ldots \ldots \ldots \ldots \ldots \ldots \ldots \ldots$

2. SPRAY SYSTEM COMPONENTS AND CONFIGURATIONS ........ 10

2.1 METAI SPRAY SYSTEM $\ldots \ldots \ldots \ldots \ldots \ldots \ldots \ldots \ldots \ldots \ldots \ldots \ldots$

2.2 CONTROL AND MEASUREMENT ELECTRONICS .......... 13

2.3 NOZZLE SUPPLY GAS HEATERS $\ldots \ldots \ldots \ldots \ldots \ldots \ldots \ldots \ldots$

2.4 NOZZLE/FURNACE ASSEMBLY ................ 15

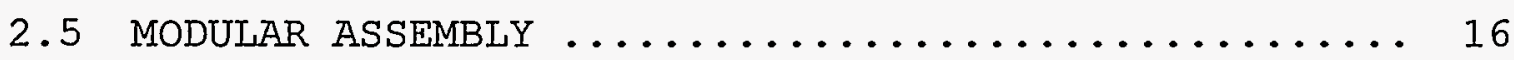

2.6 SUBSTRATE CONEIGURATIONS $\ldots \ldots \ldots \ldots \ldots \ldots \ldots \ldots \ldots \ldots$

2.7 SPRAY NOZZLE $\ldots \ldots \ldots \ldots \ldots \ldots \ldots \ldots \ldots \ldots \ldots \ldots \ldots \ldots \ldots$

3. INTEGRATED SYSTEM PERFORMANCE $\ldots \ldots \ldots \ldots \ldots \ldots \ldots \ldots$

3.1 INDUCTION POWER - LOSSES TO COOLING WATER ....... 20

3.2 INDUCTION POWER - INTERNAL ELECTRONIC COOLING .... 21

3.3 INTEGRATED SYSTEM CHECKOUT ............... 21

3.4 PRESPRAY DATA COMPARISONS ............... 23 
CONTENTS (Cont'd)

Page

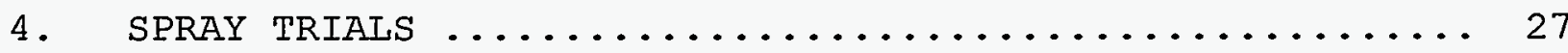

4.1 PLUME HEAT CAPACITY ..................... 29

4.2 EXPERIMENTS UTILIZING GRAPHITE SUBSTRATES $\ldots \ldots \ldots \ldots \quad 34$

4.2.1 Graphite Rod With Coatings ............. 34

4.2.1.1 Substrate Preparation ............ 34

4.2.1.2 Melting Considerations .......... 35

4.2.1.3 Spray Period - Graphite Rod ....... 38

4.2.2 Graphite Plate with Coatings ........... 40

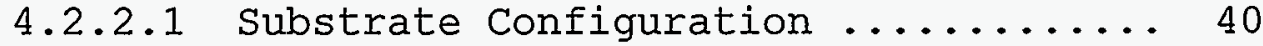

4.2 .2 .2 Spray Trial ................ 41

4.3 COLLECTION OF POTENTIALLY AIRBORNE PARTICLES .... 41

4.3.1 Description of Sampling Arrangement ....... 42

4.3.2 Cascade Impactor Collections ............. 42

4.3.3 Results From Cascade Impactor Collections .. 42

4.3.4 Airborne Particulate Generated ........... 43

5. AS-SPRAYED PRODUCT - SAMPLE ANALYSES ............ 44

5.1 OVERSPRAY $\ldots \ldots \ldots \ldots \ldots \ldots \ldots \ldots \ldots \ldots \ldots \ldots \ldots \ldots$

5.2 PLUME COLLECTIONS ................... 45

5.3 GRIT BLASTED CARBON STEEL TUBE ............. 45

5.3.I First Carbon Steel Tube ............... 45

5.3.2 Second Carbon Steel Tube .............. 48

5.4 MACHINED GRAPHITE ROD WITH COATINGS $\ldots \ldots \ldots \ldots \ldots \ldots .55$

5.5 MACHINED GRAPHITE PLATE WITH COATINGS ......... 55

5.5 .1 Effects on Coating Materials ........... 56

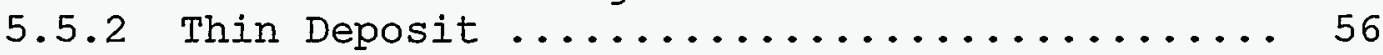

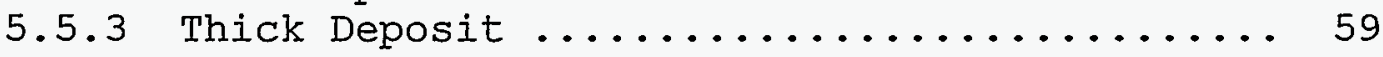

6. FINDINGS AND CONCLUSIONS $\ldots \ldots \ldots \ldots \ldots \ldots \ldots \ldots \ldots \ldots \ldots \ldots$ 
CONTENTS (Cont'd)

Page

6.1 POWDER ANALYSES $\ldots \ldots \ldots \ldots \ldots \ldots \ldots \ldots \ldots \ldots \ldots \ldots \ldots$

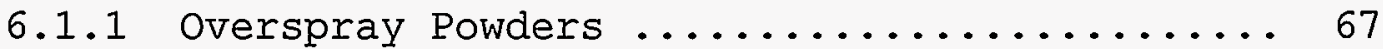

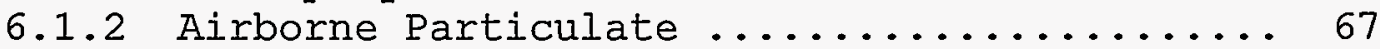

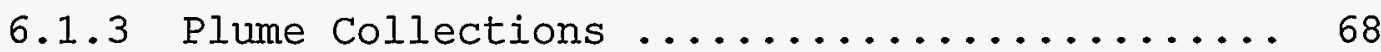

6.2 COMPONENT CERAMICS ................... 68

6.3 SPRAY NOZZLE PERFORMANCE $\ldots \ldots \ldots \ldots \ldots \ldots \ldots \ldots \ldots \ldots$

6.4 AS-SPRAYED PRODUCT PROPERTIES .............. 69

6.4.1 First Grit Blasted Carbon Steel Tube ...... 69

6.4 .2 Second Grit Blasted Carbon steel Tube ...... 69

6.4.3 Consolidation on Coated

and Uncoated Graphite ................ 70

6.4.4 Thin Deposit on Machined Graphite ......... 70

6.4 .5 Thick Deposit on Machined Graphite ....... 70

6.4 .6 Summary Status ................... 71

6.5 EXCHANGE OF TECHNICAL INFORMATION/

TECHNOLOGY TRANSFER .................. 71

7. REFERENCES .......................... 73

APPENDIXES

A: EXPERIMENTAL PLAN ................... 74

B: CASCADE IMPACTOR DATA ................. 81

C: SPRAY TRIAL DATA ..................... 97 


\section{FIGURES}

Page

1. Schematic of Spray system ................... 10

2. Major Components of Spray System ............... 12

3. Chamber Housing ......................... 12

4. Molybdenum Gas Heater with Heating Coil ............ 14

5. Graphite Gas Heater with Heating Coil ............. 14

6. Cross Section of Nozzle/Furnace Assembly ........... 15

7. Modular Assembly ........................ 17

8. Cross Section of Circular Converging/Diverging Nozzle .. 18

9. Characterization Curve - Converging/Diverging Nozzle ... 18

10. Parametric Readings for a system Heatup ............ 22

11. Equilibrium Temperatures of Coolant for Internal Electronics of the Induction Power Supply Units ...... 24

12. Equilibrium Temperatures of Cooling Water Exiting the Gas Heater and Furnace Load Coils ............. 24

13. Component Temperature Comparisons during System Heatup ....................... 25

14. Comparison Temperatures for Argon Supply Heating ..... 26

15. Spray Trial Measurements ..................... 30

16. First Spray Period ...................... 31

17. Second Spray Period ...................... 32

18. Final Spray Period ....................... 33

19. Melt Temperature ......................... 35

20. Effect on Melt Temperature Due to Incrementing Mass .... 36

21. Graphite Rod Spray Trial Parameters .............. 39 
FIGURES (Cont'd)

Page

22. Parametric Recordings ..................... 40

23. Overspray from Chamber Floor, $100 x \ldots \ldots \ldots \ldots \ldots . \ldots 46$

24. Overspray from Chamber Floor, $10,000 x \ldots \ldots \ldots \ldots . \ldots 46$

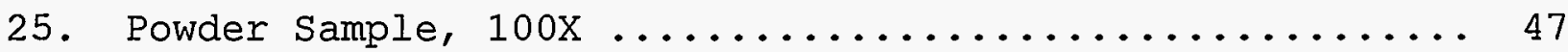

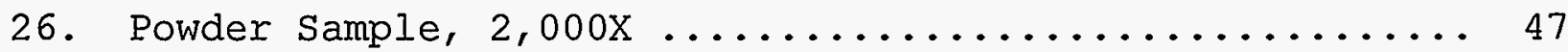

27. Grit Blasted Carbon Steel Tube, 500x ............ 49

28. EDS Spots, Grit Blasted Carbon Steel Tube, 500X ...... 49

29. Section of Substrate Tube with

As-Sprayed Product, $0.97 \mathrm{x} \ldots \ldots \ldots \ldots \ldots \ldots \ldots \ldots \ldots . \ldots \ldots$

30. Cross Section of As-Sprayed Material on

Substrate Tube, $4.3 \mathrm{X} \ldots \ldots \ldots \ldots \ldots \ldots \ldots \ldots \ldots \ldots \ldots$

31. Illustration - Sample Layer Boundaries ............ 54

32. Mo Coating, $100 \mathrm{x} \ldots \ldots \ldots \ldots \ldots \ldots \ldots \ldots \ldots \ldots \ldots \ldots \ldots \ldots \ldots \ldots \ldots$

33. $\mathrm{ZrO}_{2}$ Coating, $500 \mathrm{x} \ldots \ldots \ldots \ldots \ldots \ldots \ldots \ldots \ldots \ldots \ldots \ldots \ldots \ldots \ldots \ldots$

34. $\mathrm{Y}_{2} \mathrm{O}_{3}$ Coating, $1,000 \mathrm{X} \ldots \ldots \ldots \ldots \ldots \ldots \ldots \ldots \ldots \ldots \ldots \ldots \ldots$

35. Section 2, EDS Spots, $40.0 \mathrm{X} \ldots \ldots \ldots \ldots \ldots \ldots \ldots \ldots \ldots . \ldots \ldots$

36. Section 4, EDS Spots, $20.0 \mathrm{X} \ldots \ldots \ldots \ldots \ldots \ldots \ldots \ldots \ldots \ldots$

37. Section 4, Area 5, EDS Spots, 2,000X ............ 61

38. Spray Trial 8, Thick Deposit, 4.5x ............. 61

39. Spray Trial 8, BSE Image, $100 x \ldots \ldots \ldots \ldots \ldots \ldots \ldots \ldots \ldots \ldots \ldots$

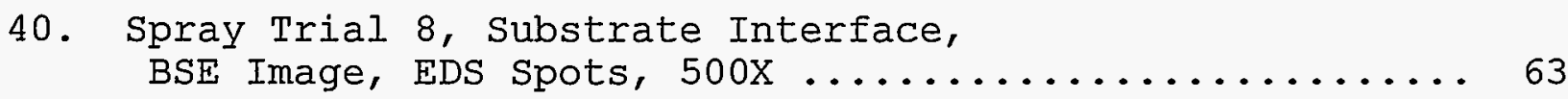

41. Spray Trial 8, Layer 1-2 Interface, $500 x \ldots \ldots \ldots \ldots 64$

42. Spray Trial 8, Area Raster 1, 2,000x ............ 66 
43. Spray Trial 8, Area Raster 2, 2,000x ........... 66

44. Magnification of Collection Plate Depicting Surrogate Alloy Particulate (Stage 2-1) ........... 83

45. Magnification of Collection Plate Depicting Nonmetal Particulate (Stage 2-2) .............. 84

46. Magnification of Collection Plate Depicting Surrogate Alloy Particulate (Stage 3-1) .......... 85

47. Magnification of Collection Plate Depicting Nonmetal Particulate (Stage 3-2) ............. 86

48. Magnification of Collection Plate Depicting Surrogate Alloy Particulate (Stage 4-1) .......... 87

49. Magnification of Collection Plate Depicting Nonmetal Particulate (Stage 4-2) $\ldots \ldots \ldots \ldots \ldots \ldots \ldots 88$

50. Magnification of Collection Plate Depicting Surrogate Alloy Particulate (Stage 5-1) ........... 89

51. Magnification of Collection Plate Depicting Nonmetal Particulate (Stage 5-2) .............. 90

52. Magnification of Collection Plate Depicting Surrogate Alloy Particulate (Stage 6-1) ........... 91

53. Magnification of Collection Plate Depicting Nonmetal Particulate (Stage 6-2) ............... 92

54. Magnification of Collection Plate Depicting Surrogate Alloy Particulate (Stage 7-1) ........... 93

55. Magnification of Collection Plate Depicting Nonmetal Particulate (Stage 7-2) ............... 94

56. Magnification of Collection Plate Depicting Surrogate Alloy Particulate (Filter-1) ........... 95

57. Magnification of Collection Plate Depicting Nonmetal Particulate (Filter-2) ............... 96

58. Spray Trial 8, Period 11, Area 5 (Sect. 5.5.3) ...... 101 viii 
FIGURES (Cont'd)

Page

59. Spray Trial 8, Period 11, Area 6 (Sect. 5.5.3) ...... 101

60. Spray Trial 8, Period 11, Area 7 (Sect. 5.5.3) ..... 102

61. Spray Trial 8, Period 11, Area 8 (Sect. 5.5.3) ...... 102

62. Spray Trial 8, Period 11, Spot Locations .......... 103

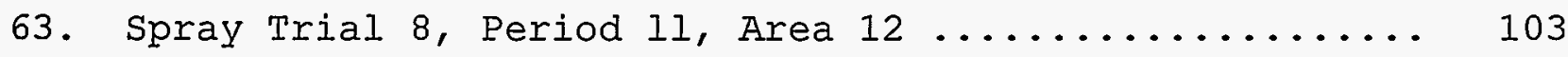

64. Spray Trial 8, Period 11, Area $13 \ldots \ldots \ldots \ldots \ldots \ldots \ldots . \ldots . \ldots$

65. Spray Trial 8, Period 11, Area $14 \ldots \ldots \ldots \ldots \ldots \ldots . \ldots . \ldots . \ldots$

66. Spray Trial 8, Period 1l, Area $15 \ldots \ldots \ldots \ldots \ldots \ldots . \ldots . \ldots . \ldots$

67. Spray Trial 8, Period 11, Area $16 \ldots \ldots \ldots \ldots \ldots \ldots$ 


\section{TABLES}

Page

1. Parametric Summary - CST2734 Spray Trials .......... 28

2. Spot Analysis Data - Iron \& Tungsten Enrichment ...... 50

3. Diamond Pyramid Number (Vickers) ................ 51

4. Weight Percent Composition Summary .............. 60

5. Cascade Impactor, Particle Analysis, Stage 2-1 ...... 83

6. Cascade Impactor, Particle Analysis, Stage 2-2 ...... 84

7. Cascade Impactor, Particle Analysis, Stage 3-1 ....... 85

8. Cascade Impactor, Particle Analysis, Stage 3-2 ...... 86

9. Cascade Impactor, Particle Analysis, Stage 4-1 ...... 87

10. Cascade Impactor, Particle Analysis, Stage 4-2 ...... 88

11. Cascade Impactor, Particle Analysis, Stage 5-1 ...... 89

12. Cascade Impactor, Particle Analysis, Stage 5-2 ...... 90

13. Cascade Impactor, Particle Analysis, Stage 6-1 ...... 91

14. Cascade Impactor, Particle Analysis, Stage 6-2 ...... 92

15. Cascade Impactor, Particle Analysis, Stage 7-1 ...... 93

16. Cascade Impactor, Particle Analysis, Stage 7-2 ...... 94

17. Cascade Impactor, Particle Analysis, Filter-1 ....... 95

18. Cascade Impactor, Particle Analysis, Filter-2 ....... 96

19. Parametric Summary - Spray Trials 1-6 ............. 99

20. Parametric Summary - Spray Trials 7-10 ............ 100 


\section{EXECUTIVE SUMMARY}

U.S. Department of Energy facilities responsible for processing heavy metals continue to evaluate advanced technologies that simplify component fabrication, reduce handling steps, and minimize final machining.

One advanced technology processing technique, under development at Custom spray Technologies, Inc. (CST), is near-net shape spray forming. CST, under subcontract to Martin Marietta Energy systems, Inc. (MMES), has focused its efforts on developing a process that could be automated to reduce personnel risk, provide a net-formed product, minimize radioactive contaminated waste material, and release no contaminants to the atmosphere.

The Program's initial activities consisted of three distinct phases of spray forming investigation. Phase I efforts confirmed the viability of spraying high-density metals at the temperature range of interest (i.e., between $1300^{\circ} \mathrm{C}$ and $1500^{\circ} \mathrm{C}$ ). Subsequent to completion of this work, a restructuring of defense-related program budgets resulted in a reassessment of reactivity experiments initially planned for Phase II. As a result of this reassessment, the Program at CST was revised for a more narrow scope. In this revision, reactivity experiments were conducted using aluminum and irontungsten alloys. These experiments were performed as an addendum to Phase $I$ and were conducted in the Phase I spray chamber. The construction of the high-purity chamber was deleted from the Program, along with Phase III planned activities. The effort to spray net shapes was also deleted and replaced with Extended Surrogate Alloy Experiments.

This Summary Progress Report presents the results and conclusions of the Extended Surrogate Alloy Experiments. The alloy used during these spray trials was furnished by MMES; the weight percent composition given was $49.6 \%$ iron, 49.6\% tungsten, and $0.8 \%$ carbon. After modifications to the spray system were completed, 6.2 $\mathrm{kg}$ (14 lb) of the surrogate alloy were sprayed in ten spray trials. This large sample base was spray-formed using gas-to-metal mass ratios ranging from $0.8: 1$ to $4: 1$. Metallography on some samples revealed areas that were fully dense and homogeneous at 5,000x. These areas averaged grain sizes of $1 \mu \mathrm{m}$ diameter. Other samples when viewed at 2,000X were highly segregated in the $10 \mu \mathrm{m}$ diameter range. Examination of discharge gases identified airborne particulates generated by the spray process and established that these particulates could be measured. Program efforts confirmed the feasibility of spray forming to fabricate materials from highdensity, reactive metals. 


\section{ABSTRACT}

The Extended Surrogate Alloy Experiments utilized a convergingdiverging nozzle to spray-form an alloy having a weight percent composition of $49.6 \%$ iron, $49.6 \%$ tungsten, and $0.8 \%$ carbon into samples for analysis.

The alloy was provided by MMES as a surrogate alloy that displays metallurgical characteristics similar to the alloys used in the heavy metals processing industry. U.S. Department of Energy facilities are evaluating advanced technologies which can simplify component fabrication, reduce handling steps, and minimize final machining.

The goal of producing net-shaped components can be approached from several directions. In spray forming, molten metal is converted by a nozzle into a plume of fine droplets which quickly cool in flight and solidify against a substrate. The near-final dimension product that is formed receives additional benefits from rapid solidification. This single-step processing approach would aid the heavy metals industry by streamlining fabrication, improving production yields, and minimizing the generation of processing wastes.

This Program effort provided a large selection of as-sprayed specimens. These samples were sprayed with gas-to-metal mass ratios ranging from $0.8: 1$ to $4: 1$. Samples targeted for analysis were produced from different spray conditions. Metallography on some samples revealed areas that were fully dense and homogeneous at 5,000X. These areas averaged grain sizes of $1 \mu \mathrm{m}$ diameter. Other samples when viewed at 2,000X were highly segregated in the $10 \mu \mathrm{m}$ diameter range. Deposit efficiencies of greater than $90 \%$ were demonstrated using the untailored spray system. Discharge gases were analyzed and two categories of particles were identified. One category of particle had a chemical composition characteristic of the alloy being sprayed and the second type of particle had a chemical composition characteristic of the ceramics used in the spray system component fabrication. Particles ranged in size from 0.07 to $3 \mu \mathrm{m}$ in diameter. 


\section{INTRODUCTION}

U.S. Department of Energy facilities responsible for processing heavy metals are under increasing pressure to modernize operations, increase process yields, and minimize generation of radioactive contaminated wastes. As a result of these pressures, advanced technologies are being evaluated that simplify component fabrication, reduce handling steps, and minimize final machining.

One advanced technology processing technique, under development at Custom Spray Technologies, Inc. (CST), is near-net shape spray forming. CST, under subcontract to Martin Marietta Energy systems, Inc. (MMES), has focused its efforts on developing a process that could be automated to reduce personnel risk, provide a net-formed product, minimize radioactive contaminated waste material, and release no contaminants to the atmosphere.

\subsection{OBJECTIVES}

Originally, the research program to study the feasibility of the patented Controlled Aspiration Process (CAP) was comprised of three experimental phases.

- Phase I consisted of efforts to determine the feasibility of spraying high-density metals. Molten gold was sprayed to simulate the melting points, fluid densities, and heat capacities of high-density alloys.

- Phase II would have embodied the spraying of net-formed, aluminum-iron alloys in a high-purity spray chamber to verify negligible contamination by reactive gases.

- Phase III of the Program would have involved the installation of a high-purity chamber at the MMES facility in Oak Ridge, Tennessee and would have included training requirements for personnel on its operation.

The first two phases of the Program were designed to investigate three key, sequential areas to evaluate the technical feasibility of spray forming heavy metals. The first evaluation involved spraying fine-grain, low-porosity, high-density metals onto a substrate. The second study investigated the ability to spray chemically reactive metals with a negligible introduction of gaseous impurities, and the final test would have involved spraying hemispherical net-shapes with a high melt-to-deposit conversion efficiency. 
The intended end product was the development of a system to process heavy metal alloys into various usable structures with minimal losses and zero emissions of impurities into the environment. The results from each area of study were carefully reviewed prior to proceeding to the next task. These bench mark decisions ensured that funds were judiciously and economically expended and that endeavors were firmly justified to prevent the continuation of work prematurely.

Subsequent to the completion of the Phase I Summary Progress Report, a restructuring of defense-related program budgets resulted in a reassessment of reactivity experiments initially planned for Phase II. As a result of the reassessment, the Program at CST was revised for a more narrow scope. In this revision, reactivity experiments were conducted using aluminum (Al) and iron-tungsten (Few) alloys. These experiments were performed as an addendum to Phase $I$ and were conducted in the Phase I spray chamber. The construction of the high-purity chamber was deleted from the Program, along with phase III planned activities. The effort to spray net shapes was also deleted and replaced with Extended Surrogate Alloy Experiments.

Statements of Work for Addendum I and the Extended Surrogate Alloy Experiments also factored in the exchange of technical information and technology transfer efforts. Through a Memorandum of Understanding (MOU) between the Department of Energy (DOE) and the United States Air Force (USAF), technical results of the work being conducted at CST were shared with MSE, Inc. MSE was also conducting spray-forming work for DOE. In recognition of the MOU, this exchange of technical assistance was entered into to promote efforts specific to advancing spray-forming technology. In concert with supporting and participating in this technical exchange effort, CST identified opportunities for MMES technology transfer of spray forming for private industry (Ref. 1).

This report presents the findings and conclusions of the Extended Surrogate Alloy Experiments, including plume and product analyses. Metallography data cited within this report were provided and approved for reprint by EG\&G Idaho, Inc. Previous reports on this Program include: "Summary Progress Report, Phase I: High-Density Trials, SCIE-ORNL-101-92", Phase I - Addendum I Draft Reports entitled, "Reactivity Experiments, CST-2283", and "Surrogate Alloy Experiments, CST-2353".

\subsection{BACKGROUND}

The goal of producing net-shaped components can be approached from several directions, including one emerging technique--spray forming. In spray forming, molten metal is converted by a nozzle 
into a plume of fine droplets which quickly cool in flight before solidifying against a substrate. Besides providing components in near-final dimensions in an economical single-step operation, spray forming receives additional benefits from rapid solidification. As a result of rapid solidification, superior mechanical properties can be consistently achieved in sprayed components (Ref. 2), while concurrently satisfying the critical objectives of minimizing wastes, streamlining fabrication, and improving production yields.

The spray-forming process aspirates molten metal from an integral reservoir (i.e., tundish) through a small-diameter liquid orifice into the throat of a converging/diverging nozzle (Refs. 3 and 4). There, a flow of inert gas nebulizes the incoming metal stream into a plume of fine droplets and accelerates the droplets toward a substrate. The droplets impact the substrate before completely solidifying. Under suitable operating conditions, metal droplets consolidate into a strong deposit of high-purity, lowporosity material (Ref. 5).

Because of their high surface area-to-volume ratios, the tiny droplets cool very rapidly in flight by radiation and convection. Droplets can arrive at the substrate in a variety of conditions. These conditions can range from molten, superheated droplets to partially solidified droplets (i.e., molten cores surrounded by solid crusts) with an average temperature near the metal's melting point, to fully liquid undercooled droplets well below the melting point. The actual situation depends upon the droplet size distribution and the metal's heat capacity and thermal conductivity, along with other variables such as melt superheat, nebulizing gas temperature, gas-to-metal mass ratio, and droplet flight time.

The droplets deform into pancake-shaped splats upon impacting the substrate, whereupon residual heat is primarily removed by conduction into the substrate. Solidification rates can be extremely rapid for splats from partially solidified droplets and undercooled droplets. Rapid solidification effectively freezes the homogeneous composition of the molten metal which can improve the mechanical properties in several respects; e.g., (1) Impurities cannot cluster into inclusion defects, (2) Precipitation of metallurgical phases during cooldown is confined to small particles uniformly dispersed throughout the matrix, and (3) When the substrate provides an ample heat sink, little opportunity exists for equiaxed grain growth. In most metals, important properties such as yield strength and ultimate tensile strength are inversely proportional to the square root of grain size.

The patented CAP makes use of a converging/diverging nozzle whereby flow of molten metal into the nozzle throat is jointly 
governed by suction present at the liquid orifice and the liquid metal's kinematic viscosity (Ref. 6). Contributions from the height of molten metal in a shallow tundish are minor by comparison to suction effects even for high-density metals. CAP nozzles are designed to provide suction over a limited range of upstream gas pressures with a broad maximum at a certain operating pressure. This unique CAP feature not only permits turning the nebulizer on and off with a simple pressure regulator, but it also enables continuously adjusting the aspiration rate and the gas-to-metal mass ratio in the spray plume. Droplet cooling rates can thus be optimized enabling flexible parameter control to account for varying process requirements.

Another method of affecting droplet cooling rates is altering the gas temperature entering the nozzle. Melt superheat is controlled primarily by the heat of the nozzle body and tundish, along with an auxiliary melting furnace for large metal charges. Heat transfer rates from droplets to the substrate and the associated extent of splat consolidation can further be influenced by preheating the substrate or by supplying additional cooling to the substrate during deposition. All component temperatures in a CAP spray-forming system can be carefully adjusted to afford maximum flexibility in choice of operating parameters for meeting specific product requirements (Ref. 7).

An additional virtue of the CAP technique is the shaping of the spray plume. In other versions of spray forming, a hole in a crucible base forms a liquid stream that is nebulized by concentric gas jets immediately below the crucible. Melt stream breakup is inefficient and incomplete here, by comparison to gas shearing in the confined interaction zone provided by a converging/diverging nozzle throat. Concentric nozzles thus create a plume with larger droplets concentrated near the plume center, resulting in deposits with a pronounced Gaussian shape. Most of the heat flux is also biased toward the plume center, which inhibits rapid solidification in the crowned portion of the deposit. Meanwhile, the smaller droplets found around the plume periphery tend to solidify preferentially. These are the first droplets to impact a moving substrate or mold, and they often form a porous "chill zone" in the deposit at the substrate interface that must be machined off later.

A circular converging/diverging nozzle also produces a deposit with tapered edges. However, CAP designs can be tailored to govern the spatial distributions of mass and thermal flux in the plume (Ref. 8). The extent of plume expansion is determined pri- marily by the exit cone contour, but upstream gas pressure can also be adjusted to focus or defocus the plume. Furthermore, efficient breakup in the nozzle throat tends to yield narrowly distributed droplet sizes that do not change between the plume center and 
periphery. In the CAP approach, equal solidification rates among the nearly identical splats ensure consistent deposit microstructures.

A final important feature of spray forming for fabricating net shapes using highly reactive alloys is an inert environment. Spraying can be conducted inside a sealed chamber to prevent chemical reactions with gaseous contaminants, and an inert gas can be used to nebulize the molten metal and purge the spray chamber. Argon gas has been used most often in CAP systems for this dual purpose.

The ability to completely enclose the entire process is well suited for fabricating components using high-density, reactive metals. The sealed chamber naturally isolates personnel from sources of contamination and electrical and particulate hazards. Chamber exhaust gas can be filtered thoroughly, such that minimal, if any, detectable airborne particles are released to the external environment. Furthermore, under optimal conditions, over 99\% of the sprayed droplets are successfully consolidated into the deposit. The small amounts of unconsolidated overspray are extensively diluted by the flow of purging gas. Volumetric concentrations of loose particulates within the chamber are orders of magnitude below the threshold for pyrophoric and explosive hazards, in the event of an accidental ingress of oxygen. Data from previously conducted experiments indicated low concentrations of overspray powders. Section 4.3 addresses the collection of potentially airborne particles.

In combination, these features provide considerable assurance that even spray forming of hazardous material would be a safe, environmentally benign fabrication process.

\subsection{WORK SCOPE}

Research and development activities were planned to sequentially confirm the feasibility of spray forming high-density, reactive metals in three critical areas:

(1) Demonstrate nozzle performance in high-density materials by producing as-sprayed, fine-grained, low-porosity articles.

(2) Determine the sensitivity of the spray-forming process to oxygen contamination near the substrate surface.

(3) Analyze as-sprayed material in a surrogate iron-tungsten alloy which possesses many of the metallurgical anomalies, such as alloy segregation, found in materials of interest. 
Measurements recorded during these spray trials approximate overspray and determine the kinds of particulate that might be found in the discharge gases from the spray system.

\subsubsection{Phase I: High-Density Experiments}

Gold was used to demonstrate nozzle performance in highdensity materials. Gold has a density of $19.3 \mathrm{~g} / \mathrm{cm}^{3}$ at room temperature and a melting point of $1065^{\circ} \mathrm{C}$. An added advantage to using gold was its relatively low reactivity with all elements, even at elevated temperatures. Because of these characteristics, conclusions about nozzle performance in relationship to the density of the material could be postulated.

Upon determining that gold could be effectively nebulized under various spray conditions, $17 \mathrm{w} / 0$ (weight percent) manganese was alloyed with the gold. This provided an alloy which would normally segregate under most cooling conditions.

The products produced in Phase I had the approximate shape of a 50 cent piece. With time and funding available, the system performance was improved from producing samples with porosity in the $12 \%$ range to producing samples with porosity in the 1 to $2 \%$ range. Photomicrographs revealed fine dendritic microstructure in the as-sprayed material. Chemical analysis of the as-sprayed goldmanganese alloy demonstrated the sample material was homogeneous within the limits of the scanning electron microscope/energy dispersive X-ray spectrometry (SEM/EDS) unit. Detailed discussion is included in "Summary Progress Report, Phase I: High-Density Trials, SCIE-ORNL-101-92".

\subsubsection{Phase I - Addendum I: Reactivity Experiments}

To demonstrate the sensitivity of the process to the spray environment, pieces of construction grade aluminum (alloy 6061) were melted and sprayed. Spray system components were fabricated from graphite. The system was operated at elevated superheat temperatures to increase the likelihood of oxidation. Atmospheres of $2 \%$, 5\%, and $10 \%$ oxygen were provided near the substrate surface using cover gases. Chemical analysis, using EDS, was performed on the as-sprayed material for the $2 \%$ and $10 \%$ spray trials. The results of these analyses did not reveal a difference in the oxide contamination in the as-sprayed material. This was encouraging since the oxygen level of the spray environment differed by a factor of five.

With the positive results from the aluminum spray trials, a surrogate alloy was introduced. The composition was $49.6 \mathrm{w} / 0$ iron, $49.6 \mathrm{w} / 0$ tungsten, and $0.8 \mathrm{w} / 0$ carbon. The new alloy had an 
increased density due to the tungsten and served as a reactive component with oxygen. The melting point was considerably higher and metallurgical anomalies, such as alloy segregation, were exhibited that simulate some of the problems in the current heavy metals processing methods.

During the Phase I - Addendum I spray trials, it was determined that the rapid solidification that occurs when using spray forming provides a process that is relatively insensitive to the reactive gases around the net-formed product. The surrogate alloy could be sprayed using machinable ceramics for the spray component assemblies, however, the wear factor would be quite high. Detailed discussions are included in Phase I - Addendum I Draft Reports entitled, "Reactivity Experiments, CST-2283", and "Surrogate Alloy Experiments, CST-2353".

\subsubsection{Extended Surrogate Alloy Experiments}

The objectives for this portion of the Program were to provide a large selection of as-sprayed products to determine what kinds of metallurgical properties were present in the as-sprayed, surrogate alloy; identify the type of powder accumulations that would occur in the chamber area; and determine whether particles could be identified in the discharge gases. This report describes the activities and results of the Extended Surrogate Alloy Experiments.

\subsection{TASK DESCRIPTION}

This Program effort was organized into the following tasks.

\section{Task 1: $\quad$ System Configuration and Modification}

- Add additional temperature indicators for substrate monitoring.

- Provide overspray collections.

- Optimize substrate configuration.

- Configure Data Acquisition system (DAS) for additional apparatus.

Task 2: $\quad$ Spray Trials with Surrogate Alloy

- Determine the spray rate of the current nozzle design. Use the information from these runs to determine substrate temperature and thickness for producing samples for analyses. 
- Conduct controlled spray runs to produce a selection of samples. Perform preliminary evaluations and select a set of these samples for further analyses.

Vary nozzle design to optimize performance and increase production rate; determine appropriate substrate material, thickness of substrate, and surface texture for optimum samples; and preheat substrate surface.

- Conduct a second, controlled set of spray runs to produce another selection of samples. These samples will be evaluated and a selection sent for analyses.

Task 3: Plume and Product Analyses by Powder Collection from Nozzles

- Collect samples from within the spray plume with Cascade Impactors for particle distribution analyses. Use SEM photos of impactor stages to confirm size and shape.

- Collection of particles using cyclones and/or liquid argon reservoirs for plume characterization and product evaluation.

Task 4: Exchange of Technical Information

- Exchange of technical information between the Seller and MMES based on the results of the spray trials with the surrogate alloy, and the plume and product analyses by powder collection from nozzles.

- Coordinate the choice of substrate with MMES.

- Submit Monthly Status Reports to MMES.

Task 5: Technology Transfer

- Identify possible opportunities for technology transfer of spray-casting technology developed in this spray-casting effort with private industry.

- Submit Monthly Status Reports to MMES. 
Task 6: Final Report

- Combine the results and conclusions in Tasks 1 - 5 into a final report format.

- Submit a final report following customer review and approval.

Weekly Progress Reports were also submitted to MMES throughout the Program. 


\section{SPRAY SYSTEM COMPONENTS AND CONFIGURATIONS}

The operating schematic in Figure 1 depicts the spray system used during the Phase I - Addendum I spray trials. As outlined in Appendix A, Experimental Plan, modifications to the existing spray system were necessary. In particular, these changes involved replacing the flexible power leads in use on the two induction power supply units with solid copper tubing. This eliminated high losses to the cooling water due to the resistive component of the flexible leads. A recirculating system for the induction power electronics was necessary to accommodate the numerous spray trials required to provide a large sample base for analysis. For the induction power cooling system, glycol and distilled water were used in a combined liquid-to-air and liquid-to-liquid heat exchange system.

D1213RFD.CST

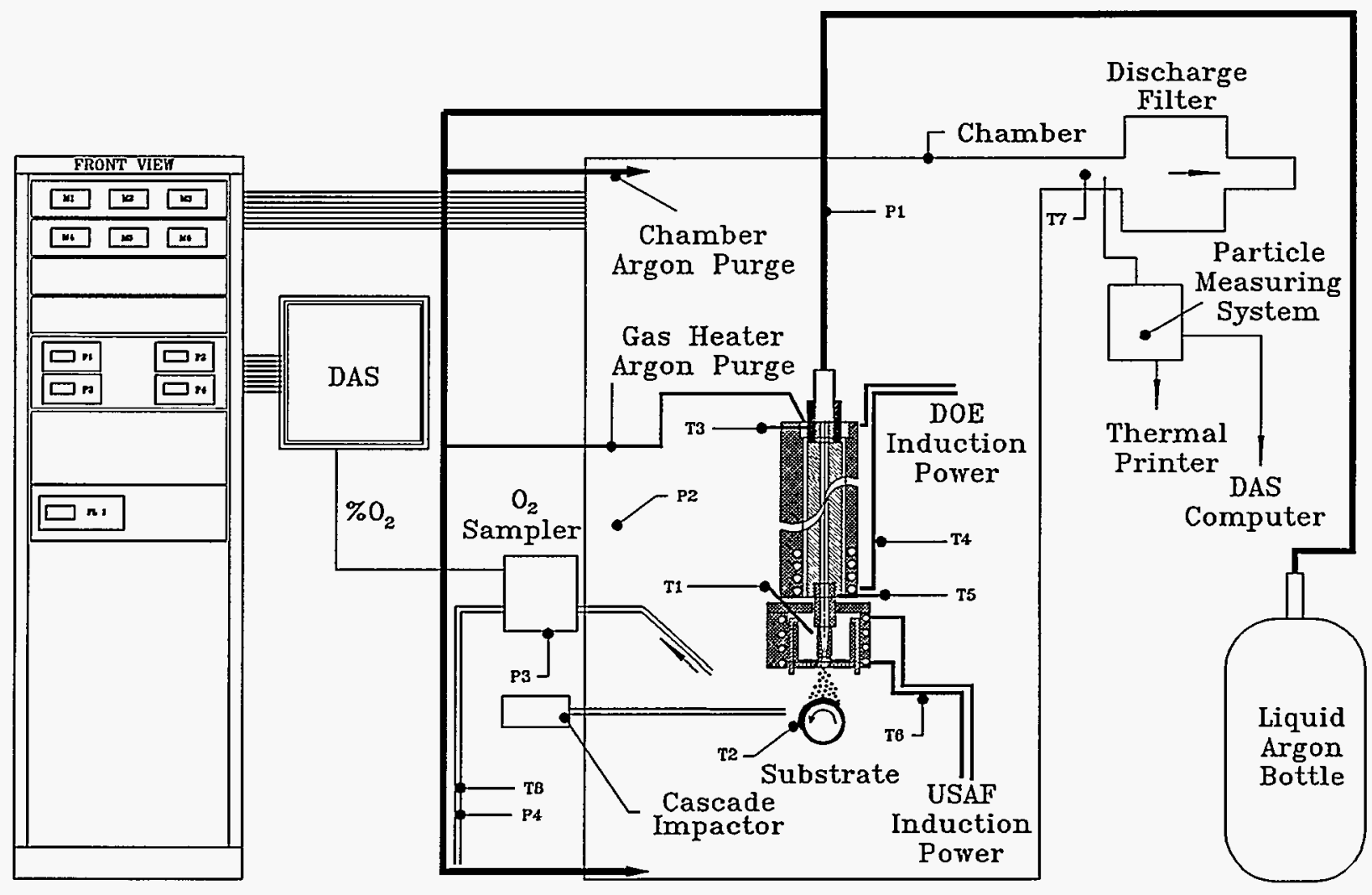

Figure 1. Schematic of Spray System. 
An additional feature to the spray system used during the Phase I - Addendum I spray trials was incorporation of a cascade impactor sample line. This feature allowed collection of overspray material for chemical analysis. The cascade impactor used during the Extended Surrogate Alloy Experiments was a seven stage, In-Tox Model 02-250. This unit is a cylindrical shaped, particle separating device designed to remove airborne particulates from a gas stream. By supplying a vacuum at the outlet end of the unit, an aerosol stream is forced to enter the other end of the cascade impactor. The aerosol stream is then forced through jets with diameters that are progressively smaller at each stage. Accordingly, the stages are located closer to the smaller jets to make increasingly sharper bends around flat stages within the outer cylinder. When the gas makes a sharp bend, the larger particles cannot make the bend and thus, impact against a thin plate. The stage at the inlet to the cascade impactor, identified as stage 1, collects the largest particles. A filter is located at the outlet to the cascade impactor. A 0.2-micrometer $(\mu \mathrm{m})$, fiber filter was used during the Extended Surrogate Alloy Experiments. Chemical analysis data and photomicrographs associated with each stage of the cascade impactor collections obtained during Spray Trial 9 are provided in Appendix B.

\subsection{METAI SPRAY SYSTEM}

The major components of the spray forming system are depicted in Figure 2. An illustration of the chamber housing with view ports and exhaust filters is displayed in Figure 3. Components within the chamber are firmly mounted on a stationary, horizontal platform. The chamber housing moves on rollers over the platform to close and seal the contents of the spray chamber from the surrounding lab environment. The open experimental platform within the spray chamber provides convenient access for personnel to perform experimental modifications. The experimental platform is rigidly attached to the left side of the chamber which contains all penetrations including power lines, supply lines, sample lines, and instrumentation leads. With this arrangement, connections to the spray apparatus are not interrupted when access to the experimental area is needed.

As indicated in Figure 2, the gas heater is mounted vertically and supports the nozzle which is concentrically located within the furnace assembly. A substrate assembly can then position the substrate material vertically or horizontally beneath the spray assembly. During this work effort, substrate geometries included rotating tubes and rods of carbon steel and graphite, flat plates of carbon steel and graphite, and 6-inch (in.) diameter rotating hemispheres. 


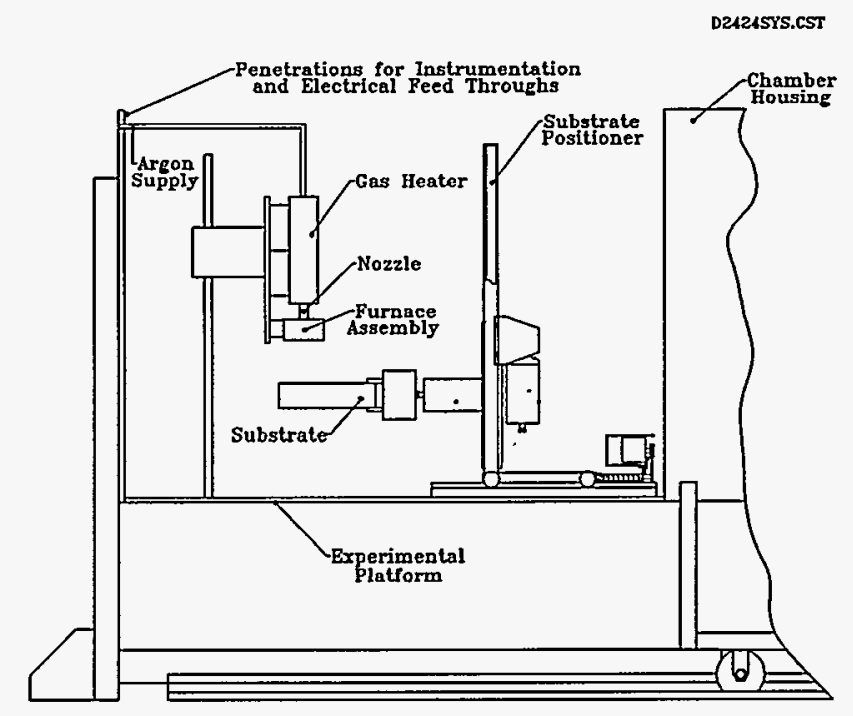

Figure 2. Major Components of Spray System.

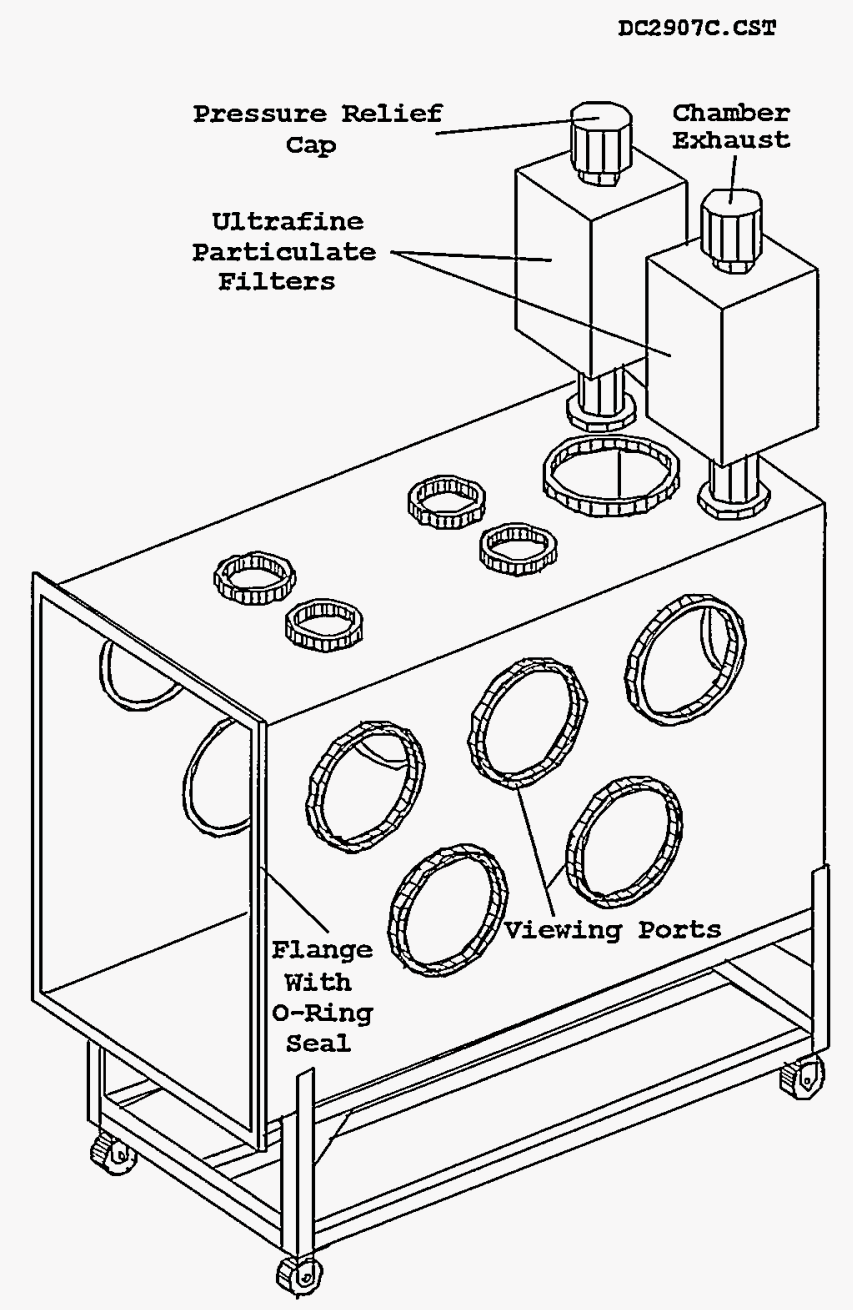

Figure 3. Chamber Housing. 


\subsection{CONTROL AND MEASUREMENT ELECTRONICS}

The outputs from the temperature (T) and pressure (P) indicators illustrated in Figure 1 are linked to signal conditioners. Amplified outputs from these signal conditioners were digitized prior to computer processing. After routing through a Data Translation 707 terminal, each signal was fed to a dedicated channel on a Data Translation 2801 interface. Up to 32 analogueto-digital converters were available for data acquisition. There are four digital-to-analogue channels available for programmable control functions. An Advanced Logic Research (ALR) Powerflex computer was used to record and arrange on-line data outputs. This computer is driven by an Intel Corp. 80286 microprocessor and features two 44 megabyte Bernoulli disk drives. Hard copy is generated on a Hewlett-Parkard PaintJet XI and/or a Hewlett-Packard LaserJet $4 \mathrm{I}$ printer.

The data acquisition system (DAS) is utilized during characterization of system components, performance testing of system components, and during the actual spray trials. A versatile software package, Labtech Notebook/XE, streamlines execution of software configurations for the DAS. Setup files formulated for each of the experimental exercises allow different scale factors, offset constants, and buffer sizes to be established for each of the 32 data channels. Iabtech Notebook/XE allows dynamic data display to screen. The analogue outputs from the various sensors can be displayed, through a windows selection option, as on-line graphing, meter readings, or a combination of both. Data is also stored to disc via direct-to-file backup.

\subsection{NOZZLE SUPPLY GAS HEATERS}

Two styles of gas heaters were used during these extended surrogate alloy spray trials. Figure 4 illustrates the molybdenum gas heater with its heating coil. This gas heater was constructed during the initial Phase I activities. Figure 5 illustrates the graphite gas heater that was first implemented during the Phase I Addendum I work. Nozzle designs were adjusted during the Extended Surrogate Alloy Experiments to enable these gas heaters to operate at full capacity.

The molybdenum gas heater is a heavy-walled tube constructed of molybdenum with traces of titanium and zirconium (TZM alloy) with small diameter, thin-walled molybdenum tubes held in position with the entrance and exit connectors. The 10-kilohertz (kHz) frequency of the induction power (IP) supply unit preferentially heats the thinner walled, inner tubes. 


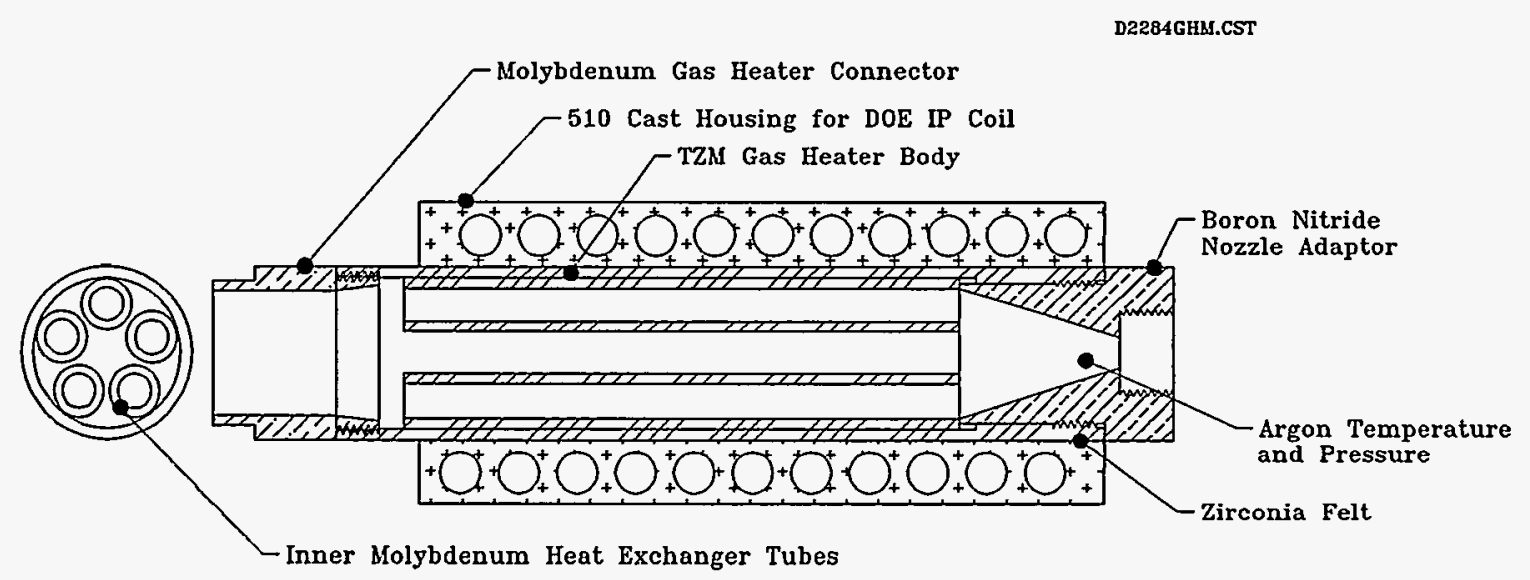

Figure 4. Molybdenum Gas Heater with Heating Coil.

D2284GHC.CST

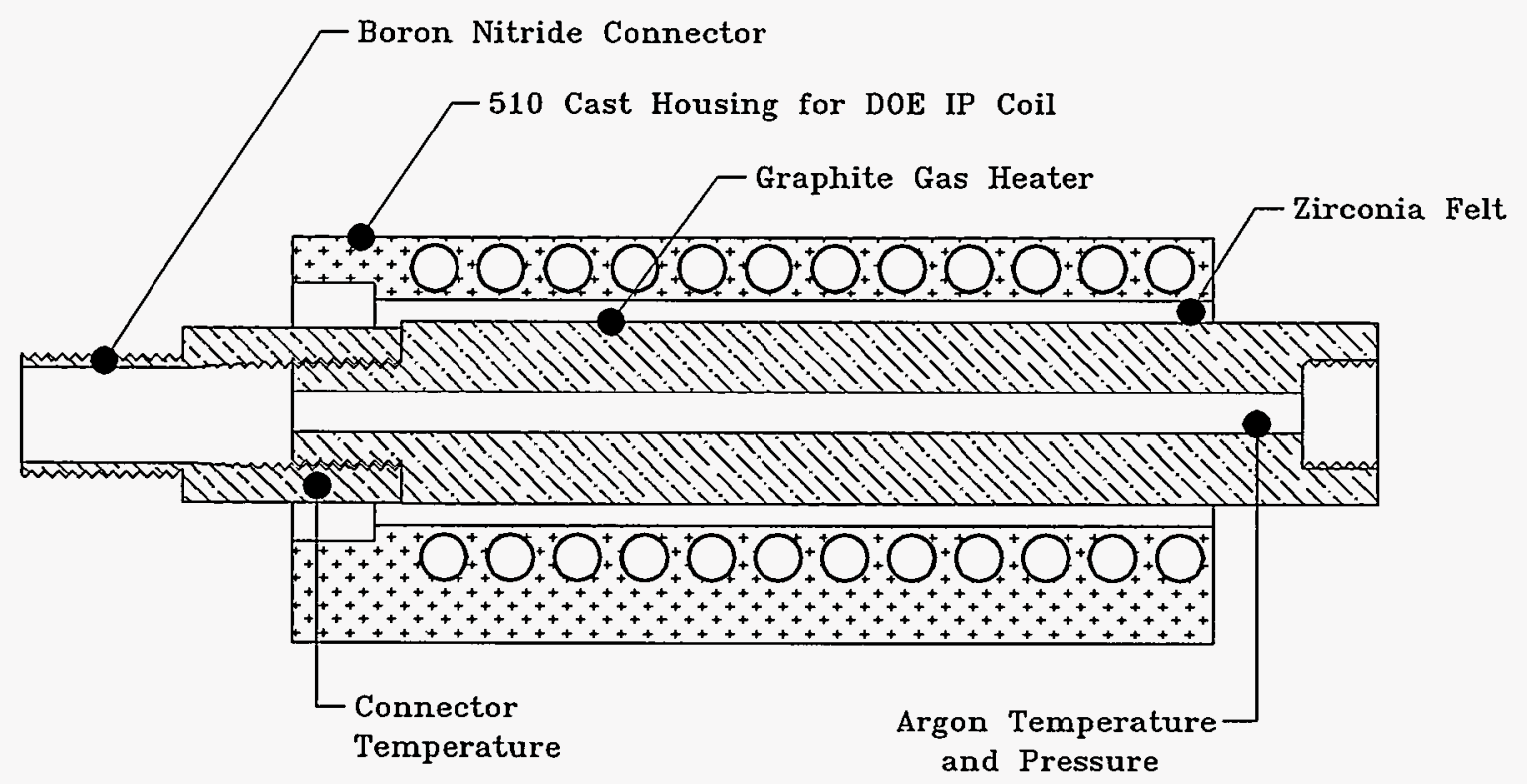

Figure 5. Graphite Gas Heater with Heating Coil. 
The graphite gas heater measured 1.8-in. in diameter and 14in. in length. The inside diameter at the entrance of the heater was $1 / 2$ in. This diameter was maintained for 9 in. The inside diameter was then reduced to $3 / 8 \mathrm{in}$. which is the inside diameter of the nozzle entrance. It has been determined, empirically, that the hottest location in this type of gas heater (i.e., a gas heater with a uniform inside diameter) occurs approximately two thirds of the distance from entrance to exit. Having the inside diameter decrease slightly at this position causes wall turbulence. This wall turbulence increases the gas heating efficiency while decreasing the actual gas heater wall temperature. Also at this position, there remains 5 in. (i.e., 13 times the 3/8-in. inside diameter) of gas heater length that allows the supply gas to reach an equilibrium condition prior to entering the nozzle.

The exit connection to each of these gas heaters was designed to be compatible. This compatibility enabled the same nozzle/furnace assembly to be mounted to either gas heater.

\subsection{NOZZLE/FURNACE ASSEMBLY}

A cross section of the nozzle/furnace assembly is shown in Figure 6. The furnace is a circular boron-nitride cup with a boron-nitride nozzle centrally located. Around the furnace is a thin-walled graphite sleeve that acts as a susceptor to uniformly heat the furnace walls. Inductive coupling for heating occurs

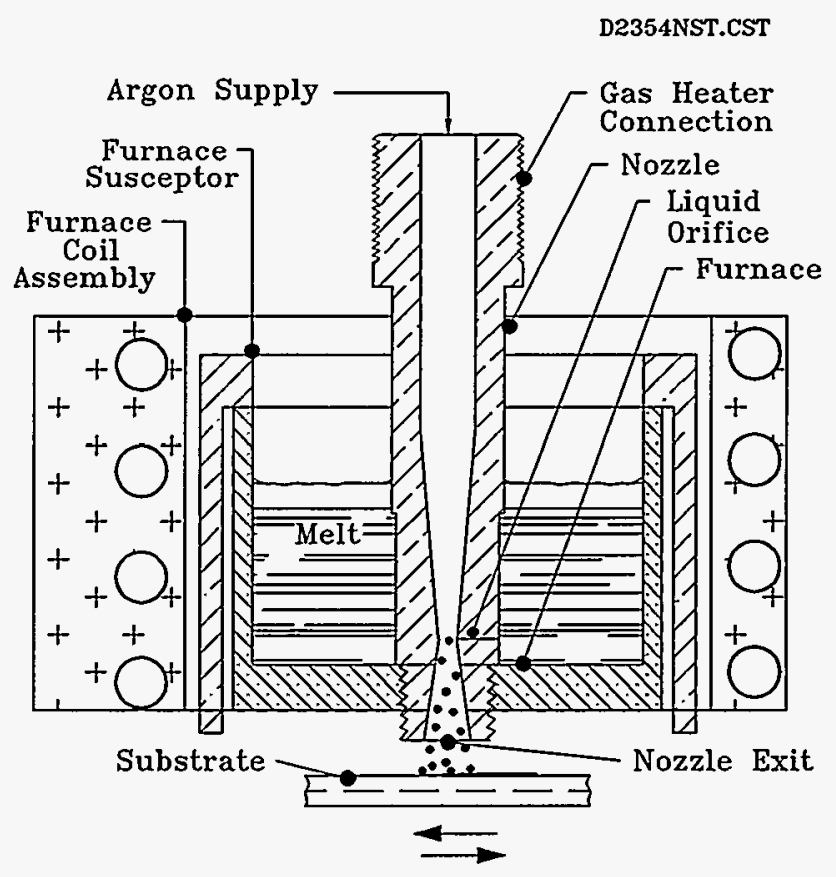

Figure 6. Cross Section of Nozzle/Furnace Assembly. 
within the graphite susceptor as well as in the metal located within the furnace. A boron-nitride pyro-paint was applied to the threads that mate with the gas heater connector. This enables removal of the nozzle/furnace assembly without disturbing the gas heater and monitor connections. This high-temperature coating also aided in providing a gas seal at high temperatures at the entrance to the nozzle. Zirconia adhesive was used on the threads around the outside of the nozzle exit to assure a liquid-metal seal in the floor of the furnace. The furnace coil was 3/8-in. diameter copper tubing cast in an alumina based ceramic cement.

\subsection{MODULAR ASSEMBLY}

A complete graphite heater assembly with the nozzle/furnace assembly mounted below is shown in Figure 7. Also illustrated is the mounting plate. The mounting plate holds all the components in a modular array. Construction of one spray assembly could be completed on the bench in the shop and lab areas, while a second spray assembly could be operating in the spray chamber. Given this type of arrangement, additional time could be allotted for the curing of ceramic adhesives and coatings without causing a delay in experimental activities.

A boron-nitride connector was fabricated for the graphite gas heater. This provided thermal isolation from, and facilitated matching expansion coefficients to, the incoming argon supply line. The molybdenum gas heater was supplied with a longer molybdenum connector that accomplished the same effect.

The gas heater and furnace coils were attached to the mounting plate with studs made from brass threaded stock. Gas heater body temperatures were periodically measured through coil housing penetrations at the T3 (entrance) and T9 (exit) locations identified in Figure 7.

\subsection{SUBSTRATE CONEIGURATIONS}

Specific consideration of substrate material will be discussed in Section 4, Spray Trials. The modular assembly design would accommodate a rotating tube or rod measuring up to 10 in. in diameter and $14 \mathrm{in.} \mathrm{in} \mathrm{length.} \mathrm{Plate} \mathrm{material} \mathrm{could} \mathrm{be} \mathrm{used} \mathrm{which}$ measured 12-in. wide and 14-in. long. Hemispheres could be accommodated up to $14 \mathrm{in.}$. in diameter. 
D2144A.CST

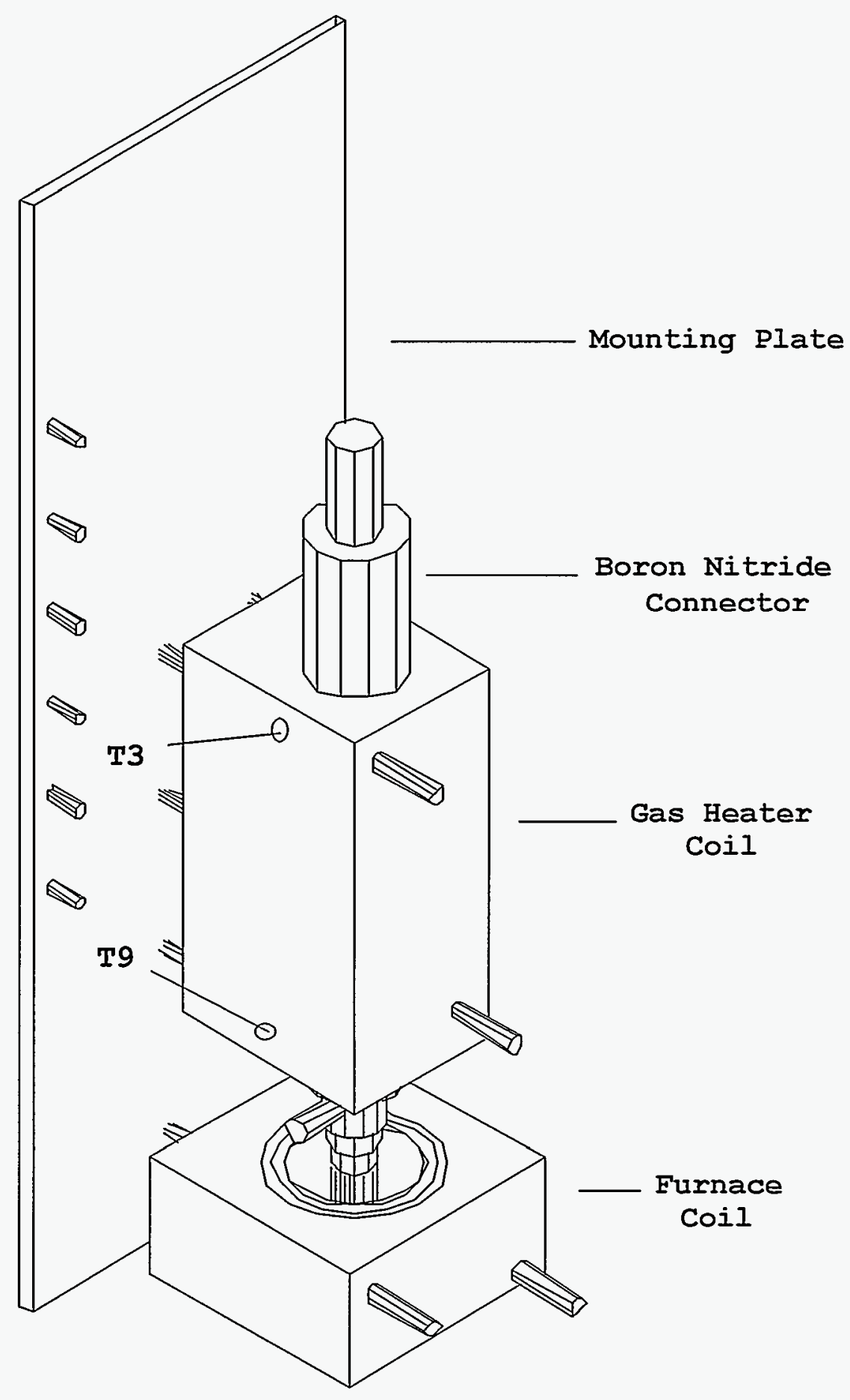

Figure 7. Modular Assembly. 


\subsection{SPRAY NOZZLE}

One general type of nozzle design used throughout this Program is illustrated in Figure 8. The extended surrogate alloy spray trials incorporated two adaptations of this general nozzle design. The first variation had a single liquid orifice located in the nozzle throat. The second incorporated three liquid orifices at 120 degree radial separations. These two adaptations of the nozzle design were similar in that the ratio of the gas orifice area of the nozzle throat to the liquid orifice area was maintained at a ratio of approximately 25:1. Typical liquid orifice diameters ranged from 0.016 to $0.040 \mathrm{in}$.

D2354N.CST

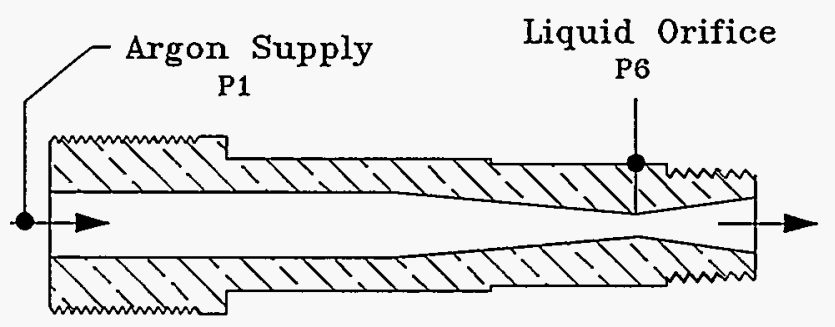

Figure 8. Cross Section of Circular Converging/Diverging Nozzle.

When operating with supply pressures from 24 pounds per square inch absolute (psia) to 28 psia, the nozzle adaptations behaved similarly. However, at lower supply pressures, the variation with the single liquid orifice would not function as efficiently. This was predictable since the lower velocity gas at reduced supply pressures would be forced to breakup a large, single liquid stream entering the nozzle throat opposed to using a nozzle with multiple orifices that provided three, smaller liquid streams.

Both nozzle styles had the same characterization curve that is shown in Figure 9. This curve is developed by placing a pressure

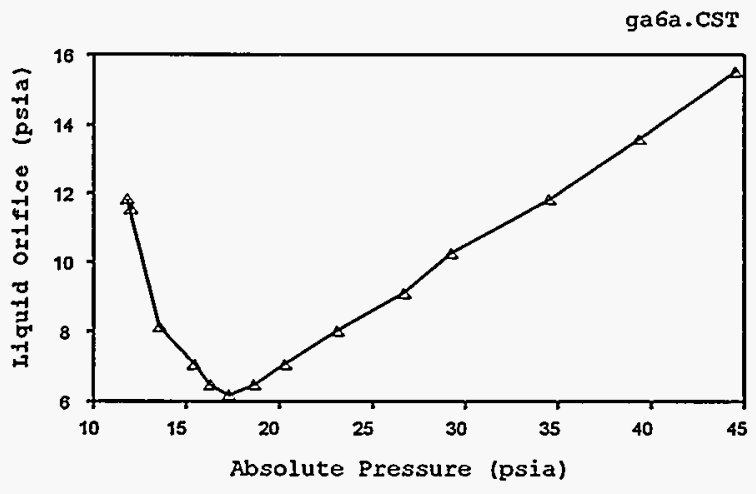

Figure 9. Characterization Curve - Converging/Diverging Nozzle. 
monitor(s) on the liquid orifice(s) and then increasing the supply pressure to the nozzle in increments. At each supply pressure reading, the liquid orifice(s) pressure reading(s) is also monitored.

As-sprayed samples were produced with nozzle supply pressures from 20 to 30 psia. The pressure drop across the liquid orifice under these conditions ranges from 5.1 pounds per square inch (psi) at a supply pressure of 20 psia to 1.8 psi at a supply pressure of 30 psia. The atmospheric pressure in Rigby, Idaho is 12.4 psia.

With the aspiration ranging from 5.1 to 1.8 psi, samples were produced with varying gas-to-metal mass ratios. The effect of different mass ratios is stated in Section 5, As-Sprayed Product Sample Analyses, where the as-sprayed product is discussed. 


\section{INTEGRATED SYSTEM PERFORMANCE}

To perform extended experiments with the surrogate alloy, modifications to the induction power supply units were necessary. The first equipment modification involved decreasing the power losses observed in the flexible power leads that connected the power supply units to the chamber housing. Although convenient for short-term use, these power leads had resistive components which caused large heating losses in the load coil circuitry.

The second modification involved establishing an inert, liquid-to-air, liquid-to-liquid heat exchange system for the internal electronics of the two induction power supply units. This system modification prevented mineral deposits from forming on the internal, electrical components during extended operating times.

\subsection{INDUCTION POWER - LOSSES TO COOLING WATER}

During the surrogate alloy experiments in Phase I - Addendum I, the temperature of the water in the gas heater coil and furnace assembly coil was excessive for continuous operation. Based on this, the flexible power leads that caused high power losses to the cooling water during the Addendum I spray trials were replaced with soft-drawn copper tubing that measured $3 / 4$ in. in diameter. The power losses to the cooling water before and after reconfiguration of the flexible leads are provided below:

Power Losses Prior to Reconfiguration

Water Flow Gas Heater Coil

Water Flow Furnace Coil

Water Temperature Increase - Gas Heater Coil

Water Temperature Increase - Furnace Coil

Gas Heater

$$
4.187\left(\mathrm{~J} / \mathrm{g}{ }^{\circ} \mathrm{C}\right) \times 138(\mathrm{~g} / \mathrm{s}) \times 6\left({ }^{\circ} \mathrm{C}\right)=3.5 \mathrm{~kW}
$$

Furnace

$$
4.187\left(\mathrm{~J} / \mathrm{g} *{ }^{\circ} \mathrm{C}\right) \times 163(\mathrm{~g} / \mathrm{s}) \times 19\left({ }^{\circ} \mathrm{C}\right)=13.0 \mathrm{~kW}
$$

\section{Power Losses Following Reconfiguration}

Water Flow Gas Heater Coil

Water Flow Furnace Coil

Water Temperature Increase - Gas Heater Coil

Water Temperature Increase - Furnace Coil
$138 \mathrm{~g} / \mathrm{s}$

$163 \mathrm{~g} / \mathrm{s}$

$6^{\circ} \mathrm{C}$

$19^{\circ} \mathrm{C}$ 
Gas Heater

$$
4.187\left(\mathrm{~J} / \mathrm{g} *{ }^{\circ} \mathrm{C}\right) \times 15.9(\mathrm{~g} / \mathrm{s}) \times 15\left({ }^{\circ} \mathrm{C}\right)=1.0 \mathrm{~kW}
$$

Furnace

$$
4.187\left(\mathrm{~J} / \mathrm{g} *{ }^{\circ} \mathrm{C}\right) \times 12.8(\mathrm{~g} / \mathrm{s}) \times 17\left({ }^{\circ} \mathrm{C}\right)=0.9 \mathrm{~kW}
$$

\subsection{INDUCTION POWER - INTERNAL ELECTRONIC COOLING}

A noncorrosive liquid with a high thermal conductivity and a low electrical conductivity was required for extended operation of the induction power supply units. The two liquids commonly used are distilled water and/or glycol. For these experiments, a mixture of distilled water and glycol was used. The ratio of the mixture was approximately 50:50.

A reservoir was established which contained approximately 18 gallons (gal) of the distilled water/glycol mixture and copper cooling coils connected to the Facility's water well (i.e., $11^{\circ} \mathrm{C}$ ). The inlet of the recirculating pump for the induction power supply electronics was supplied by the reservoir. The discharge of the recirculating pump was connected to the inlet of each of the 20 kilowatt $(\mathrm{kw})$ induction power supply units; this enabled the cooling water to be supplied in parallel at $45 \mathrm{psi}$. As the cooling water exited the DOE induction power supply electronics, it passed through a large coil of copper tubing. This tubing provided an air-to-Iiquid heat exchange. The discharge from the USAF induction power supply electronics was routed directly to the reservoir. This reservoir coolant was dependent on a liquid-to-liquid heat exchange; liquid-to-liquid heat exchange was provided by water from the well pump flowing through the copper cooling coil in the reservoir. Temperatures were monitored at each of the discharge points on the induction power supply units and within the cooling reservoir itself. The recirculating pump required for this configuration provided 25 gallons per minute (gpm) at 40 psi and was monitored with a pressure gauge on the discharge. An oversized recirculating pump would cause excessive water supply pressure which in turn would represent a hazard to the flexible rubber hose joining the electrical components. Conversely, too small a recirculating pump would not provide sufficient cooling.

\subsection{INTEGRATED SYSTEM CHECKOUT}

After completing the alterations to the spray system, a heatup trial was performed using the first modular assembly. The purpose of this performance run was to establish that appropriate temperatures of the spray components could be achieved while maintaining comfortable operating temperature ranges depicted by the equipment monitors. 
As displayed in Figure 10, furnace temperatures were attained in excess of $1750^{\circ} \mathrm{C}$. This was adequate for the first scheduled spray trial. This figure also illustrates the argon supply temperature readings which reflect a distinct drop in temperature when the nozzle supply pressure was increased to slightly above operating conditions. This reduced temperature indicates what temperature can be sustained with argon flowing through the gas heater. For this system heatup, the data confirms that during actual spraying the maximum argon supply temperature will be close to $1400^{\circ} \mathrm{C}$.

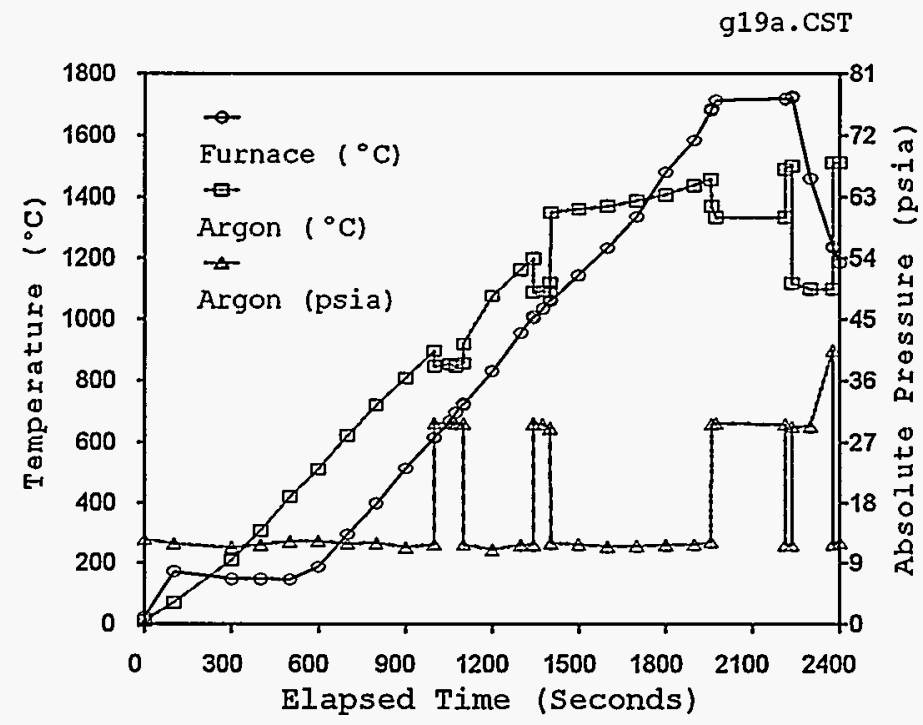

Figure 10. Parametric Readings for a System Heatup.

The temperature of the gas for the nozzle supply affects the properties of the as-sprayed material. For the Extended Surrogate Alloy Experiments, nozzle parameters and metal throughputs were selected that were within the maximum power range of the DOE induction power supply unit.

In a production spray system, the monitors sensing the melt and gas temperatures could have outputs that would control the power delivered to the respective induction power supply units.

The temperature of the water which cools the internal electronics of the two induction power supply units is illustrated in Figure 11. It is desirable to maintain these temperatures between 25 and $30^{\circ} \mathrm{C}$. If the water is too cold, condensation can form on internal components; if the water is too hot, the components do not function efficiently. In a production spray system, these monitors would likely service an alarm system. 
Another preformance verification involves monitoring the temperature of the cooling water in the load coils while the components are at their maximum operating conditions. Figure 12 illustrates the temperatures obtained from the thermocouples located in the cooling water exiting the gas heater coil and the furnace coil. When using soft-drawn copper fixtures for the load coils, the continuous operating temperature of the cooling water is maintained below $50^{\circ} \mathrm{C}$. A maximum temperature of $75^{\circ} \mathrm{C}$ is safe in this system.

The reconfiguration of the spray system allowed for the water flow in these coils to be increased or decreased during system operation. The flow was adjusted in each of these coils to maintain the temperatures observed. In a production type spray system, these monitors would, at a minimum, service an alarm. More likely, the monitors would control automatic water adjustment as well as system shutdown. In a well designed spray system, the liquid from these coils could be channeled through a heat exchange system to provide preheating of the incoming nozzle supply gas.

\subsection{PRESPRAY DATA COMPARISONS}

Maintaining a record of comparisons during a series of spray trials establishes a data bank that enables the operator to assess parametric values in the event a sensing component fails. Hand transcribed data that complements the data acquired by the data acquisition system are also recorded during a spray trial. These records include induction power supply unit settings at synchronized elapsed time intervals, water supply pressures where applicable, and the temperature at which the metal charge becomes molten.

While determining proper operation of equipment during a system heatup, other measurements and comparisons are also established. The harsh environment of spraying molten metal places extreme demands on all sensing elements in the system. To the extent that related temperatures can be compared, this data serves as a backup mechanism in the event one sensing element fails.

One such parameter is the temperature of the nozzle supply gas as the gas enters the nozzle body. This temperature is the most accurate measurement that can be made to determine the actual temperature of the gas in the nozzle throat. Because it would disturb the gas flow field and alter operation of the nozzle, a sensing element is not located in the nozzle throat.

There are two temperatures related to the temperature of the argon gas entering the nozzle. The temperature of the outside of the gas heater body at the gas heater entrance (Gas Heater 


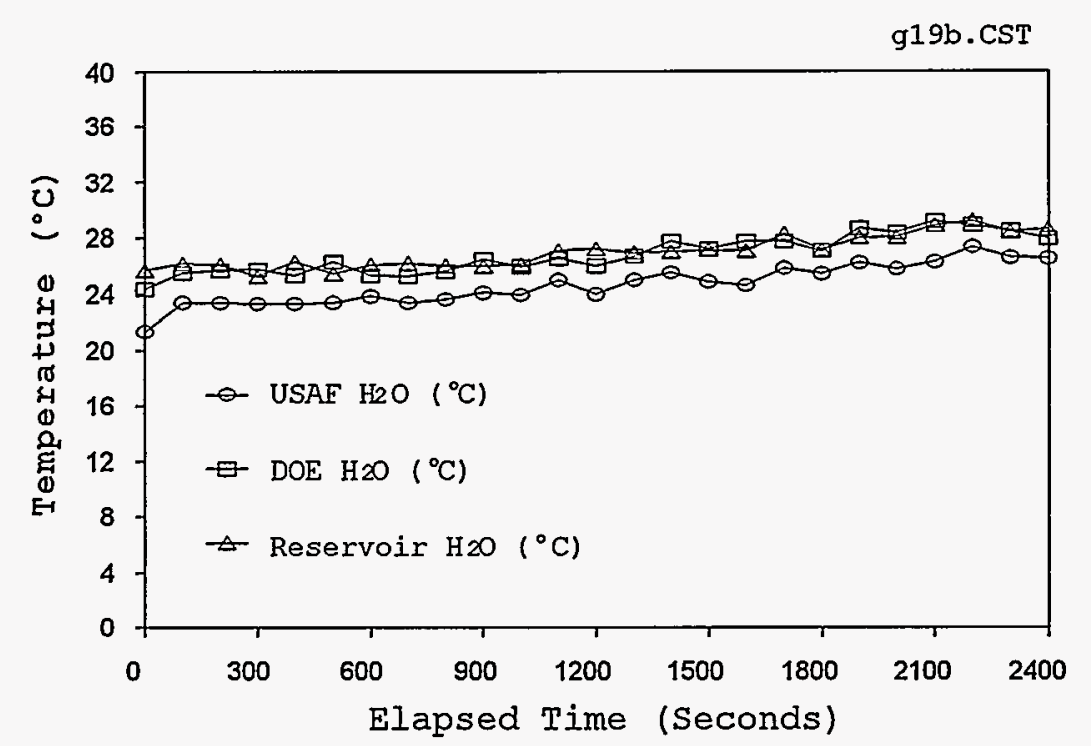

Figure 11. Equilibrium Temperatures of Coolant for Internal Electronics of the Induction Power Supply Units.

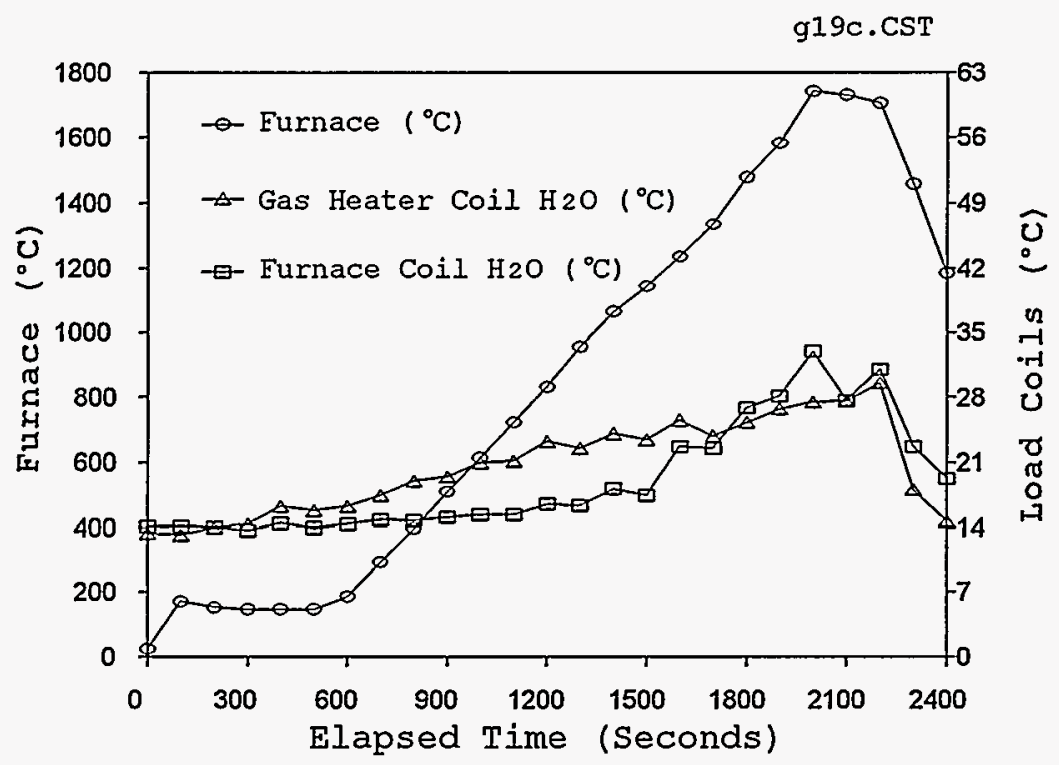

Figure 12. Equilibrium Temperatures of Cooling Water Exiting the Gas Heater and Furnace Load Coils. 
Connector ${ }^{\circ} \mathrm{C}$ ) and the temperature of the outside of the gas heater body at the gas heater exit (Gas Heater Body ${ }^{\circ} \mathrm{C}$ ). By establishing the temperature of the gas in the nozzle throat and the gas pressure, calculations can be made relative to gas flow through the nozzle. The measured values of flow through the nozzle can then be confirmed with calculations. It is also critical that the temperature of the gas in the nozzle throat be assessed to determine when the gas may or may not freeze the liquid metal in the liquid orifices, thereby causing the nozzle to cease operating.

Another temperature assessment is performed by comparing the temperature in the nozzle throat with the temperature of the supply gas at the nozzle exit. This enables calculations to be made relative to the potential cooling rate a nozzle design can effect. When these temperatures can be measured prior to a spray trial and the results then compared to measurements obtained during a spray trial, a more detailed explanation of the as-sprayed material can be rendered.

Figure 13 compares the outer gas heater body temperature, at the gas heater exit, to the temperature of the argon at the nozzle exit. As the argon supply pressure is increased to slightly above spray trial conditions, the temperature of the argon at the nozzle exit is drastically reduced. In this example, at 1800 seconds, the gas exiting the nozzle will be maintained at $530^{\circ} \mathrm{C}$ when the gas heater body temperature is $1170^{\circ} \mathrm{C}$ and the nozzle supply pressure is sustained at 40 psia.

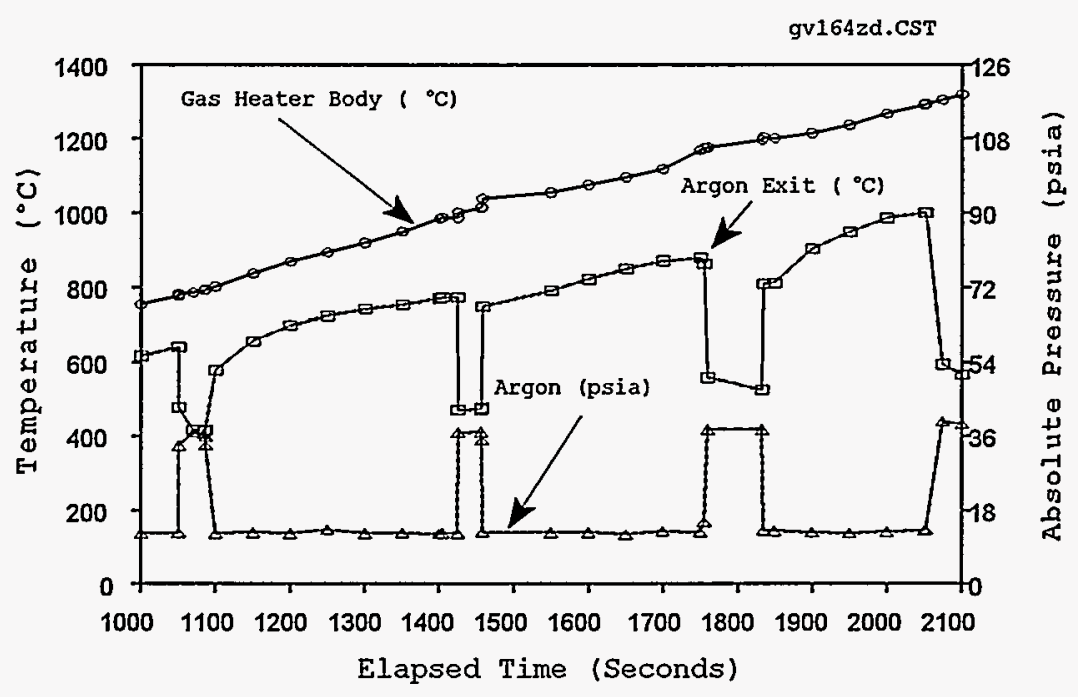

Figure 13. Component Temperature Comparisons during System Heatup. 
In Figure 14, the temperature of the argon gas as it enters the nozzle has the higher values (Argon ${ }^{\circ} \mathrm{C}$ ). At 1360 seconds, when the nozzle supply pressure is kept at 40 psia (Argon psia) and the temperature of the gas heater body at the gas heater entrance (Gas Heater Connector ${ }^{\circ} \mathrm{C}$ ) is $632^{\circ} \mathrm{C}$, the temperature of the gas entering the nozzle will be $758^{\circ} \mathrm{C}$.

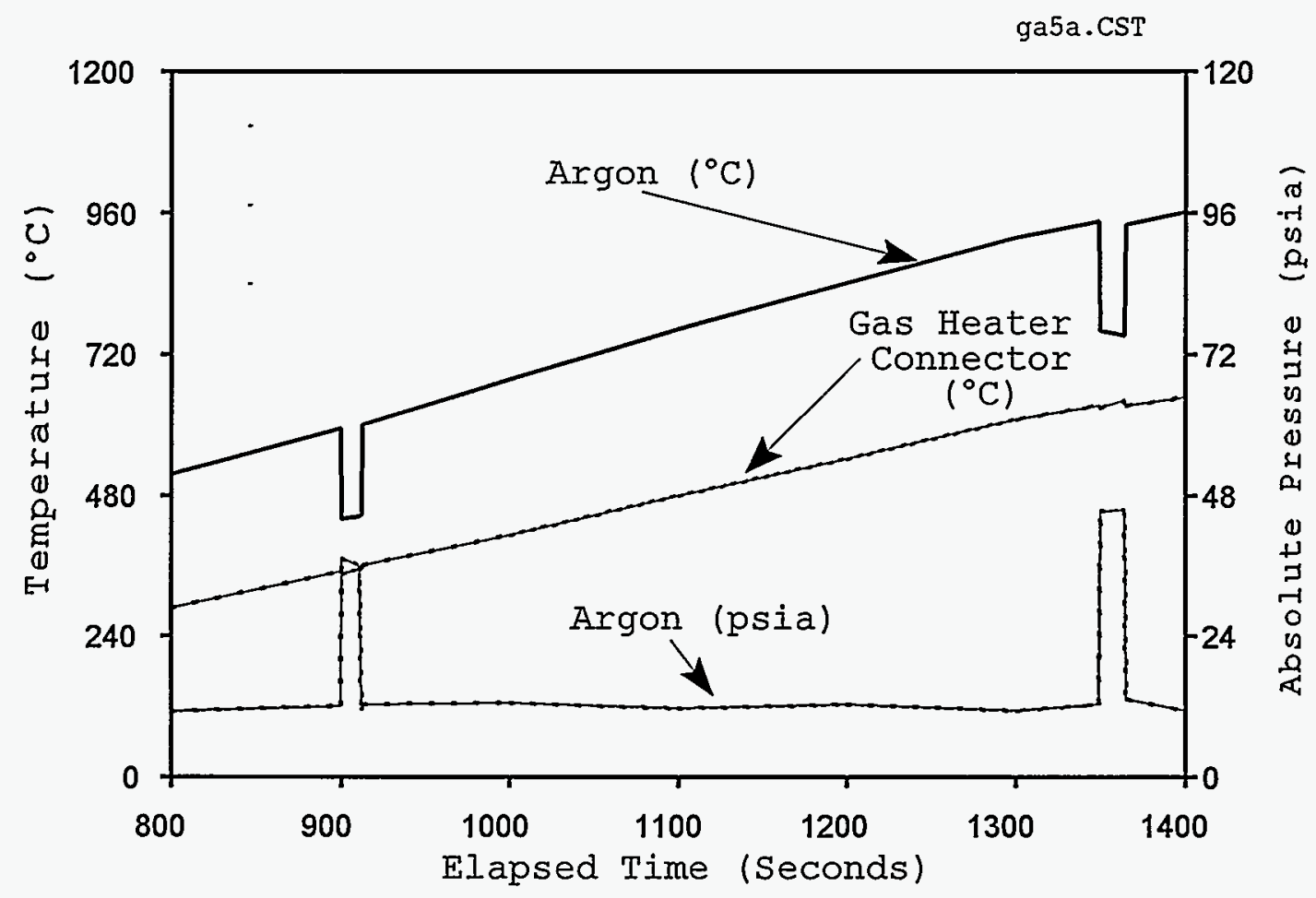

Figure 14. Comparison Temperatures for Argon Supply Heating.

Collectively, the data illustrated and discussed in sects. 3.3 and 3.4 confirm the system is ready for a spray trial.

Data plots and values referred to within this report are averaged representations. Precise discussion of the experiments can be acquired by analyzing the original data files. 


\section{SPRAY TRIALS}

To continue the surrogate alloy experiments, it was necessary to make modifications to the spray system. Upon completion of the required alterations, the remainder of the spray experiments were conducted using the surrogate alloy $(49.6 \mathrm{w} / 0$ iron, $49.6 \mathrm{w} / 0$ tungsten, $0.8 \mathrm{w} / 0$ carbon). Approximately $6.2 \mathrm{~kg}\left(\begin{array}{ll}14 & 1 \mathrm{~b}\end{array}\right)$ of surrogate alloy were sprayed in ten spray trials. These trials involved the use of carbon steel tubes machined to specified thicknesses with the surfaces grit blasted, carbon steel plate with the surfaces grit blasted, a coated and uncoated machined graphite rod, coated and uncoated machined graphite plates, and sandblasted carbon steel hemispheres that measured 6 in. in diameter.

This section describes the experimental setup, parameter settings and comparisons, and substrate configurations. Graphs display the type of data collected during the ten spray trials and serve to illustrate how some of the correlations were determined. Table 1 depicts information from the spray trials discussed within this report. This information is also representative of the type of data collected during the other spray trials. A parametric summary of each of the ten spray trials is provided in table format, Appendix C. The as-sprayed product results are discussed in Sect. 5 with a brief spray trial explanation.

In all spray trials, excessive wear on the spray components was noted. In most cases, alumina components had dissolved by the end of the spray run, however, wear on the boron nitride and alumina components was effectively reduced by using zirconia coatings. The most effective zirconia coating was the Aremco brand, 516 Adhesive. During the early spray trials, a boiling action was observed in the melt when the temperature reached $1550^{\circ} \mathrm{C}$. This vigorous boiling action generated more waste on the chamber floor than what occurred from nozzle overspray. This boiling action resulted from the surrogate alloy reacting with the boron-nitride nozzle body located concentrically in the tundish (illustrated in Figure 6). When the outside of the nozzle body was coated with zirconia, the boiling action ceased. Small diameter alumina tubes were used in the nozzle body to provide the flow of metal into the nozzle throat. During the course of a spray run, these small tubes would sometimes dissolve into the surrogate alloy and become part of the spray. When this happened, the boronnitride body would deteriorate and high deposition rates would occur. It was postulated that incorporating zirconia products during fabrication of the spray components would have alleviated these problems, however, due to the long lead time required to procure the products, vendors were unable to meet the time-frame requirements of this Program. 
T4A.CST

Table 1. Parametric Summary - CST2734 Spray Trials

Based on Extended Surrogate Alloy Experiments

\begin{tabular}{lcccc}
\hline $\begin{array}{l}\text { Spray } \\
\text { Period }\end{array}$ & Argon & Argon & Furnace & Substrate \\
$($ psia) & $\left({ }^{\circ} \mathrm{C}\right)$ & $\left({ }^{\circ} \mathrm{C}\right)$ & \\
\hline
\end{tabular}

Carbon Steel Tube - Spray Trial 1

$\begin{array}{lllll}1 & 18 & 1400 & 1705 & 350 \\ 2 & 22 & 1372 & 1705 & 500 \\ 3 & 28 & 1304 & 1705 & 600\end{array}$

Graphite Rod - Spray Trial 5

$\begin{array}{lllll}1 & 16-24 & 1250 & 1750 & \text { NA } \\ 2 & 16-24 & 1250 & 1750 & \text { NA } \\ 3 & 16-24 & 1250 & 1750 & \text { NA } \\ 4 & 16-24 & 1250 & 1750 & \text { NA } \\ 5 & 16-24 & 1250 & 1750 & \text { NA }\end{array}$

Graphite Plate - Spray Trial 8

$\begin{array}{rllll}6 & 35 & 1475^{*} & 1730 & \text { NA } \\ 7 & 38 & 1475^{\star} & 1730 & \text { NA } \\ 9 & 41 & 1475^{\star} & 1730 & \text { NA } \\ 10 & 31 & 1475^{\star} & 1730 & \text { NA } \\ 11 & 21 & 1475^{\star} & 1730 & \text { NA }\end{array}$

Cascade Impactor - Spray Trial 9

$\begin{array}{lllll}1 & 32 & 1561 & 1700^{*} & \text { NA } \\ 2 & 28 & 1561 & 1700^{*} & \text { NA } \\ 3 & 25 & 1561 & 1700^{*} & \text { NA } \\ 4 & 18 & 1561 & 1700^{*} & \text { NA } \\ 5 & 35 & 1561 & 1700^{*} & \text { NA }\end{array}$

*Asterisk denotes estimated temperature. 
The consolidation efficiency of the spray-forming process is an important area of interest. This efficiency establishes the value the spray-forming process may offer over other methods of processing. Throughout the spray experiments conducted during this Program, a measured amount of material was placed in the furnace. This definitive amount of material was then compared to the amount consolidated on the substrate, the amount recovered from the chamber floor, and the amount, if any, that remained in the furnace at the conclusion of the spray run. This provided information for making general statements relative to the consolidation efficiency of the spray nozzle used in that spray trial.

The majority of spray trials required a 600-g charge of the surrogate alloy. Five hundred $g$ would be consolidated on the substrate surface, fifty $g$ would be large particulate on the chamber floor, and fifty $g$ would remain in the furnace. Potential airborne material was too small to measure directly. Discussions of these results are presented in sect. 4.3, Collection of Potentially Airborne Particles.

A second area of interest in the spray-forming process is to establish the requirements for continuous operation of a spray system. One necessary requirement is the ability to add material to the furnace during the spray process. Data regarding the amount of additional power required for adding metal during a spray trial are included in Sect. 4.2.1.2, Melting Considerations.

\subsection{PLUME HEAT CAPACITY}

In the first spray trial, data specific to the average thermal properties of the spray plume were obtained. This provided information relative to the properties that would be required in the substrate material.

To obtain these results, a piece of standard weight steel pipe measuring $12 \mathrm{in.}$. in length was prepared for use as the substrate in this spray trial. The outside diameter of the pipe (nominally 3.5 in.) was machined to $3.3 \mathrm{in.}$ The inside diameter was turned to 3.26 in. for a length of 2 in., then machined to an inside diameter of 3.22 in. for a length of 2 in., and finally machined to an inside diameter of $3.18 \mathrm{in.}$ for a length of $2 \mathrm{in.} \mathrm{By} \mathrm{varying} \mathrm{the}$ thickness of the substrate, heat loss calculations at the different substrate temperatures can be determined. The outside surface was sandblasted with 60 grit alumina to an even luster. The extra length on the steel tube allowed the positioner to be kept away from the spray plume.

The tube surface was positioned $0.75 \mathrm{in}$. from the nozzle exit. The center line of the tube was offset from the center line of the 
spray plume. This alignment provided a more even flow field for the argon nebulizing gas to escape the substrate surface with minimum turbulence to the liquid droplets consolidating on the substrate surface. The rotation was $4.6 \mathrm{rpm}$ providing a surface speed of $48 \mathrm{in./min.} \mathrm{The} \mathrm{tube} \mathrm{could} \mathrm{also} \mathrm{be} \mathrm{moved} \mathrm{in} \mathrm{a} \mathrm{manner} \mathrm{that}$ was normal to the spray plume to enable single or multiple layers to be applied to the tube surface. A Type $K$ thermocouple was located on the inner surface of the tube where the spray consolidation was occurring on the outer surface.

Measurements recorded during the spray trial are illustrated in Figure 15. The sharp increases in nozzle supply pressure, before the system is ready to spray, are provided to confirm adequate purging of the argon supply line and gas heater body. These purges took place within the first $100 \mathrm{~s}$, at $1000 \mathrm{~s}$, and again at $1350 \mathrm{~s}$. After $1800 \mathrm{~s}$, all conditions necessary to commence the spray trial had been attained. During the time interval of 1850 to $2000 \mathrm{~s}$, various nozzle supply pressures were applied. This included increasing the nozzle supply pressure until the spraying ceased and bubbling of argon through the liquid orifices occurred. After documenting the conditions where an acceptable consolidation occurred, a short time interval was allotted to allow the temperatures to stabilize (2000 to $2100 \mathrm{~s}$ ). The time for the actual spray periods centered around $2150 \mathrm{~s}, 2225$ $\mathrm{s}$, and $2325 \mathrm{~s}$. These spray intervals are discussed individualiy, along with their respective graphs which reflect the expanded time scales.

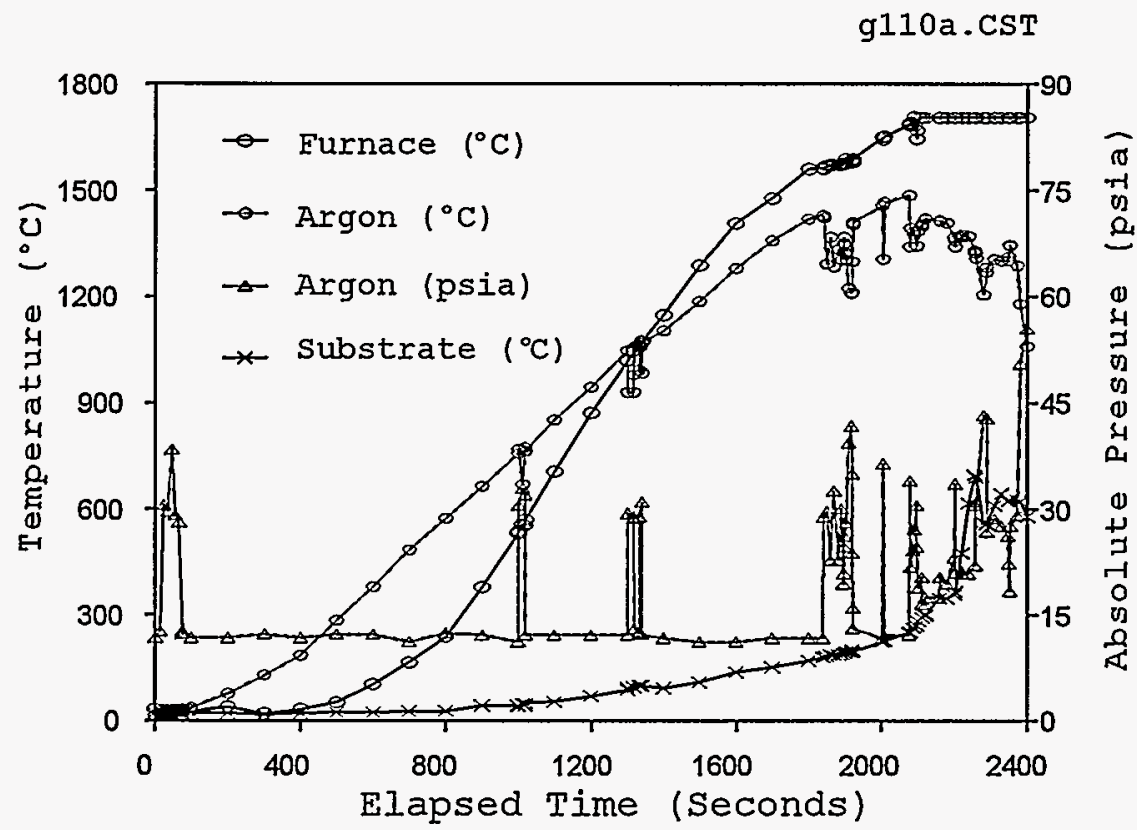

Figure 15. Spray Trial Measurements. 
The first spray period during this trial commenced at $2090 \mathrm{~s}$ and is shown in Figure 16. The argon supply temperature (Argon ${ }^{\circ} \mathrm{C}$ ) was maintained at $1400^{\circ} \mathrm{C}$. Maximum power settings were required on the induction power supply unit for the gas heater to provide this temperature. The nozzle supply pressure (Argon psia) for this spray period was nominally 18 psia. During this spray trial, the as-sprayed product was sprayed to a thickness of 0.010 in. The substrate thickness during this application was 0.040 in. The temperature of the backside of the substrate increased from $300^{\circ} \mathrm{C}$ at the beginning of the spray to $364^{\circ} \mathrm{C}$ when spraying was stopped.

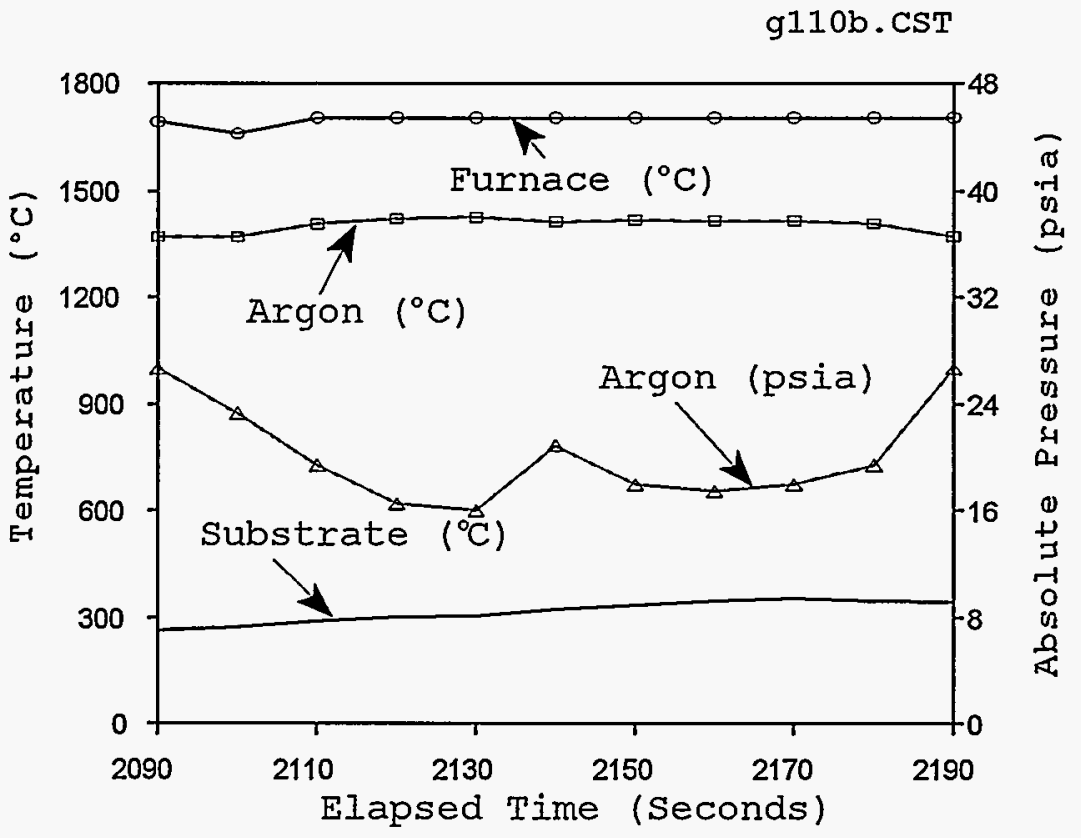

Figure 16. First Spray Period.

The mass of the substrate that the spray was consolidated onto during this $60.5 \mathrm{~s}$ time interval was $175 \mathrm{~g}$. Using these data values, the power that contributed to heating the substrate, that could not be dissipated by thermal conductivity of the substrate, nebulizing gas cooling or losses to the chamber purge, was calculated as follows:

$$
175(\mathrm{~g}) \times 0.44\left(\mathrm{~J} / \mathrm{g}^{\circ} \mathrm{C}\right) \times 64 / 60.5\left({ }^{\circ} \mathrm{C} / \mathrm{s}\right)=81 \mathrm{w}
$$

Similar kinds of analyses can be constructed for other power losses to determine how the system can be designed more efficiently. At the time, it was not cost effective to perform a complete energy balance to determine where all the power losses 
were and to further determine which ones could be reduced. These types of analyses would be valuable for a system that is set up and tailored to consistently produce the same product over a long period of time.

The second spray period during this spray trial occurred during the 2200 to $2250 \mathrm{~s}$ time interval. The induction power supply unit controls for the gas heater were maintained at their maximum settings. For this spray period, the argon supply temperature was sustained at $1372^{\circ} \mathrm{C}$, and the nozzle supply pressure was increased to 22 psia.

During this spray period, the rotating tube was moved perpendicular to the spray plume. By observing the substrate temperature in Figure 17, a drastic rise in temperature is seen when the spray plume was being consolidated on the 0.04-in. thick substrate at the beginning of the spray period as contrasted to spraying on the 0.02-in. thick substrate at the end of the spray period.

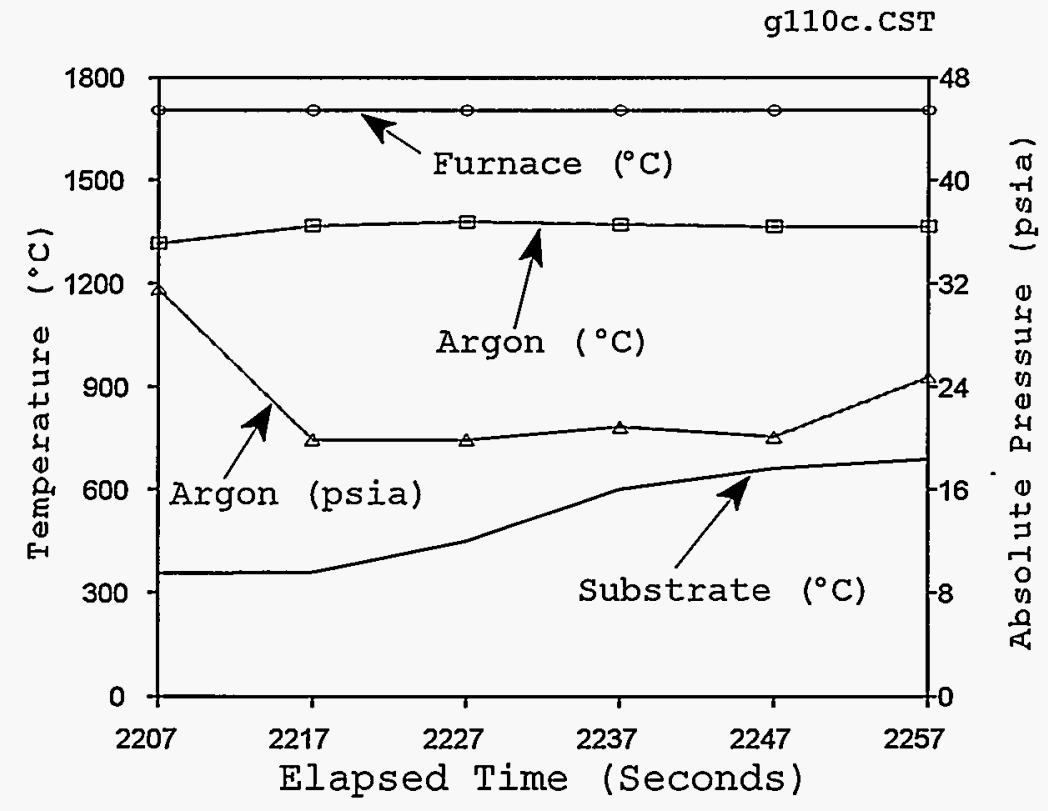

Figure 17. Second Spray Period. 
The measurements recorded for the final spray period for this spray trial were between $2280 \mathrm{~s}$ and $2350 \mathrm{~s}$ and are depicted in Figure 18. The argon supply temperature could be maintained at $1304^{\circ} \mathrm{C}$. The nominal nozzle supply pressure used was 28 psia. During this spray period, the particle consolidation occurred on the portion of the tube with a wall thickness of 0.02 in. This is further evidenced by the high substrate temperature of $600^{\circ} \mathrm{C}$.

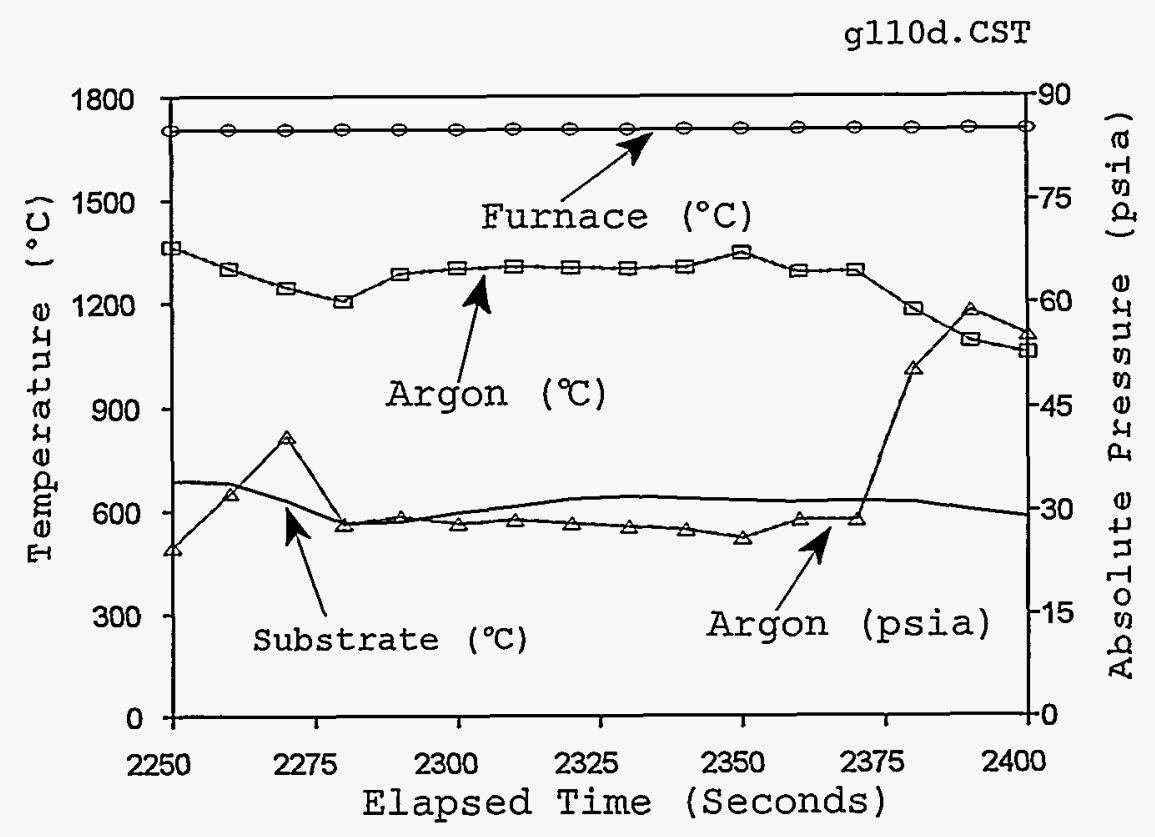

Figure 18. Final Spray Period.

other parameters which have been calculated and/or measured for the three spray periods include:

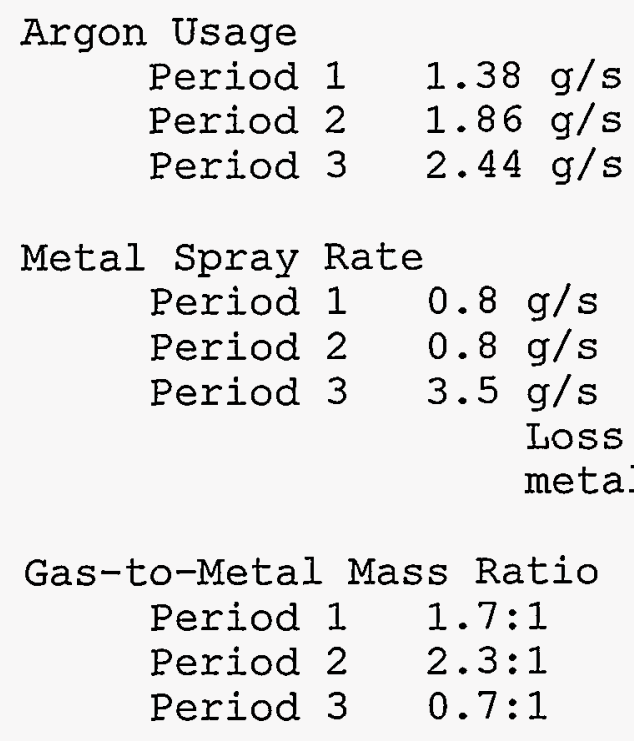
Gas-to-Metal Mass Ratio
Period 1 1.7:1
Period 2 2.3:1
Period $30.7: 1$


The metal charge used in this spray trial was $544 \mathrm{~g}$. An estimated $40 \mathrm{~g}$ remained in the crucible, $34 \mathrm{~g}$ was collected from the chamber floor, and $470 \mathrm{~g}$ was consolidated on the substrate.

\subsection{EXPERIMENTS UTILIZING GRAPHITE SUBSTRATES}

Current processing techniques in the heavy metals industry use graphite as furnace/crucible material, mold material, etc. It was, therefore, desirable to know how the surrogate alloy would behave using coated and uncoated graphite as the substrate material. Results of experiments using graphite substrates are documented in Sect. 4.2.1 and sect. 4.2.2.

\subsubsection{Graphite Rod With Coatings}

\subsubsection{Substrate Preparation}

Grade AGSX graphite rod was used for the first spray trial. The objectives of this spray trial were to compare the effects of spraying on uncoated graphite to spraying on various hightemperature coatings. A 3.3-in. diameter rod measuring 14 in. in length was machined to 3.2-in. diameter. The first 2 in. of the rod were left uncoated. The coatings used were Aremco Products, Inc., Pyro Paints. The coatings were applied in 2-in. wide bands around the 3.2-in. diameter machined graphite. The second 2-in. band on the rod was coated with yttrium oxide $\left(634-\mathrm{Y}_{2} \mathrm{O}_{3}\right)$, the third band was molybdenum (634-Mo), the fourth band was zirconium oxide $\left(634-\mathrm{ZrO}_{2}\right)$, and the final band was boron nitride (634-BN).

Application of these coatings was first made on sections of test graphite. The amount applied was governed by how much coating material was required to provide a uniform coated appearance. A half-inch wide, camel hair brush was mounted in the threading assembly on a machine lathe. The threading assembly was set at 20 threads per in. The machine lathe was set to turn at $80 \mathrm{rpm}$. The coating material was applied to the camel hair brush with a syringe having a 16 gauge needle.

The coatings were applied as follows:

Yttrium Oxide $\left(\mathrm{Y}_{2} \mathrm{O}_{3}\right)$

$16 \mathrm{~g}$ of liquid over $20 \mathrm{sq}$ in. to provide a 0.015 -in. thick coating when dried.

Molybdenum (Mo)

$8.5 \mathrm{~g}$ of liquid over $20 \mathrm{sq}$ in. to provide a 0.008 -in. thick coating when dried. 
Zirconium Oxide $\left(\mathrm{ZrO}_{2}\right)$

$6 \mathrm{~g}$ of liquid over $20 \mathrm{sq}$ in. to provide a $0.003-\mathrm{in}$. thick coating when dried.

Boron Nitride (BN)

$5 \mathrm{~g}$ of liquid over $20 \mathrm{sq}$ in. to provide a $0.003-i n$. thick coating when dried.

Having applied the coatings as described above, the machine lathe was left running at $80 \mathrm{rpm}$ for 3 hours. This provided a slow air dry, while keeping the coating material at a uniform thickness. The Pyro Paint series coatings required a minimum drying time of 2 hours at room temperature. The graphite rod was allowed to cure overnight before being used in the spray trial.

\subsubsection{Melting Considerations}

Before the spray period commenced in this spray trial, a brief time interval was devoted to incrementally adding mass to the furnace after the material in the furnace had melted. By evaluating these data, the operator can determine how much additional power will be required in a subsequent spray trial to add material to the furnace while spraying.

The temperature of the system components was brought to $1700^{\circ} \mathrm{C}$ and allowed to stabilize. As the small pieces of surrogate alloy were added to the furnace, the decrease in melt temperature was recorded on the DAS system. The melt temperature during this spray trial is illustrated in Figure 19. This temperature differs from the melt temperature curve shown in Figure 15, Sect. 4.1, by a distinct dip in the curve at $2120 \mathrm{~s}$.

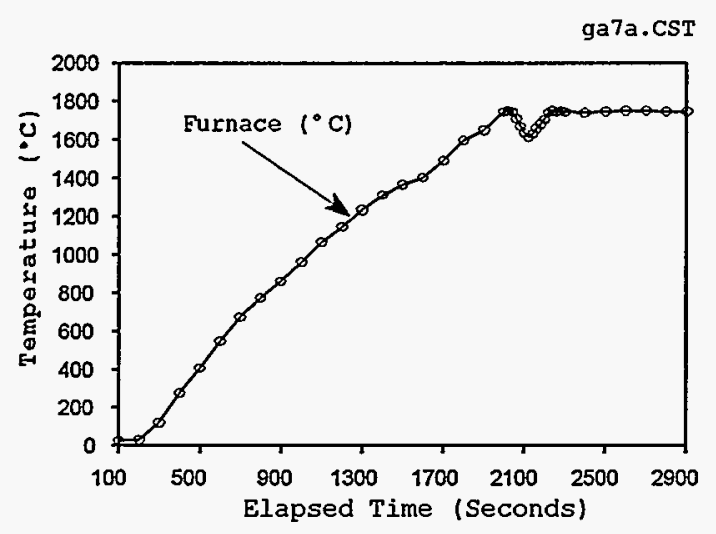

Figure 19. Melt Temperature. 
The small pieces of surrogate alloy added at the time/temperatures indicated in Figure 20 include:
A: $\quad 17 \mathrm{~g}$ at time/temperature
B: $\quad 34 \mathrm{~g}$ at time/temperature
C: $\quad 45 \mathrm{~g}$ at time/temperature
D: $\quad 54 \mathrm{~g}$ at time/temperature

ga7b.CST

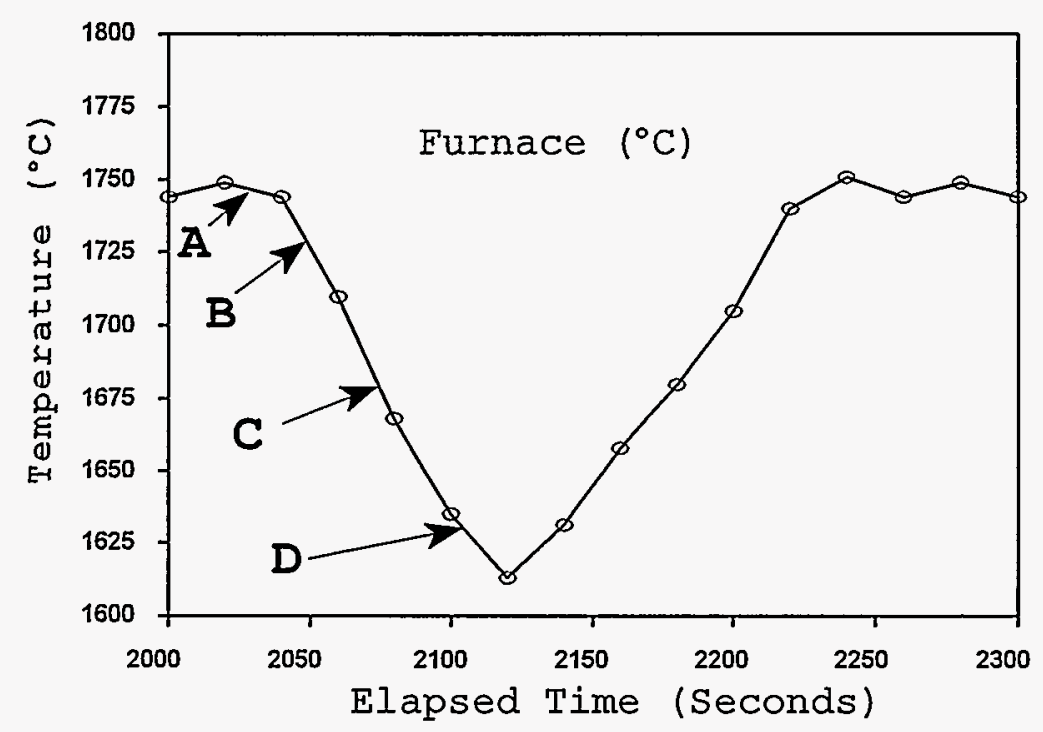

Figure 20. Effect on Melt Temperature Due to Incrementing Mass.

The addition of these incremental masses will approximate adding the surrogate alloy at the rate of $1.766 \mathrm{~g} / \mathrm{s}$. Upon adding these four pieces of material to the melt, the furnace temperature decreased to $1620^{\circ} \mathrm{C}$. The power controls were then increased in the induction power supply unit. This caused the furnace temperature to be elevated again to the $1750^{\circ} \mathrm{C}$ starting point in the same approximate time interval that the furnace had been cooled by adding the unmelted surrogate alloy.

The theoretical power required to create this temperature change in the surrogate alloy over this time interval is computed here. The total amount of surrogate alloy in the furnace at the $2120 \mathrm{~s}$ time interval was $719 \mathrm{~g}$. The calculations are dependent upon 50\% of the alloy being tungsten and 50\% of the alloy being iron. The temperature increased from $1620^{\circ} \mathrm{C}$ to $1750^{\circ} \mathrm{C}$ in $100 \mathrm{~s}$. 
For tungsten component of alloy:

$$
0.13\left(\mathrm{~J} / \mathrm{g}^{\circ} \mathrm{C}\right) \times 359.5(\mathrm{~g}) \times 130 / 100\left({ }^{\circ} \mathrm{C} / \mathrm{s}\right)=61 \mathrm{w}
$$

For iron component of alloy:

$$
0.44\left(\mathrm{~J} / \mathrm{g}^{\circ} \mathrm{C}\right) \times 359.5(\mathrm{~g}) \times 130 / 100\left({ }^{\circ} \mathrm{C} / \mathrm{s}\right)=205 \mathrm{w}
$$

The total theoretical power required to raise the temperature of $719 \mathrm{~g}$ of the surrogate alloy from $1620^{\circ} \mathrm{C}$ to $1750^{\circ} \mathrm{C}$ in $100 \mathrm{~s}$ :

$$
61 w+205 w=266 w
$$

The amount of power required to service the induction power supply unit was also measured during this time period. An additional $850 \mathrm{w}$ were needed by the induction power supply to raise the melt temperature the $130^{\circ} \mathrm{C}$ in $100 \mathrm{~s}$.

Based on these computations, projections specific to the amount of additional power needed for continuous operation of the current spray system can be assessed. First, the theoretical power to heat and melt the surrogate alloy at $1 \mathrm{~g} / \mathrm{s}$ is calculated as follows.

For the tungsten component heat of fusion:

$$
35.4(\mathrm{~kJ} / \mathrm{mole}) \times 1 / 183.5(\mathrm{~mole} / \mathrm{g}) \times 0.5(\mathrm{~g} / \mathrm{s})=96 \mathrm{w}
$$

For the tungsten component temperature change:

$$
0.13\left(\mathrm{~J} / \mathrm{g}^{\circ} \mathrm{C}\right) \times 0.5(\mathrm{~g} / \mathrm{s}) \times 1700\left({ }^{\circ} \mathrm{C}\right)=110 \mathrm{w}
$$

For the iron component heat of fusion:

$$
13.8(\mathrm{~kJ} / \mathrm{mole}) \times 1 / 55.85(\mathrm{~mole} / \mathrm{g}) \times 0.5(\mathrm{~g} / \mathrm{s})=124 \mathrm{w}
$$

For the iron component temperature change:

$$
0.44\left(\mathrm{~J} / \mathrm{g}^{\circ} \mathrm{C}\right) \times 0.5(\mathrm{~g} / \mathrm{s}) \times 1700\left({ }^{\circ} \mathrm{C}\right)=374 \mathrm{~W}
$$

The total theoretical power to heat and melt $1 \mathrm{~g} / \mathrm{s}$ of the surrogate alloy would be:

$$
96 w+110 w+124 w+374 w=704 w
$$

As presented earlier, it requires $850 \mathrm{w}$ of power to the induction power supply for $250 \mathrm{w}$ to be delivered to the melt. Given this figure, the power requirement per gram of alloy for continuous operation at $1 \mathrm{~g} / \mathrm{s}$ is computed as: 


$$
850 \mathrm{~W} / 250 \mathrm{~W} \times 704 \mathrm{w}=2394 \mathrm{~kW}
$$

When using an induction heating system in industry, the size of the induction power unit, the frequency of its operation, and the load coils that are being operated are all optimized. With such optimization, as much as $70 \%$ of the input power can be recovered. Industry uses $0.87 \mathrm{~J} / \mathrm{g}^{\circ} \mathrm{C}$ for melting commercial steels. This converts to having 50\% of the input power delivered as theoretical energy to melting the metal. For the experimental system used in this exercise, it was not cost effective to order electronic components to optimize the power supply. However, with optimization of an induction system, one additional kw of electrical power will generally provide 0.7 additional $\mathrm{kw}$ of theoretical power delivered to the system.

\subsubsection{Spray Period - Graphite Rod}

During this spray period, the 3.2-in. diameter graphite rod discussed earlier in this section was positioned beneath the spray nozzle. The surface of the rod was 2 in. from the nozzle exit, and the substrate positioner was set to travel perpendicular to the spray plume. The 10-in. length of coated and uncoated graphite surface passed under the nozzle during the $367 \mathrm{~s}$ spray period. Each 2-in. band required $73 \mathrm{~s}$ of spray time. As each of the bands passed through the spray plume, the rotation of the rod was varied from 10 to $14 \mathrm{rpm}$. The distance from the nozzle exit was varied from the beginning $1.5 \mathrm{in}$. to $.5 \mathrm{in}$. and back to $1.5 \mathrm{in}$.

Figure 21 illustrates the temperature of the liquid metal (Furnace ${ }^{\circ} \mathrm{C}$ ), the nebulizing gas temperature (Argon ${ }^{\circ} \mathrm{C}$ ), and the nozzle supply pressure (Argon psia). Sections of this spray period are further identified in Figure 21 as:

A: Prespray period to determine operating supply pressure desired.

B: $\quad$ Spray period applying a coating (2334 to 2700 s):

Machined graphite

Yttrium oxide coated graphite

Molybdenum coated graphite

Zirconium oxide coated graphite

Boron Nitride coated graphite
2334 to $2407 \mathrm{~s}$

2407 to $2481 \mathrm{~s}$

2481 to $2554 \mathrm{~s}$

2554 to $2627 \mathrm{~s}$

2627 to $2700 \mathrm{~s}$

C: Spray period cleaning furnace. 


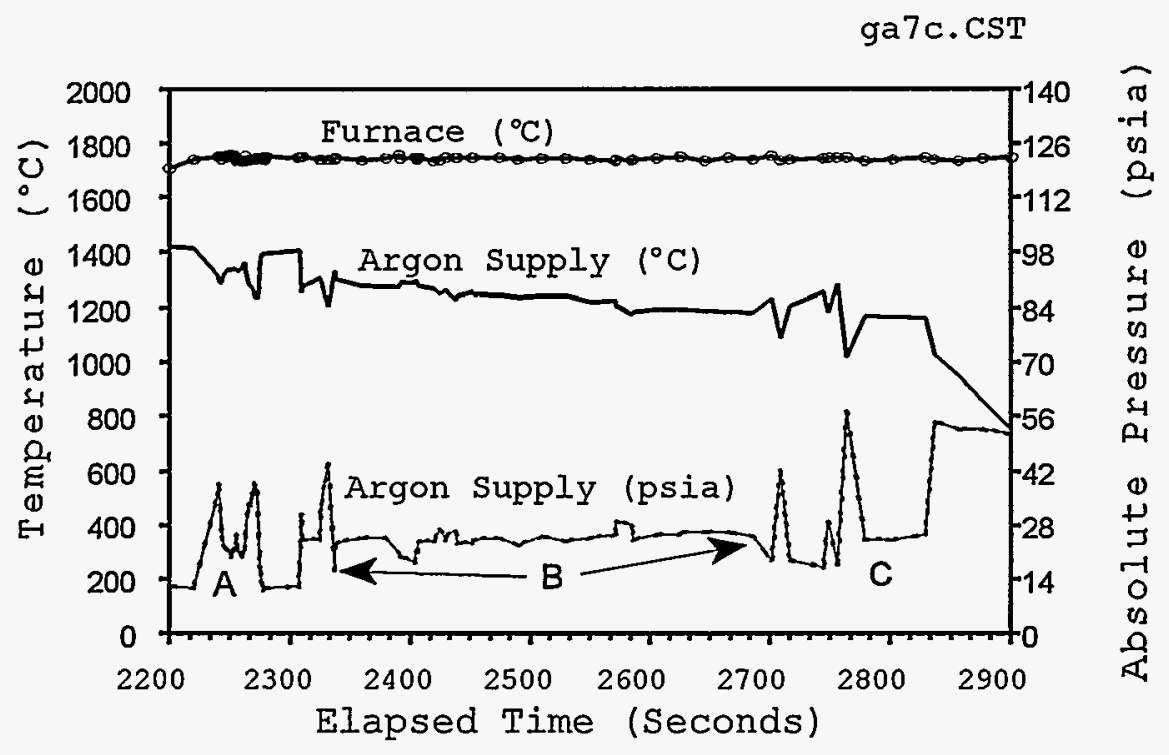

Figure 21. Graphite Rod Spray Trial Parameters.

Collectively, these spray periods were of sufficient duration for other spray parameters to come to equilibrium. Figure 22 depicts recordings of temperatures from the various other sensors. By examining these values, requirements for specific component parts can be determined. For example:

The connector (Gas Heater Connector ${ }^{\circ} \mathrm{C}$ ) which attaches the argon supply line to the gas heater must be capable of withstanding $800^{\circ} \mathrm{C}$ at the gas heater end while maintaining a safe working temperature of 100 to $200^{\circ} \mathrm{C}$ at the inlet.

Also represented is the ambient chamber temperature (Chamber $\left.{ }^{\circ} \mathrm{C}\right)$ which is monitored near the spray area. The temperature of the exiting chamber gases (Exhaust ${ }^{\circ} \mathrm{C}$ ) is monitored just prior to entering the exhaust filter illustrated previously in Figure 1. At this location, the purge gases have mixed with the nebulizing gas. 


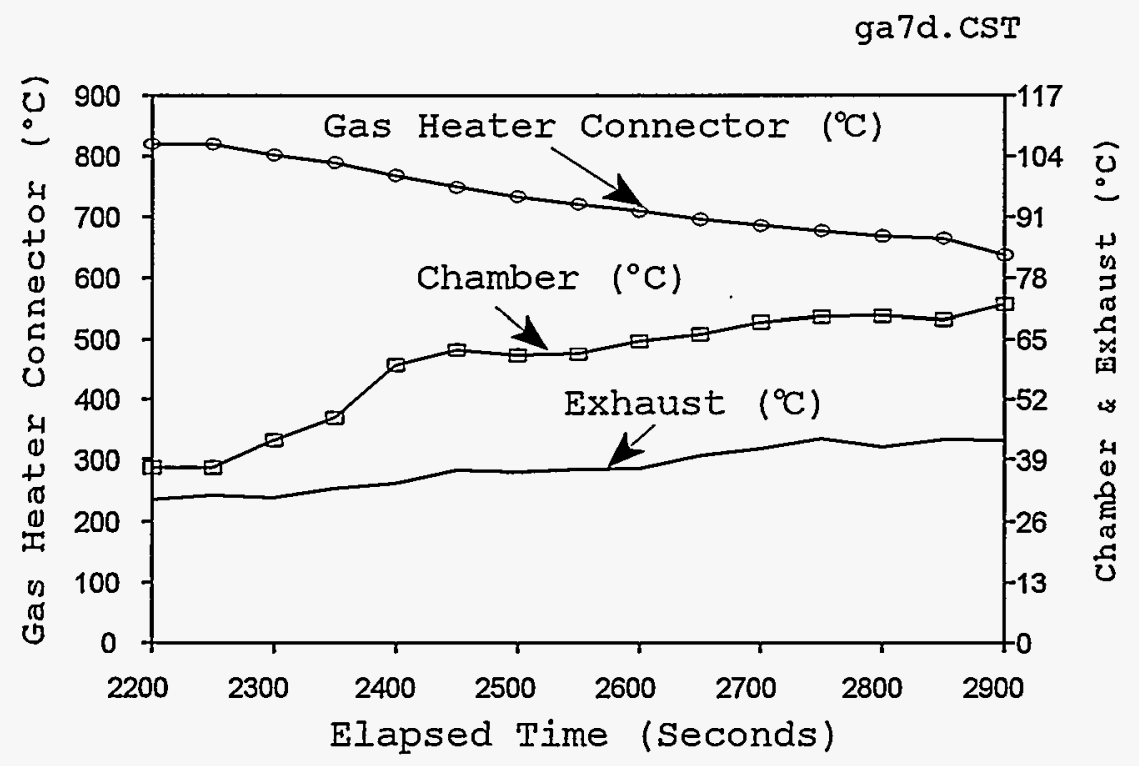

Figure 22. Parametric Recordings.

\subsubsection{Graphite Plate With Coatings}

This spray trial was designed to investigate the following four areas: (1) Evaluate Type CS grade graphite as a substrate material; (2) evaluate the effect of four distinct coating materials applied to the graphite; (3) obtain as-sprayed material using various nozzle supply pressures and substrate speeds; and (4) collect samples for analyses from the spray plume.

\subsubsection{Substrate Configuration}

The spray trial utilized a substrate fabricated from two CS grade, graphite plates. The plates, when joined, measured approximately 9 in. by 10 in. Areas of the substrate ranged from $0.1-i n$. thick to $0.2-i n$. thick. Holes measuring $3 / 4$ in. in diameter were drilled in the plates. These locations allowed for periodic collection of plume particles in a container of liquid argon positioned beneath the substrate. These particles were collected to determine which particle diameter was contributing most to the mass of the spray plume. The mass of iron-tungstencarbon alloy used during the trial was $0.5 \mathrm{~kg}$. The $\mathrm{Y}_{2} \mathrm{O}_{3}, \mathrm{ZrO}_{2}$, Mo, and $\mathrm{BN}$ were applied in 1/2-in. strips on the graphite substrate. A narrow band of uncoated graphite measuring approximately 3/8-in. wide separated each of the coatings. The surrogate alloy was applied along portions of these strips and spray passes were 
directed across all the strips. Failure of the liquid orifice prior to completion of the spray run destroyed portions of the previously as-sprayed product.

\subsubsection{Spray Trial}

During the ten minute spray period, 11 distinct nozzle pressures were used. Following the spray trial, the data log was analyzed and the parametric settings identified on the samples selected for further analysis. General data from this spray trial (i.e., the time required to reach spray conditions, the maximum argon supply and melt temperatures attained, etc.) closely resembles the spray trial depicted in Figure 15 (see sect. 4.1). Data from the plume collection are presented in sect. 5.1. Information from the respective spray periods that samples were selected from was averaged, and parametric values are chronicled in Sect. 5.3, Machined Graphite Plate with Coating.

\subsection{COLLECTION OF POTENTIALIY AIRBORNE PARTICLES}

There are two types of overspray particles. The first variety are the larger diameter particles that can be swept from the spray chamber floor. These particles were discussed in the introduction of sect. 4. In addition to these powders, a potentially more hazardous particle produced by a metal spray system are those particles small enough to remain airborne. These minute particles can be transported in the discharge gases or may collect on various surfaces within the spray system. Because of their high surfaceto-volume ratios, pyrophoric concerns are of importance, particularly if there is a potential for large concentrations to accumulate.

When spraying in an atmosphere with small amounts of oxygen, these powders present less of a hazard. The powders oxidize as they are formed during the spray process and accumulate as a relatively benign product. If the spray atmosphere is free of oxygen, these particles can accumulate on surfaces within the spray system without having the protective oxide layer. A sudden ingress of gas containing oxygen can cause the particles to again become airborne and exist in concentration levels that could be explosive.

For the purpose of this Program, it was important to establish a worst case analysis to identify the powders that might be present in the discharge gases or would present a high pyrophoric danger. 


\subsubsection{Description of Sampling Arrangement}

To evaluate this type of overspray, a hemisphere with a 6-in. diameter was chosen as the substrate. The hemisphere provided a smooth contour in all directions that allowed the small particles to escape consolidation and be carried away in the discharge gases.

The inlet to a sample line was placed at the edge of the spray plume where consolidation onto the hemisphere was occurring. The center line of the hemisphere was slightly offset from the center of the spray plume. This caused the escaping gases to preferentially be deflected in the direction of the sample line.

The face velocity of the sample line inlet was established to be greater than the velocity of the deflected gases. The volumetric flow of the sample gas was regulated to be one-third of the argon flow supplying the nozzle. A horizontal sample line measuring 50 centimeters $(\mathrm{cm})$ in length and $0.9 \mathrm{~cm}$ in diameter provided a gas velocity of $468 \mathrm{~cm} / \mathrm{s}$. These conditions would ensure a worst case representation of the particles that might exist in the lower gas velocities of the chamber (e.g., gas velocities through the $10-\mathrm{cm}$ diameter chamber discharge into the filter only approximate $103 \mathrm{~cm} / \mathrm{s}$ ).

\subsubsection{Cascade Impactor Collections}

The sample gas was drawn through a seven stage, cascade impactor to collect and separate the particles for analyses by SEM/EDS. A brief explanation of the cascade impactor used during the Extended Surrogate Alloy Experiments is provided in the introduction of Sect. 2. Approximately $450 \mathrm{~g}$ of material was sprayed over a period of 4.7 minutes (min). Five distinct nozzle supply pressures were used. The gases, deflected from the hemispherical surface, were continuously sampled by the cascade impactor during the full spray period.

\subsubsection{Results From Cascade Impactor Collections}

Particles could not be located on the first cascade impactor stage. This stage is designed to collect the largest particles entering the cascade impactor (i.e., aerodynamic diameter of $15 \mu \mathrm{m}$ and larger). The largest metal particles were identified on stage 2 and were $3 \mu \mathrm{m}$ in diameter. The smaller particles identified in the filter with $10,000 \mathrm{x}$ magnification were $0.07 \mu \mathrm{m}$ in diameter. There were two categories of particles identified on the six remaining cascade impactor stages. The small, bright spheres on the back scattered electron (BSE) beam images indicate one category of particle. These images are recorded as stage 2-1, stage 3-1, etc., in Appendix B. The second category of particle displayed 
compositions characteristic of the ceramics used in the component fabrications. These particles are more evident on the forward scattered electron beam images of the photomicrographs. These are identified as Stage 2-2, stage 3-2, etc., in Appendix B. Particles in the $(-1)$ category reveal compositions commensurate with the surrogate alloy and are the particles of most interest.

The analyses of the particles on the impactor stages illustrate that as particles decrease in size, background elements surrounding the particles being analyzed will also be detected during the spot analysis (e.g., in stage 6-1, zirconium and aluminum were also identified in the analysis of the iron-tungsten particles). The diameter of the spot analysis field is $2 \mu \mathrm{m}$.

To determine the mass on the substrate surface, extensive time and special equipment would be required. From past experience in processing similar data, the cascade impactor stages will average less than 10 micrograms $(\mu \mathrm{g})$ of total particle mass per stage. The cascade impactor stages have been individually archived and are available should further analysis be requested.

\subsubsection{Airborne Particulate Generated}

Over $30 \%$ of the nebulizing gas being deflected from the substrate surface was analyzed and less than $100 \mu \mathrm{g}$ of particulate was estimated to be on the seven cascade impactor stages and filter. The total amount of airborne particulate from this spray period can then be calculated to be less than $300 \mu \mathrm{g}$. During this spray trial, $450 \mathrm{~g}$ of material was sprayed.

This spray period demonstrated that less than 0.7 milligrams (mg) of airborne particulate per $1 \mathrm{~kg}$ of as-sprayed material was generated by the nebulizing process. 


\section{AS-SPRAYED PRODUCT - SAMPLE ANALYSES}

At the conclusion of each spray trial, a preliminary data reduction was performed and the parametric data was reviewed. This data was then correlated to the as-sprayed product for that trial. selected portions of the as-sprayed product were removed and standard metallurgical mounts were prepared for examination of the product for porosity and grain structure. Special thermomechanical treatment was not performed on the as-sprayed samples.

The spray conditions that produced the sample are included with the metallurgical results. There are instances when the data are estimated. A typical example of estimated data is the temperature of the melt. The thermocouples monitoring the temperature of the melt were subject to frequent failure. When failure occurred, the averaged values from prior spray periods having identical settings on the induction power supply units were used.

\subsection{OVERSPRAY}

A sheet of mica with a 0.011-in. thickness was used to cover the chamber floor. Blanketing the chamber floor in this manner allowed for greater efficiency during retrieval of the particulate that accumulated during the spray trial. Following each spray trial, a fine bristle brush was used to clean the components and recover particulate from the chamber floor. These accumulations from the interior of the chamber were weighed and then maintained in a container. The mass values from the chamber particulate ranged from $34 \mathrm{~g}$ during Spray Trial 1 to $382 \mathrm{~g}$ during Spray Trial 5. In the spray trial that produced $34 \mathrm{~g}$ of overspray, little boiling action in the melt was noted. There were four spray trials that provided a viable representation of overspray. These included three trials coating carbon steel tubes and one trial coating a hemisphere. In these four spray trials, $2705 \mathrm{~g}$ were sprayed and $269 \mathrm{~g}$ were recovered from the chamber floor.

Extensive characterization of these powders was not part of the work scope, however, the powders have been archived and are available for further analysis.

The photomicrograph in Figure 23 illustrates a representative sample of the larger overspray particles that accumulated on the chamber floor. Ceramic material from the spray system components could also be observed in the sample. The larger particles observed in this photomicrograph are a result of the boiling action that occurred in the melt (previously discussed in sect. 4). These particles would erupt from the melt onto the chamber floor and become mixed with the overspray particles from the spray plume. 
The spray plume will not have particles larger than $75 \mu \mathrm{m}$ in diameter, unless erosion or wear is having an effect.

At 10,000X magnification, particles could be identified in the $0.2 \mu \mathrm{m}$ diameter range (see Figure 24). To provide a more complete analysis of the overspray powders, forward scattered electron beam images as well as back scattered electron beam images would need to be performed on a selection of samples from the overspray collections. Such analysis would distinguish which of the tiny particles were dense metal and which might be ceramic compositions. Analysis of this nature would also reveal what quantities exist and enable estimations to be made relative to how these quantities might accumulate to form a pyrophoric hazard.

\subsection{PLUME COLLECTIONS}

Two spray trials incorporated a liquid argon container positioned beneath a flat, plate substrate which contained holes for the spray plume to pass through and enter the reservoir. The first trial utilized a 0.08-in. thick carbon steel plate with 1/2in. holes drilled on 1-in. centers. As the spray crossed the edge of the hole, consolidated material from the edge of the flat plate dropped into the container. Following the spray trial, there were clearly two categories of particles. The larger agglomerated particles were considered to be the material observed falling from the substrate plate into the Iiquid argon.

During the spray trial utilizing the machined graphite plate, the substrate was moved at approximately 1 in. per second. Throughout one of the spray periods, five of the 3/4-in. holes traversed beneath the spray plume. Eleven $g$ of powder were collected in the liquid argon. A representative sample of this powder is shown in Figures 25 and 26.

\subsection{GRIT BLASTED CARBON STEEL TUBE}

The purpose of these spray trials was to produce samples with various cooling rates and then examine the as-sprayed product to determine if segregation of the iron-tungsten alloy could be detected. At the same time, calculations were made to determine the heat capacity for the spray plume (refer to sect. 4).

\subsubsection{First Carbon steel Tube}

In the third spray trial, a single pass coating was deposited over the surface of the grit blasted tube. There were three wall thicknesses (i.e., 0.06, 0.04 and 0.02 in.) associated with this tube. These thicknesses provided different cooling effects by the 


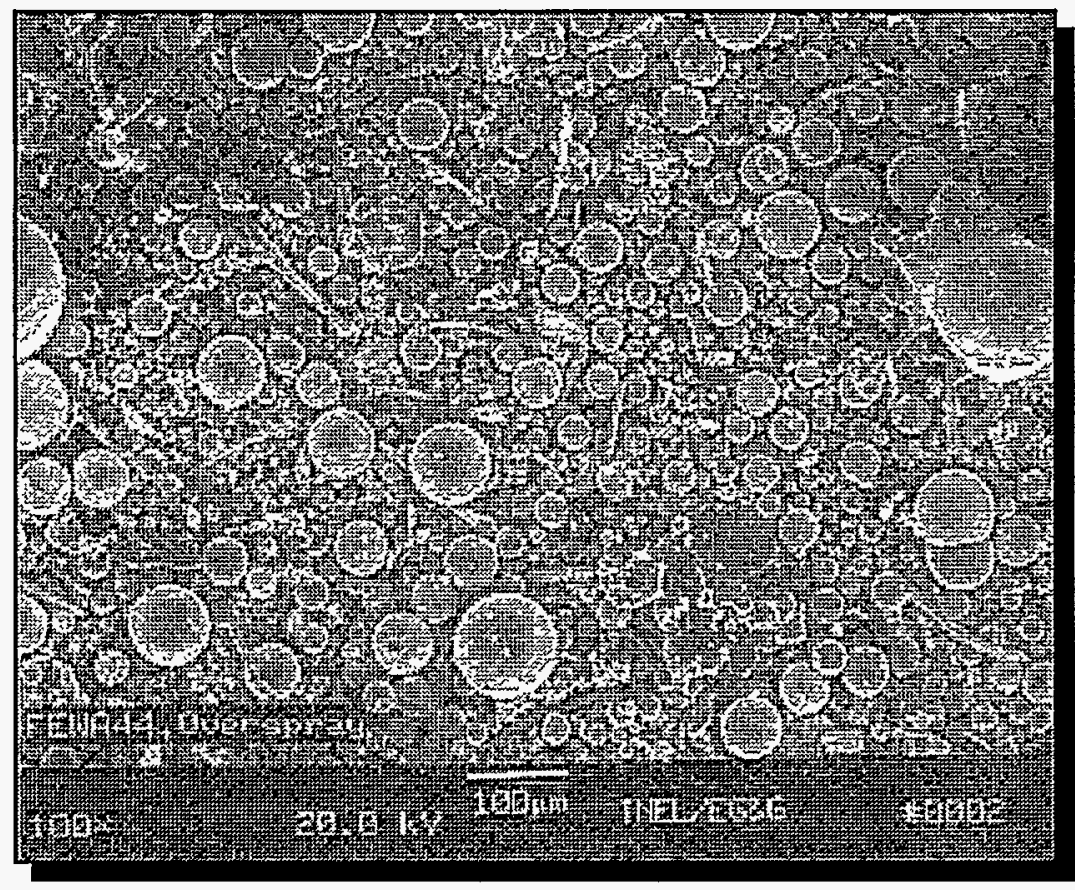

Figure 23. Overspray from Chamber Floor, 100X.

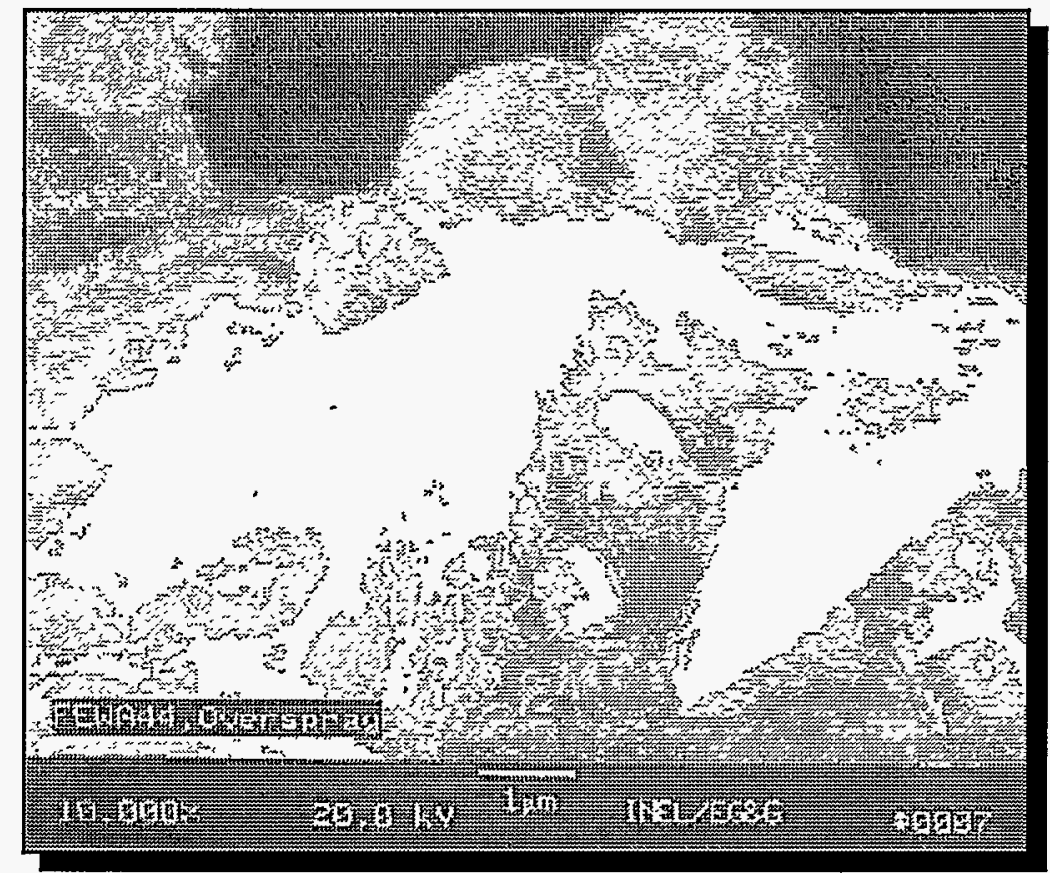

Figure 24. Overspray from Chamber Floor, 10,000x. 


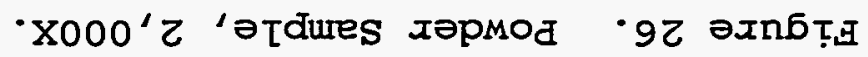

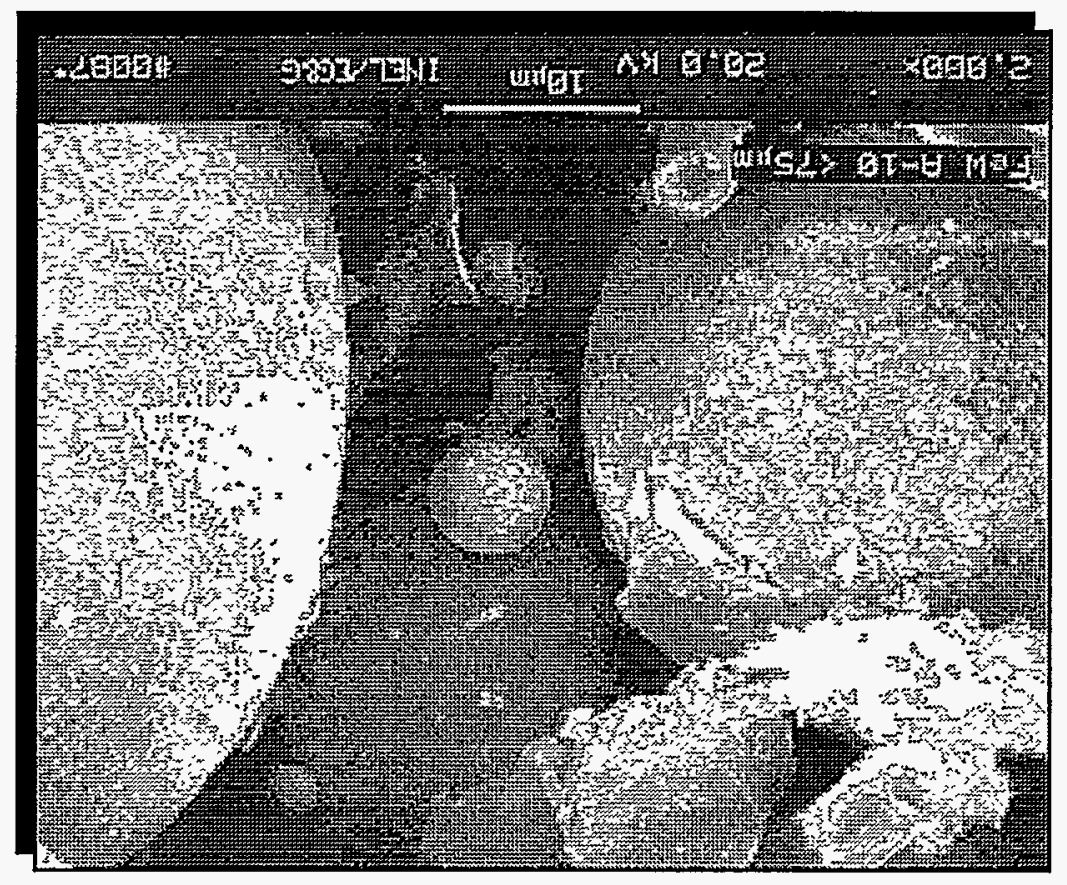

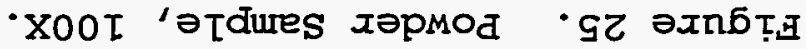

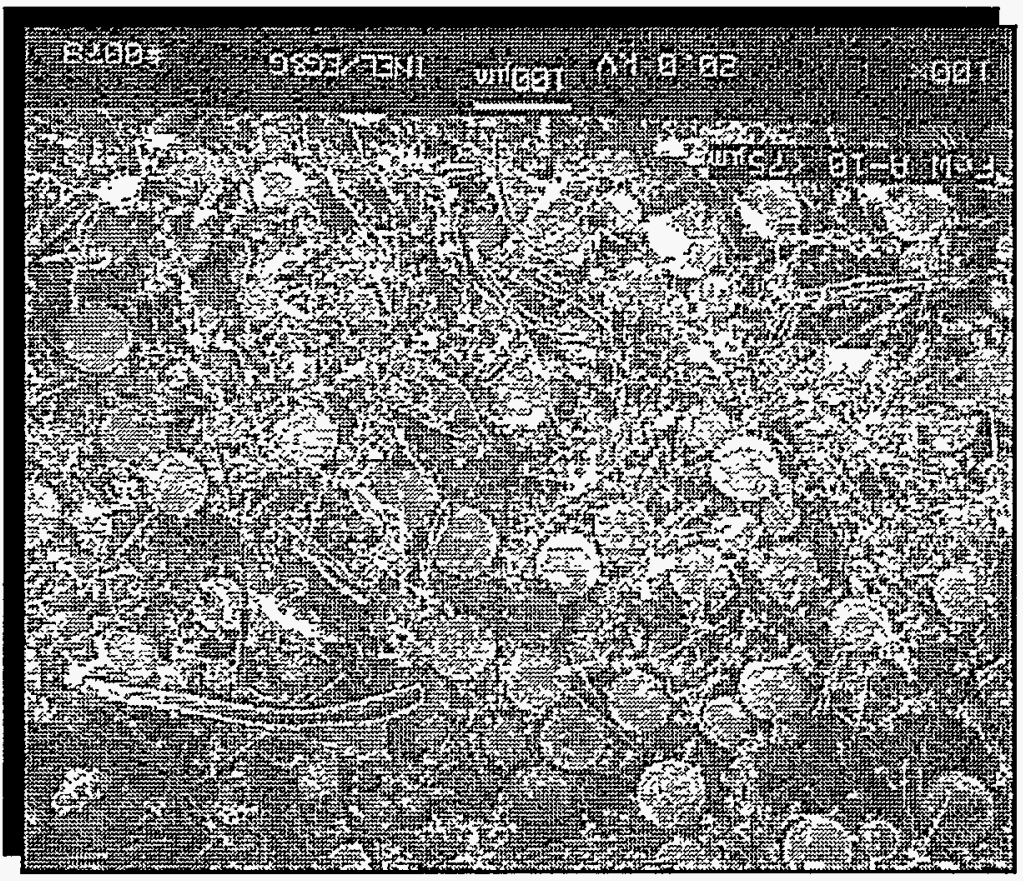


substrate on the as-sprayed product. The spray period commenced on the 0.06-in. thick portion of the tube and terminated on the 0.02in. thick portion of the tube. A section from each thickness was prepared for chemical analysis (Section 1-FewA41; Section 2FeWA42; and Section 3-FeWA43).

The photomicrographs revealed low porosity in the as-sprayed material. At 500X magnification, some surface irregularities were visible that were not filled by the consolidating spray (see Figure 27). A spot analysis was performed at selected locations for each sample. These locations included the following: (1) on the substrate material, (2) on the substrate material near the interface, (3) On the as-sprayed material near the interface, and (4) On locations in the as-sprayed material that had different physical appearances (see Figure 28).

The chemical analyses evidenced segregation in the prime constituents of the as-sprayed material when consolidation was occurring on the 0.02-in. thick wall (see Table 2). The deposition rate during this interval was sufficient to melt holes at random locations in the substrate. The nozzle supply pressure was increased from 22 to 29 psia, thereby increasing the gas cooling. This prevented further melting of the substrate, however, by the end of the spray period, the substrate and as-sprayed material were yellow.

The spot analysis technique, used to determine the chemical composition, had a detection window of $2 \mu \mathrm{m}$ diameter. The irontungsten alloy was provided by MMES, and therefore, it was not examined for compositional variations. The range of iron or tungsten enrichment at the different sample locations are listed in Table 2 .

In addition to performing the chemical analyses, hardness tests were conducted as a second means of evaluating the homogeneity of the as-sprayed material. The tests performed on each sample evidenced an as-sprayed product with a small variance in hardness. Samples 1 and 2 had the same hardness values. Sample 3 , the sample consolidated on the 0.02-in. thick portion of the substrate tube, had slightly larger values. This is the sample that also had the tungsten enriched areas (see Tables 2 and 3 ).

\subsubsection{Second Carbon Steel Tube}

Having reviewed the results of the third spray trial, a fourth spray trial was performed to produce an as-sprayed sample with constant parameters. The substrate for this spray trial had a uniform thickness of $0.06 \mathrm{in.}$ One liquid orifice failed early in the spray period. To compensate for the additional liquid metal 


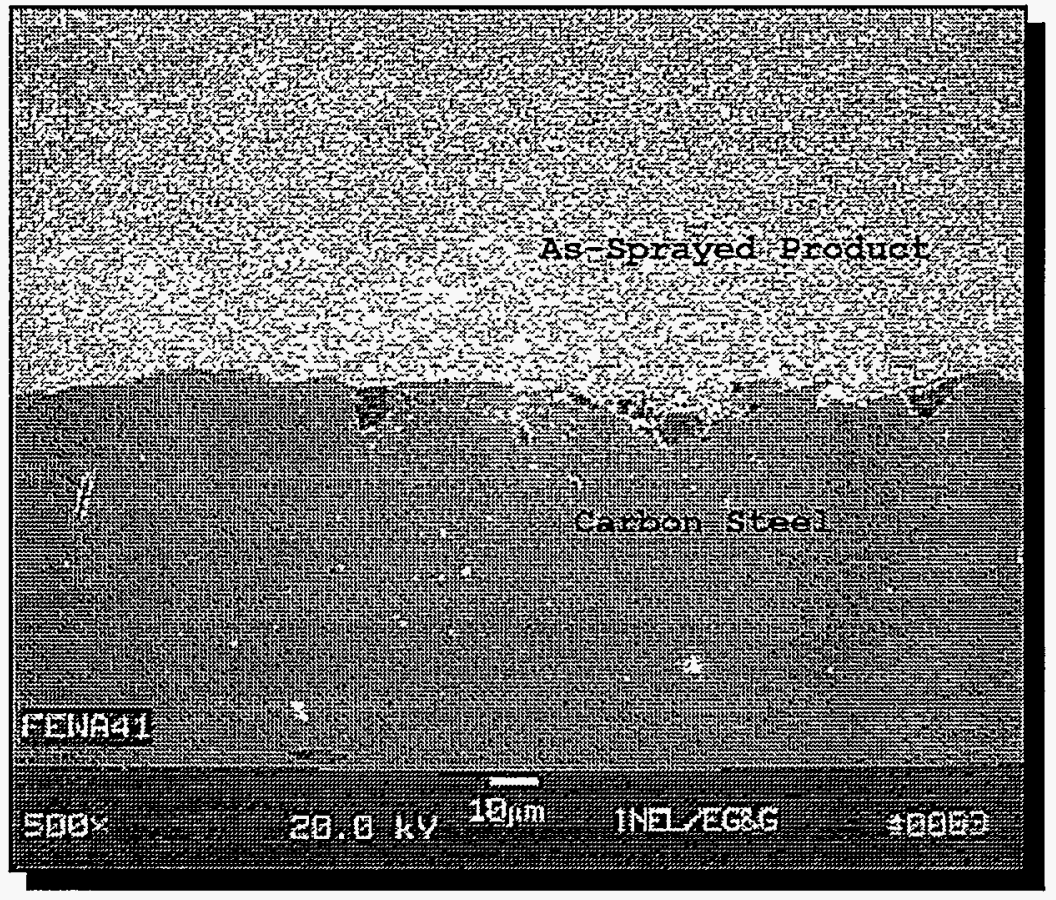

Figure 27. Grit Blasted Carbon steel Tube, 500x.

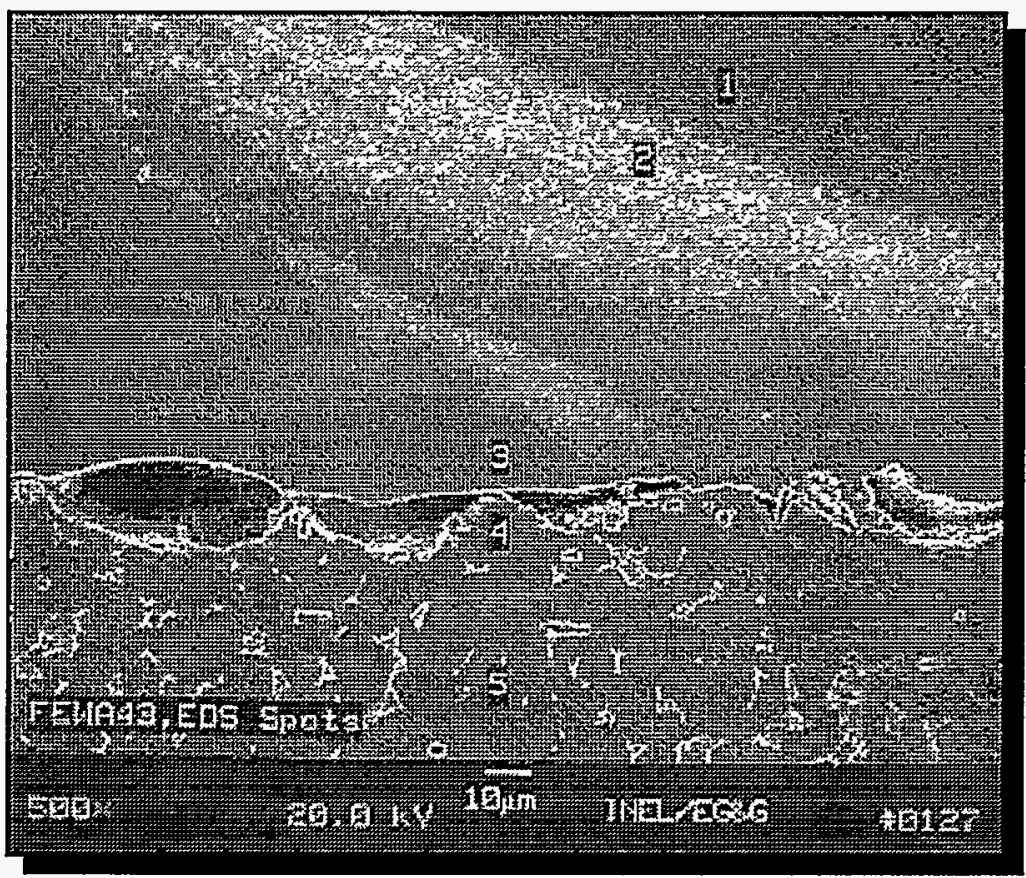

Figure 28. EDS Spots, Grit Blasted Carbon Steel Tube, 500x. 
Table 2. Spot Analysis Data - Iron \& Tungsten Enrichment Based on Standardless EDS Analysis ${ }^{a}$

\begin{tabular}{ccccccc}
\hline $\begin{array}{c}\text { Spot } \\
\text { No. }\end{array}$ & Element & Line & $\begin{array}{l}\text { Weight } \\
\text { percent }\end{array}$ & $\begin{array}{l}\text { Atomic } \\
\text { percent }\end{array}$ & $\begin{array}{l}\text { Precision } \\
\text { 2-Sigma }\end{array}$ & K-ratio \\
\hline & & & \multicolumn{2}{c}{ FewA41 } \\
1 & FE & KA & 53.85 & 79.34 & 0.50 & 0.5703 \\
& W & LA & 46.15 & 20.66 & 0.97 & 0.3891 \\
2 & Fe & KA & 51.83 & 77.98 & 0.49 & 0.5506 \\
& W & LA & 48.17 & 22.02 & 1.01 & 0.4084 \\
3 & Mn & KA & 0.40 & 0.41 & 0.08 & 0.0041 \\
& Fe & KA & 99.60 & 99.59 & 0.70 & 0.9961 \\
4 & Mn & KA & 0.39 & 0.39 & 0.08 & 0.0040 \\
& Fe & KA & 99.61 & 99.61 & 0.69 & 0.9962
\end{tabular}

Iterations $\quad 3$ to 5

FEWA42

$\begin{array}{rrrrrrr}1 & \text { Fe } & \text { KA } & 48.83 & 75.85 & 0.50 & 0.5212 \\ & W & \text { IA } & 51.17 & 24.15 & 1.05 & 0.4375 \\ 2 & \text { Fe } & \text { KA } & 55.20 & 80.22 & 0.53 & 0.5835 \\ & W & \text { LA } & 44.80 & 19.78 & 1.00 & 0.3765 \\ 3 & \mathrm{Mn} & \mathrm{KA} & 0.27 & 0.27 & 0.07 & 0.0027 \\ & \text { Fe } & \text { KA } & 99.73 & 99.73 & 0.73 & 0.9974 \\ 4 & \mathrm{Mn} & \mathrm{KA} & 0.46 & 0.46 & 0.11 & 0.0047 \\ & \mathrm{Fe} & \mathrm{KA} & 99.54 & 99.54 & 1.75 & 0.9956\end{array}$

Iterations 3 to 6

\section{FeWA43}

$\begin{array}{rrrrrrr}1 & \text { Fe } & \text { KA } & 36.27 & 65.20 & 0.42 & 0.3954 \\ & W & \text { LA } & 63.73 & 34.80 & 1.09 & 0.5657 \\ & \mathrm{Fe} & \mathrm{KA} & 45.06 & 72.97 & 0.46 & 0.4839 \\ 3 & \mathrm{~W} & \mathrm{LA} & 54.94 & 27.03 & 1.05 & 0.4749 \\ & \mathrm{Fe} & \mathrm{KA} & 39.99 & 68.69 & 0.44 & 0.4332 \\ & \mathrm{~W} & \mathrm{LA} & 60.01 & 31.31 & 1.09 & 0.5264 \\ & \mathrm{Mn} & \mathrm{KA} & 0.43 & 0.44 & 0.08 & 0.0044 \\ & \mathrm{Fe} & \mathrm{KA} & 98.05 & 99.09 & 0.72 & 0.9821 \\ & \mathrm{~W} & \mathrm{LA} & 1.53 & 0.47 & 0.31 & 0.0115 \\ 5 & \mathrm{Mn} & \mathrm{KA} & 0.36 & 0.36 & 0.08 & 0.0037 \\ & \mathrm{Fe} & \mathrm{KA} & 99.64 & 99.64 & 0.72 & 0.9965\end{array}$

Iterations $\quad 3$ to 6

Accelerating voltage

Beam - sample incidence angle

$\mathrm{X}$-ray emergence angle

$\mathrm{X}$-ray - window incidence angle
$20.0 \mathrm{KeV}$

$90.0 \mathrm{deg}$.

35.0 deg.

$0.0 \mathrm{deg}$.

BAtomic percent is normalized to 100 ; normalization factor: 1.000

${ }^{\mathrm{K}} \mathrm{K}$-ratio $=\mathrm{K}$-ratio $\times \mathrm{R}$; where $\mathrm{R}=$ reference $($ standard $) /$ reference $($ sample $)$

Source: Reprinted with permission from EG\&G Idaho, Inc. 
Table 3. Diamond Pyramid Number (Vickers), 200-Gram Load, Spray Trial 3

\begin{tabular}{|c|c|c|c|}
\hline FeWA4 & EeWA41 & EeWA42 & EeWA43 \\
\hline 1 & 1061 & 1049 & 1061 \\
\hline 2 & 1095 & 1061 & 1107 \\
\hline 3 & 1061 & 1120 & 1061 \\
\hline 4 & 975 & 1211 & 1084 \\
\hline 5 & 956 & 1095 & 1283 \\
\hline $\begin{array}{l}\text { Standard } \\
\text { Deviation }\end{array}$ & 60 & 64 & 93 \\
\hline $\begin{array}{l}\text { Sample } \\
\text { Average }\end{array}$ & 1030 & 1107 & 1119 \\
\hline Cross Section & Average & & 1085 \\
\hline Cross Section & Standard & Deviation & 80 \\
\hline
\end{tabular}

Source: Reprinted with permission from EG\&G Idaho, Inc. 
drawn into the nozzle throat, the supply pressure was increased to 45 psia. With this adjustment, a thin, uniform as-sprayed coating was applied over the surface of the tube. Prior to the end of this spray trial, the remaining two liquid orifices failed resulting in a deposition rate in excess of 14 grams per second (g/s). Near the end of the spray run, a fine spray plume occurred as a result of the furnace being nearly empty.

The as-sprayed product from this spray trial illustrated three dramatically distinct layers of as-sprayed material. The heat capacity of the substrate was the major cause for the solidification of the first layer. The second layer is a heavy deposit on a warm surface with little rapid solidification. The final layer is a fine nebulized spray applied to a very hot surface.

A 3-in. diameter, 6-in. long substrate tube is illustrated in Figure 29. From this length of tube, a section was removed from a location where the three layers were present. A cross section of this sample is shown in Figure 30. One area from this cross section was enlarged. The interfaces at the layer boundaries are represented in Figure 31. A gap can be observed at the interface between the substrate and the first layer. This is a result of the as-sprayed sample separating from the substrate during preparation.

The first layer was 0.015-in. thick. When observing this layer at 50X magnification, areas were identified with porosities as high as 30 percent. Acid etching to heighten the grain structure from the iron component and the grain structure from the tungsten component were performed. No evidence of grain structure could be found at $800 \mathrm{x}$ magnification.

The second layer was $0.06-i n$. thick and prominent grain structure was visible with the iron etching solutions. At $400 \mathrm{X}$ magnification, grain sizes from 2 to $12 \mu \mathrm{m}$ diameter could be detected. Figure 31 illustrates the layer 2-1 interface. At 200X magnification, the porosity observed was minimal in this layer.

The thicker portions of the third and final layer measured 0.006 in. The porosity associated with this layer was erratic and likely due to the intermittent operation of the nozzle as a result of the liquid level in the furnace being low. Little porosity was found at layer 1 to 2 and layer 2 to 3 interfaces. Due to the sample separating from the carbon steel surface, this interface could not be analyzed. 


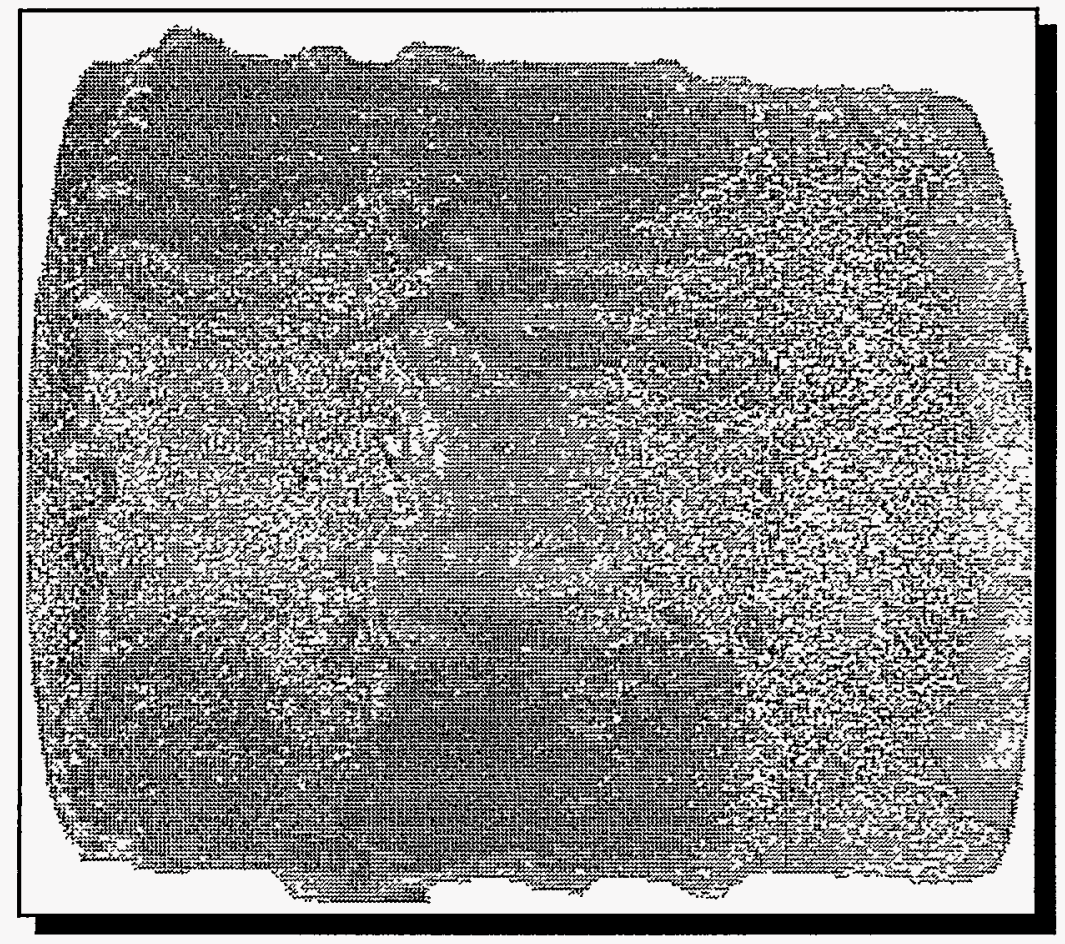

Figure 29. Section of Substrate Tube with As-Sprayed Product, $0.97 \mathrm{X}$.



Figure 30. Cross Section of As-Sprayed Material on Substrate Tube, 4.3X. 

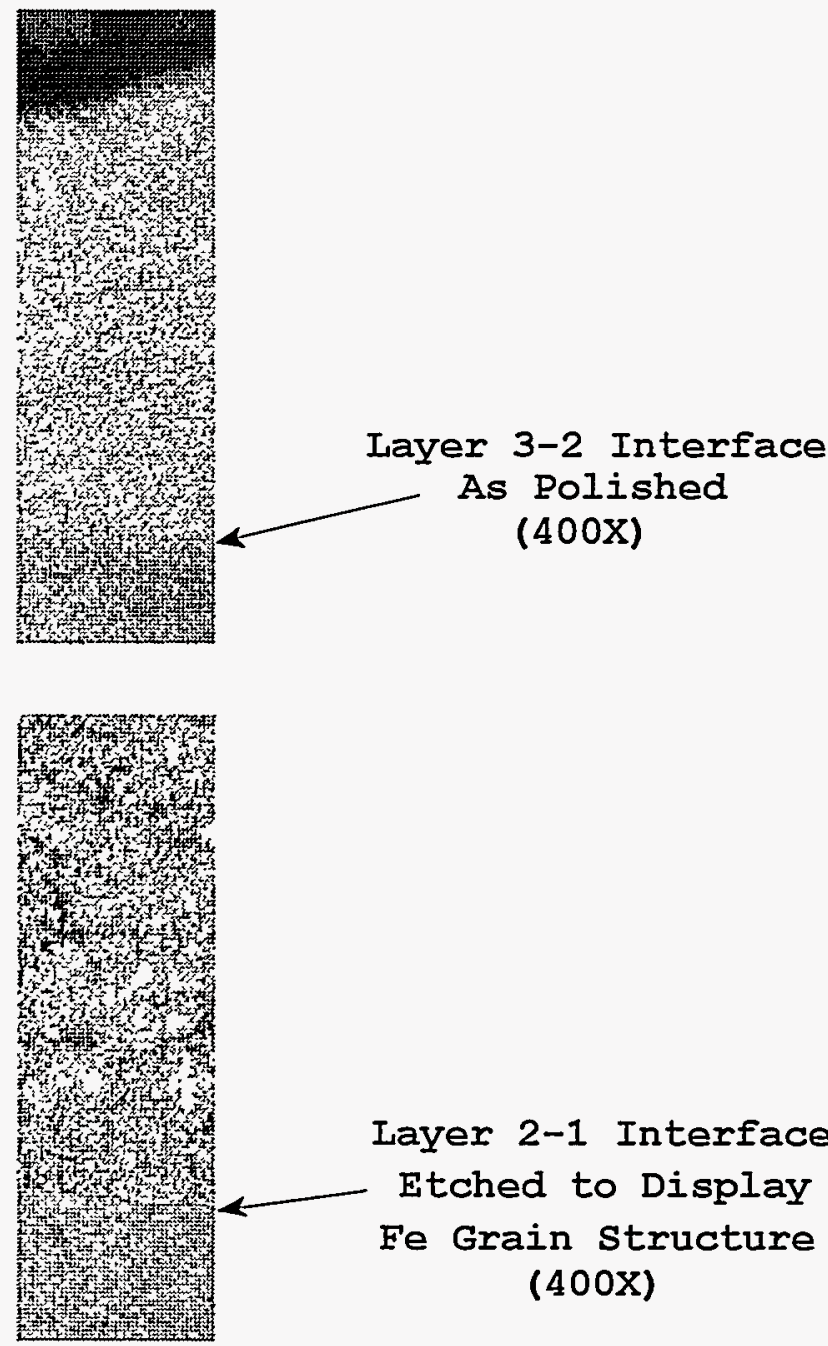

Layer 2-1 Interface Etched to Display Fe Grain Structure (400X)
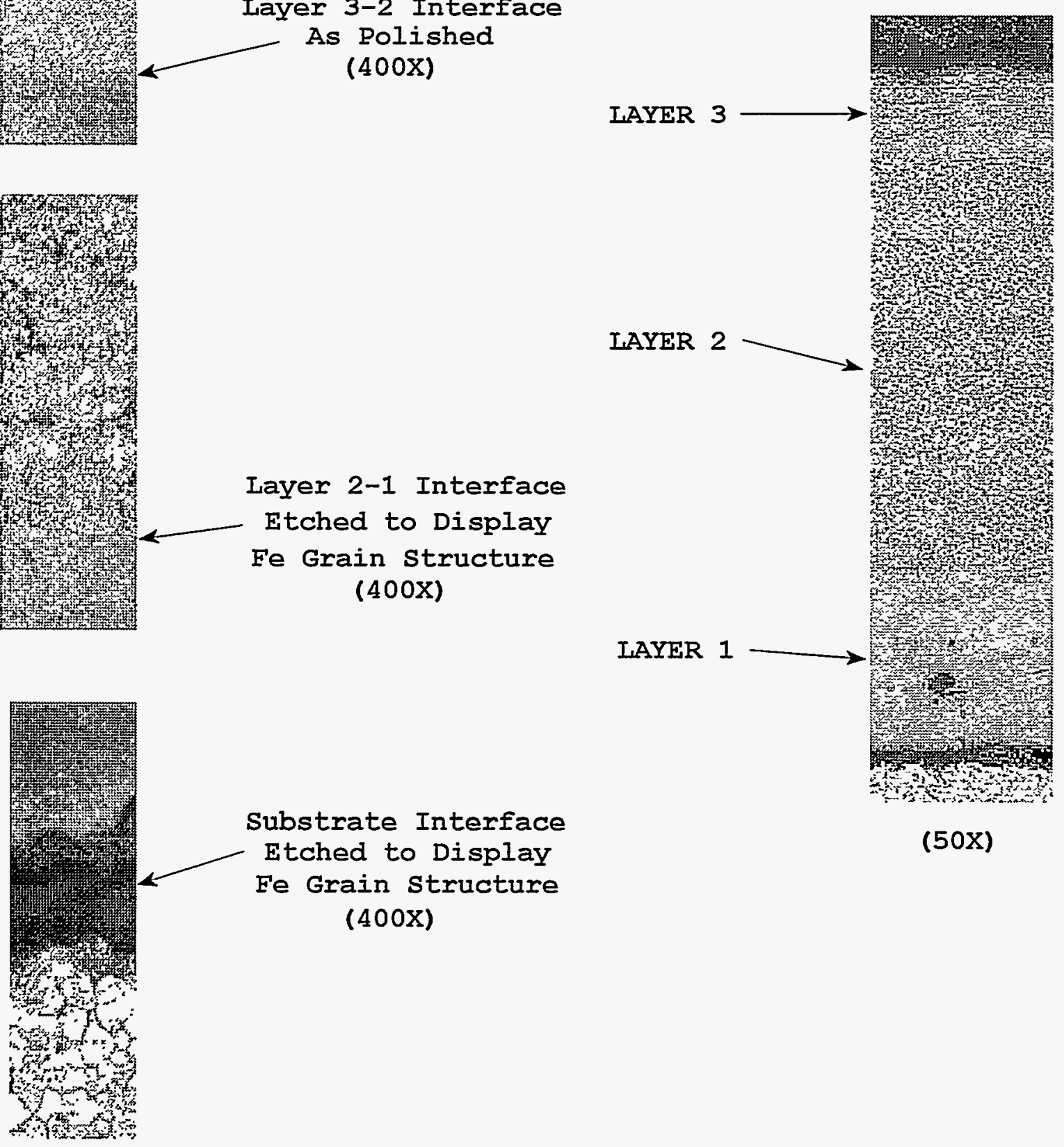

Substrate Interface Etched to Display Fe Grain Structure (400X)

Figure 31. Illustration - Sample Layer Boundaries. 


\subsection{MACHINED GRAPHITE ROD WITH COATINGS}

For Spray Trial 5, a 16-in. long graphite rod was machined to 3.2 in. in diameter. There were five distinct surfaces, prepared as described in sect. 4. The first 2 in. of the rod were uncoated. This section was followed by 2 -in. sections coated with $\mathrm{Y}_{2} \mathrm{O}_{3}$, Mo, $\mathrm{ZrO}_{2}$ and $\mathrm{BN}$ respectively. A narrow band of graphite separated each coated surface; this prevented the coatings from mixing as they were applied.

During the ten minute spray trial, there was little as-sprayed product consolidated on the rod. Melt temperatures were increased to $1980^{\circ} \mathrm{C}$ and various argon supply pressures were employed. At the high melt temperatures, small amounts of material would adhere to the uncoated surfaces. Substrate to nozzle exit separations were established from 0.5 to 1.5 -in.

The poor consolidation of this spray run was attributed to the excessive mass and high thermal conductivity of the substrate. No products from this spray trial were selected for analysis.

\subsection{MACHINED GRAPHITE PLATE WITH COATINGS}

Based on the results of Spray Trial 5, Spray Trial 8 was designed to significantly reduce the mass of the substrate. With a less massive substrate, the dominate cooling factor becomes the argon supply gas to the nozzle. The temperature of the argon supply can then be regulated to obtain good consolidation while still maintaining rapid solidification. For this spray trial, 0.1in. and 0.2-in. substrate thicknesses were utilized. Holes drilled in the substrate would periodically allow the spray plume to pass through the substrate and be collected below. As discussed in Sect. 4.2.2.1, thin strips of high-temperature coating material $\left(\mathrm{Y}_{2} \mathrm{O}_{3}, \mathrm{Mo}, \mathrm{ZrO}_{2}\right.$ and $\left.\mathrm{BN}\right)$ were applied to areas of the substrate.

Both the thermocouple measuring the argon supply temperature to the nozzle and the thermocouple measuring the melt temperature failed early in the spray trial. Once spray conditions had been achieved, the induction power controls were not varied on the gas heater coil or the furnace coil. The argon supply temperature of $1475^{\circ} \mathrm{C}$ used for this spray trial was taken from the average of data obtained from previous spray trials that used the graphite gas heater and the same induction power supply settings. The melt temperature, maintained at $1730^{\circ} \mathrm{C}$, was also based on prior data. 


\subsubsection{Effects on Coating Materials}

Coating materials were under investigation for use as releasing agents for removal of the as-sprayed product from the substrate. If durable coatings could also enable the same substrate to be refurbished and used repeatedly, the time and cost benefits would be attractive to both Government and private interests.

Following the spray trial, the as-sprayed product could be easily removed from all the coated and the uncoated graphite surfaces. It was desirable to leave the as-sprayed material in tact with the substrate surface in order that analysis of the interface could be performed. Care was taken to prevent the assprayed material and substrate from prematurely separating.

There were three areas where it was possible to prepare a metallurgical mount keeping the as-sprayed material in contact with the substrate. The molybdenum and zirconia coatings withstood the spray consolidation with minimal deterioration (see Figures 32 and 33). The yttria coating broke away from the graphite surface and mixed with the as-sprayed material (see Figure 34). No samples could be kept in tact for the boron nitride coatings. By comparison, the uncoated, machined graphite surface provided the best consolidation for the surrogate alloy. No wear was noted on the machined graphite surface, however, the spray periods were relatively short for this trial.

\subsubsection{Thin Deposit}

During Period 9 of Spray Trial 8, a 3-in. long, 0.6-in. wide, and $0.04-i n$. thick strip was consolidated over 40 seconds. This strip was divided into four sections. When viewed with the metallograph, Sections 2 and 4 displayed a representative sample of the types of structures that were apparent in the entire sample.

Vickers hardness numbers were determined for 12 randomly selected locations across the polished surface of the metallurgical mount for section 2. The average Vickers Number was 802 with a standard deviation of 144. On Section 4, five locations revealed an average Vickers Number of 714 with a standard deviation of 123 .

Based on standardless EDS analysis, seven spot locations across the thickness of the sample for sections 2 and 4 were identified. If areas were suspected of having different compositions, these areas were incorporated into the selection of 


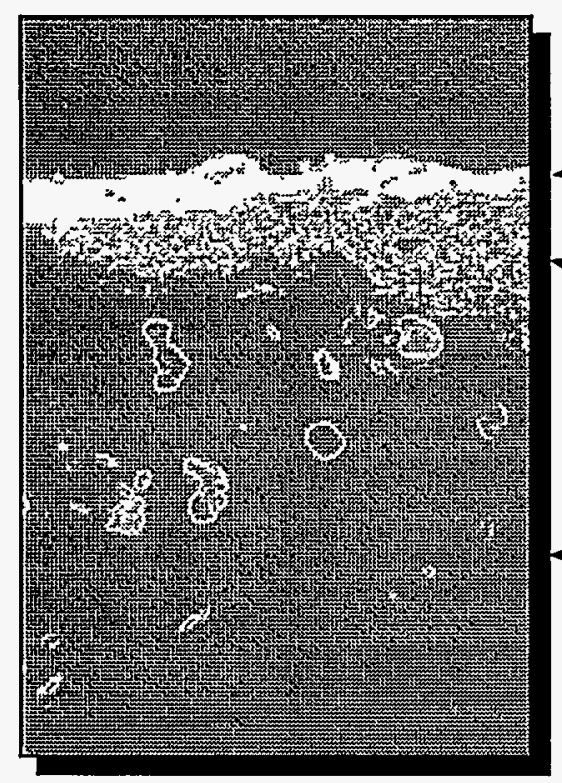

Figure 32. Mo Coating, $100 x$.

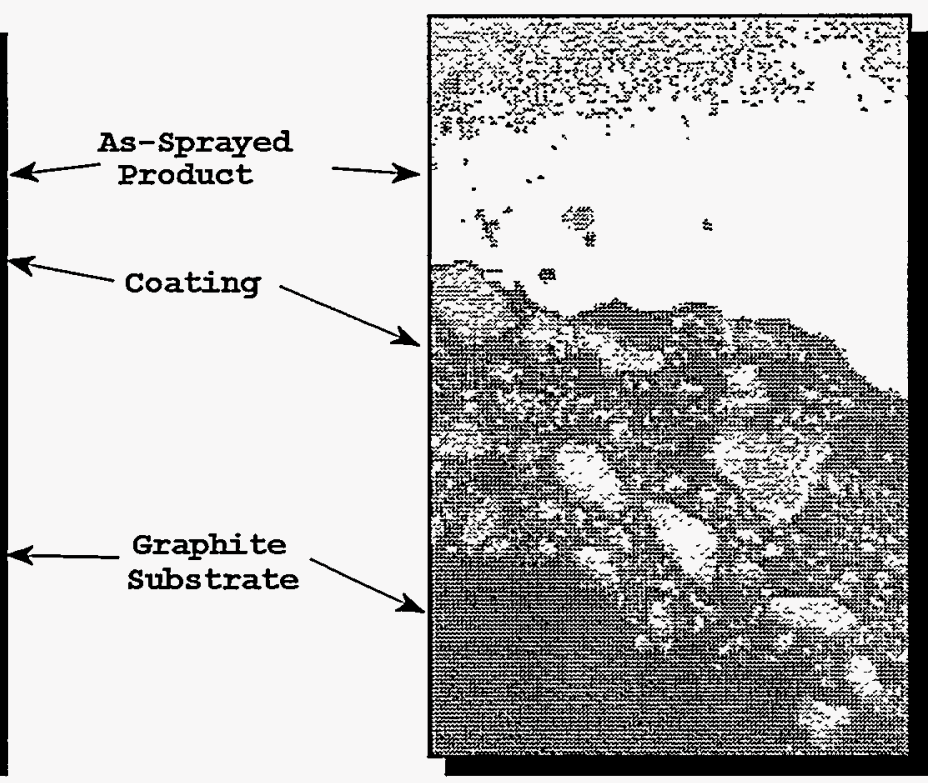

Figure 33. $\mathrm{ZrO}_{2}$ Coating, $500 \mathrm{X}$.

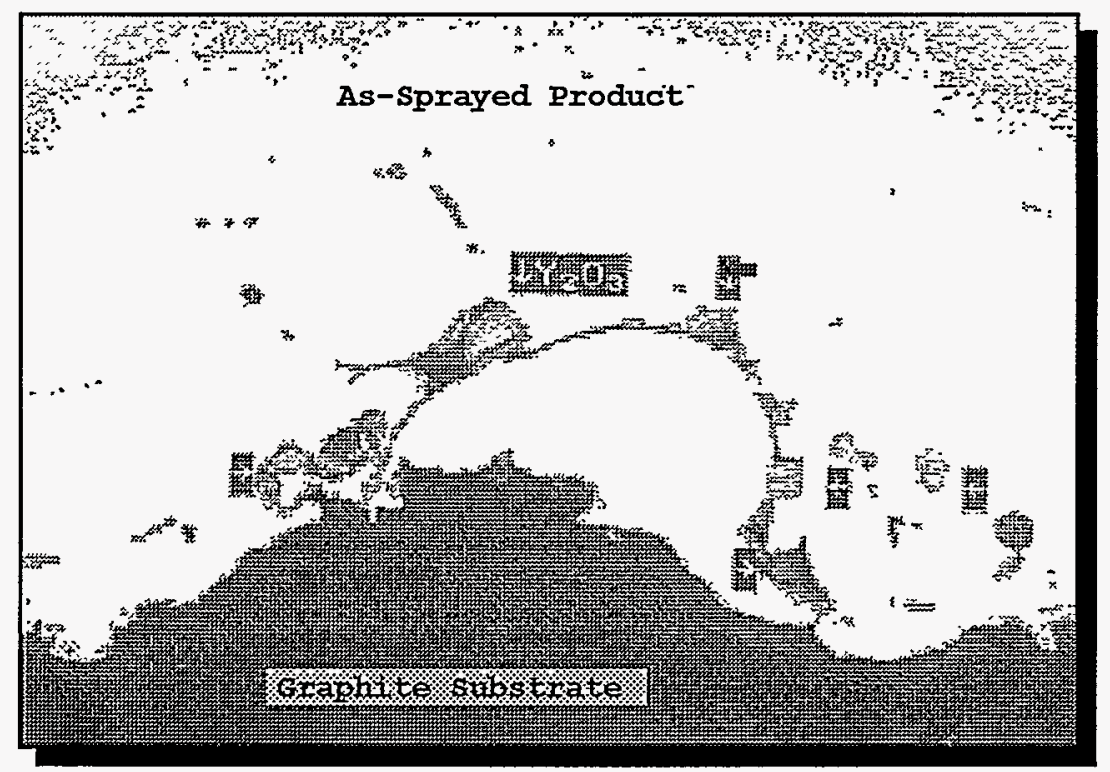

Eigure 34. $\mathrm{Y}_{2} \mathrm{O}_{3}$ Coating, $1,000 \mathrm{X}$. 


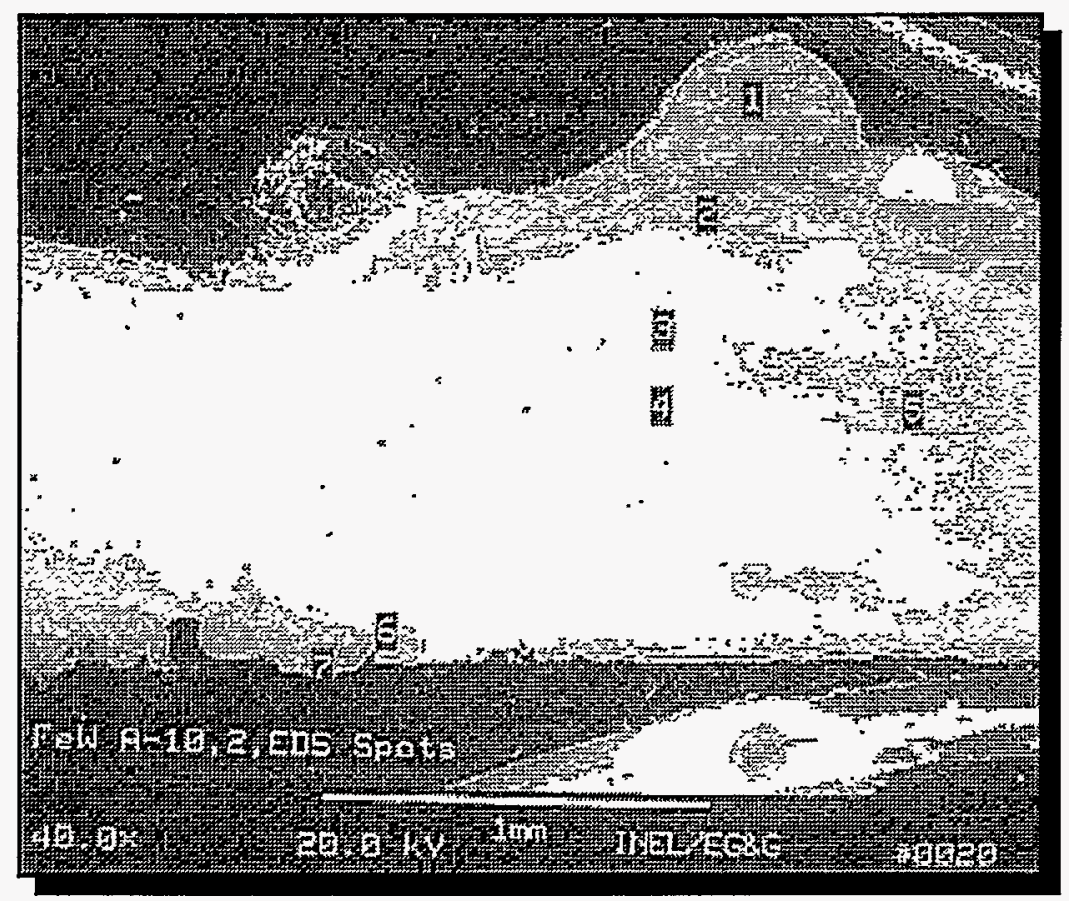

Figure 35. Section 2, EDS Spots, 40.0X.

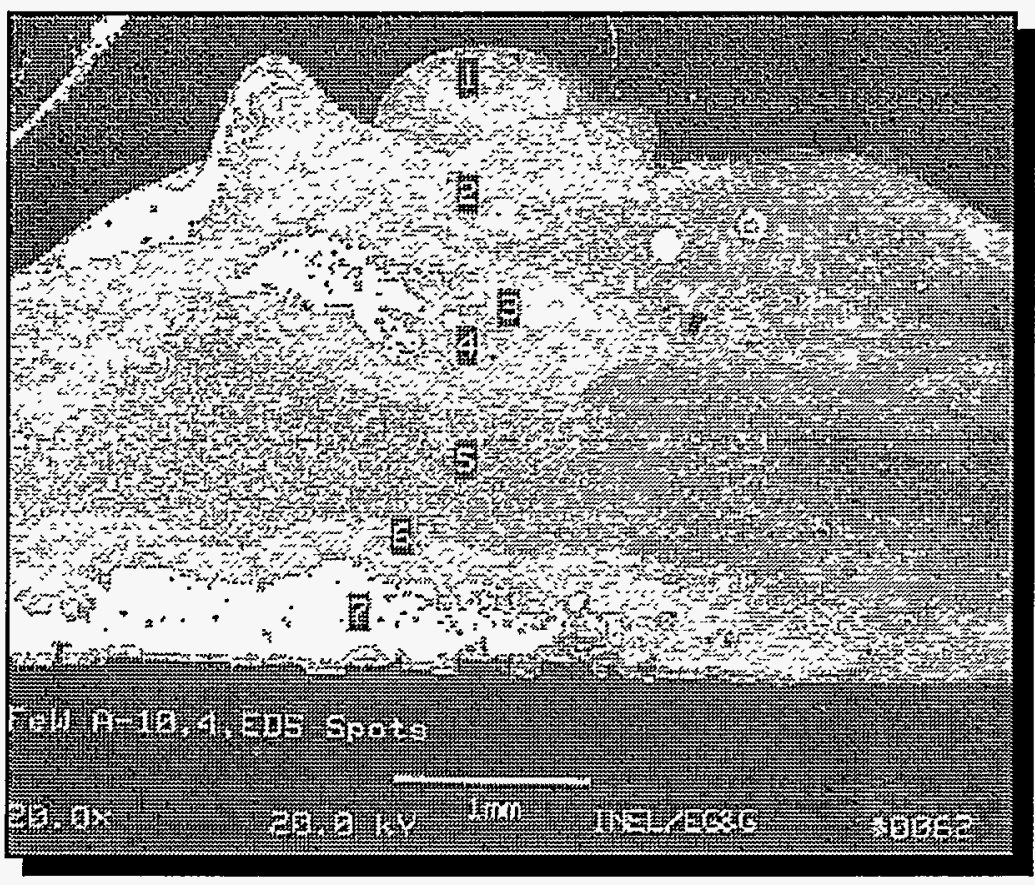

Figure 36. Section 4, EDS Spots, 20.0X. 
the sites for analysis. The spot locations are identified in Figure 35 for section 2 and in Eigure 36 for section 4.

The chemical analyses results were reviewed and averages calculated for each of the sections. For section 2, the average composition was $46.8 \mathrm{w} / 0$ iron and $53.2 \mathrm{w} / 0$ tungsten with a standard deviation of 1.8 percent for each of the elements. For Section 4, the average composition was $45.3 \mathrm{w} / 0$ iron and $54.7 \mathrm{w} / 0$ tungsten with a standard deviation of 2.8 percent for each of the elements. The weight percent compositions used to compute these averages were taken from the EDS analysis tables and are summarized in Table 4.

In sample Section 4, the dark band where spot analysis 5 was taken looked appreciably different than the rest of the sample. This area was investigated further.

When Area 5 was observed at 2,000X, three anomolies were seen in the $10 \mu \mathrm{m}$ diameter size range. These included a dark area with no special characteristics, a herringbone structure resembling the dendritic grain structure found in iron alloys, and a transparent appearing structure. These areas were identified as area 5A, 5B, and $5 \mathrm{C}$ respectively (see Figure 37 ).

The spot analysis on these individual areas revealed a significant difference in the alloy composition. The weight percents for iron and tungsten, from the analysis sheets, were presented as:

WEIGHT PERCENT COMPARISONS

Area 5 - Further Detail

$\begin{array}{lccc} & 5 \mathrm{~A} & 5 \mathrm{~B} & 5 \mathrm{C} \\ \text { Iron } & 86.5 & 38.1 & 25.9 \\ \text { Tungsten } & 13.5 & 61.9 & 74.1\end{array}$

At this point, it was observed that on the average a sample may appear to be quite homogeneous (as noted in Table 4), however, on a small scale, there can be considerable segregation.

\subsubsection{Thick Deposit}

For the final spray period in Spray Trial 8, the nozzle supply pressure was reduced to 21 psia to provide a large pressure drop across the liquid orifice. The dense appearing spray plume created a deposit 0.217-in. thick, 0.6-in. wide, and 2.5-in. long before the melt level was low enough to cause erratic operation (see Figure 38). The middle section of this sample was selected for analysis. 
T551A. CST

Table 4. Weight Percent Composition Summary

Based on EDS $2 \mu \mathrm{m}$ Diameter spot Analysis ${ }^{a}$

\begin{tabular}{ccccc}
\hline $\begin{array}{l}\text { Sample } \\
\text { Location }\end{array}$ & Iron w/o & Tungsten w/o & Iron w/o & Tungsten w/o \\
\hline 1 & 47.6 & 52.4 & 45.6 & 54.4 \\
2 & 48.5 & 51.5 & 47.4 & 52.6 \\
3 & 46.3 & 53.7 & 40.7 & 59.3 \\
4 & 48.3 & 51.7 & 46.7 & 53.3 \\
5 & 47.7 & 52.3 & 47.8 & 52.2 \\
6 & 46.2 & 53.8 & 46.7 & 53.3 \\
7 & 43.4 & 56.6 & 42.0 & 58.0 \\
Average & 46.8 & 53.2 & 45.3 & 54.7 \\
Standard & & & 2.8 & 2.8 \\
Deviation & 1.8 & 1.8 & & \\
\hline
\end{tabular}

astandardless EDS Analysis

(ZAF Corrections Via Magic V)

Source: Reprinted with permission from EG\&G Idaho, Inc. 


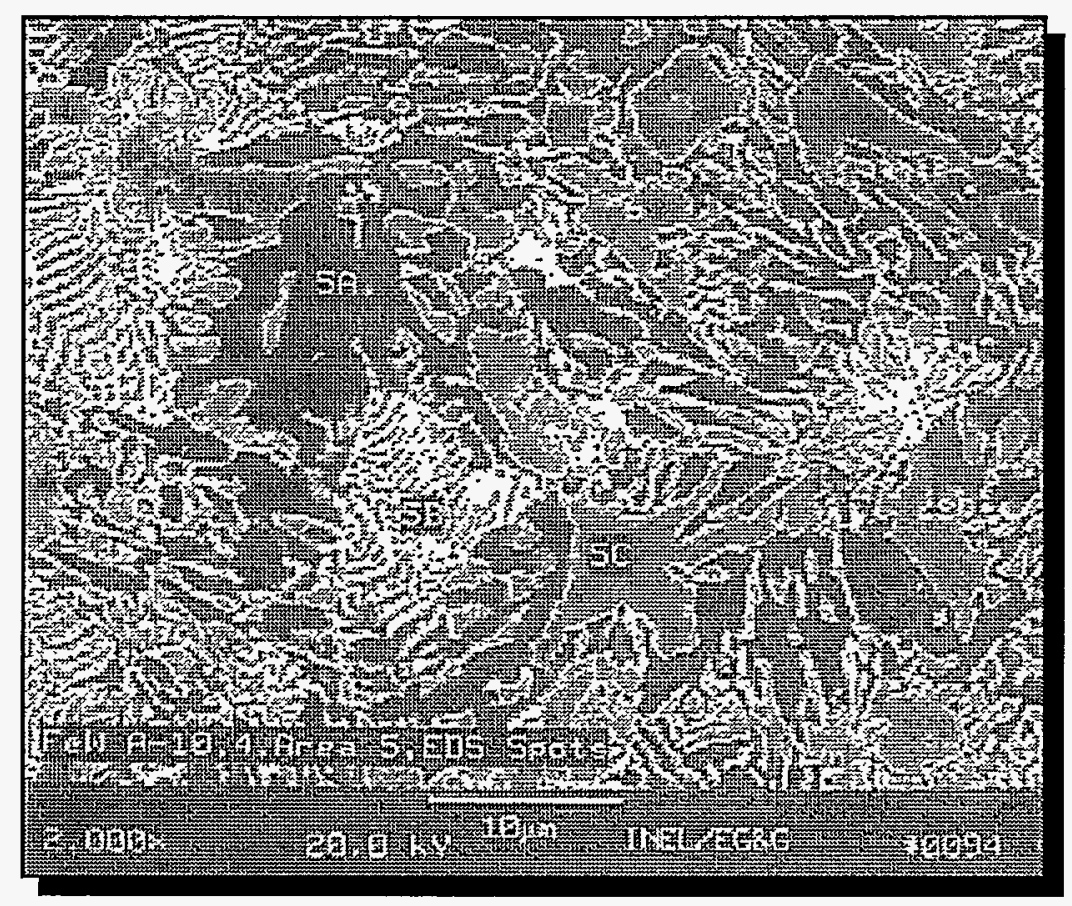

Figure 37. Section 4, Area 5, EDS Spots, 2,000x.

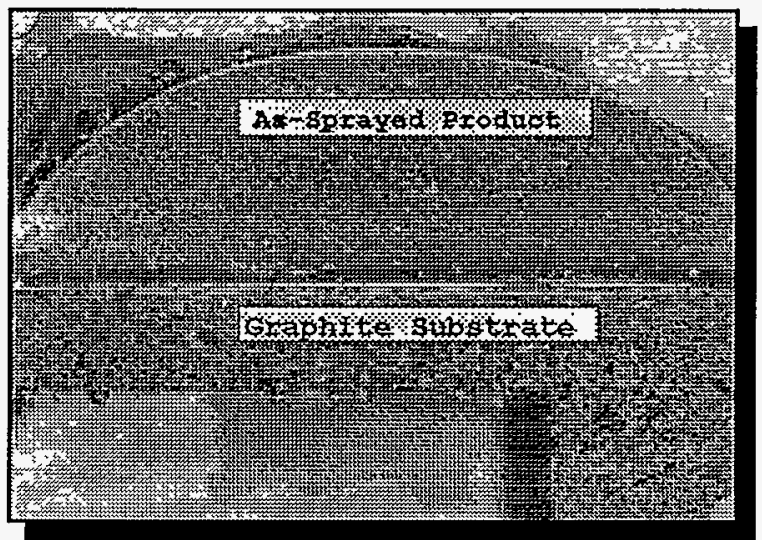

Figure 38. Spray Trial 8, Thick Deposit, 4.5X. 
A portion of the sample was consolidated on the substrate at a location where the substrate thickness was $0.1-i n$. thick. The remainder of the sample was consolidated on a portion of the substrate that was 0.2-in. thick. When observing the prepared metallurgical sample at 4.5X magnification, a thin lighter colored layer could be observed near the graphite surface. This thin layer measured 0.017-in. thick.

When the magnification was increased to $100 \mathrm{x}$, the thin layer's structure disclosed two thinner strata. The layer closest to the substrate was porous and revealed large crystals next to the graphite surface. The layer adjacent to this porous layer was smooth and revealed little structure (see Figure 39). These two layers comprised the bright, thin layer that is visible in Figure 38. When viewing at $200 \mathrm{x}$ on the metallograph, the third layer was homogeneous and displayed areas from low porosity to fully dense throughout the remaining 0.2 in. of the as-sprayed deposit.

Three areas were identified for chemical analysis next to the graphite surface. These results are presented below (see Figure 40 for spot location):

\section{WEIGHT PERCENT COMPARISONS} Substrate Interface

$\begin{array}{lrrr} & \text { Spot } 1 & \text { Spot 2 } & \text { Spot } 3 \\ \text { Iron } & 2.3 & 82.2 & 56.9 \\ \text { Tungsten } & 97.7 & 17.8 & 43.1\end{array}$

In the back scattered electron beam image, the brighter crystalline structure is observed to be nearly pure tungsten, while the darker area is iron enriched. The area appearing gray, Spot 3, is slightly iron enriched.

The second set of analysis locations were chosen near the interface of the first and second layer (see Figure 41). The weight percent compositions from the analysis sheets are provided as follows:

\begin{tabular}{lrrr}
\multicolumn{4}{c}{ WEIGHT PERCENT COMPARISONS } \\
First Layer - Second Layer & Interface \\
& Spot 6 & Spot 7 & Spot 8 \\
Oxygen & 8.4 & & \\
Chlorine & 0.9 & & \\
Iron & 37.4 & 23.2 & 23.1 \\
Tungsten & 53.3 & 76.8 & 76.9
\end{tabular}




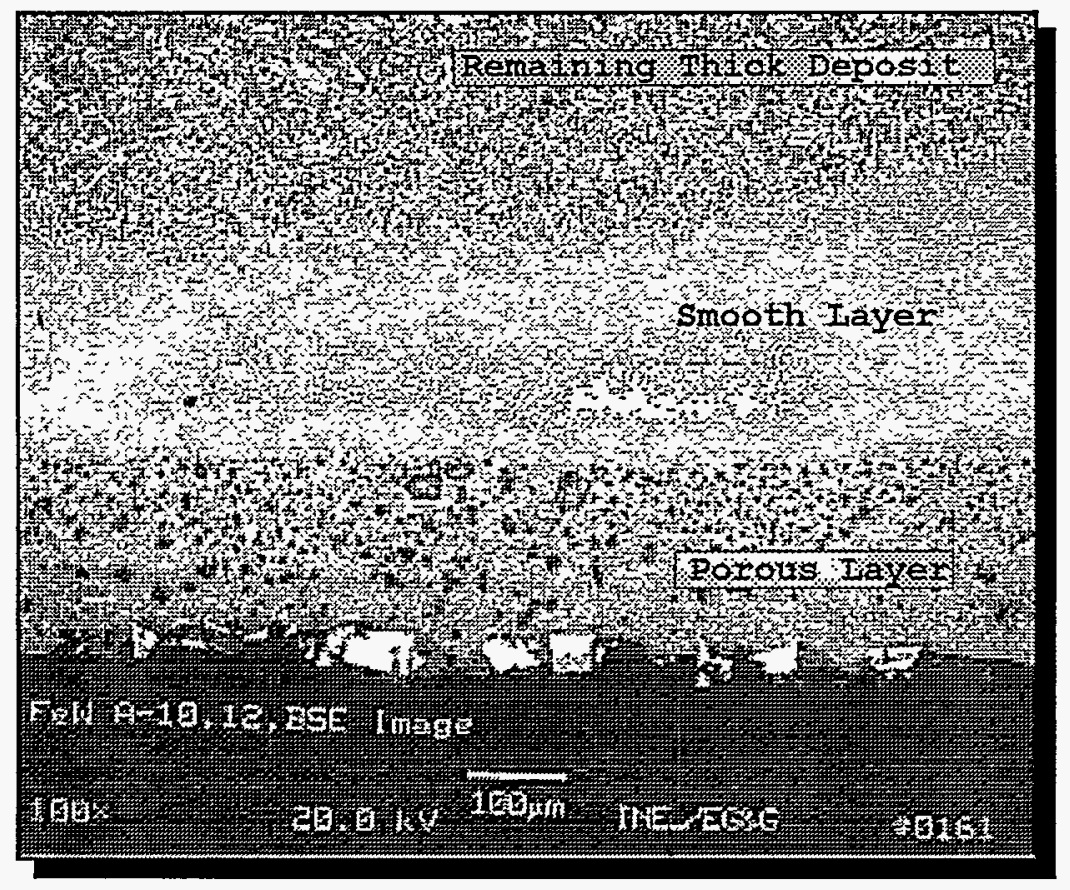

Figure 39. Spray Trial 8, BSE Image, 100X.

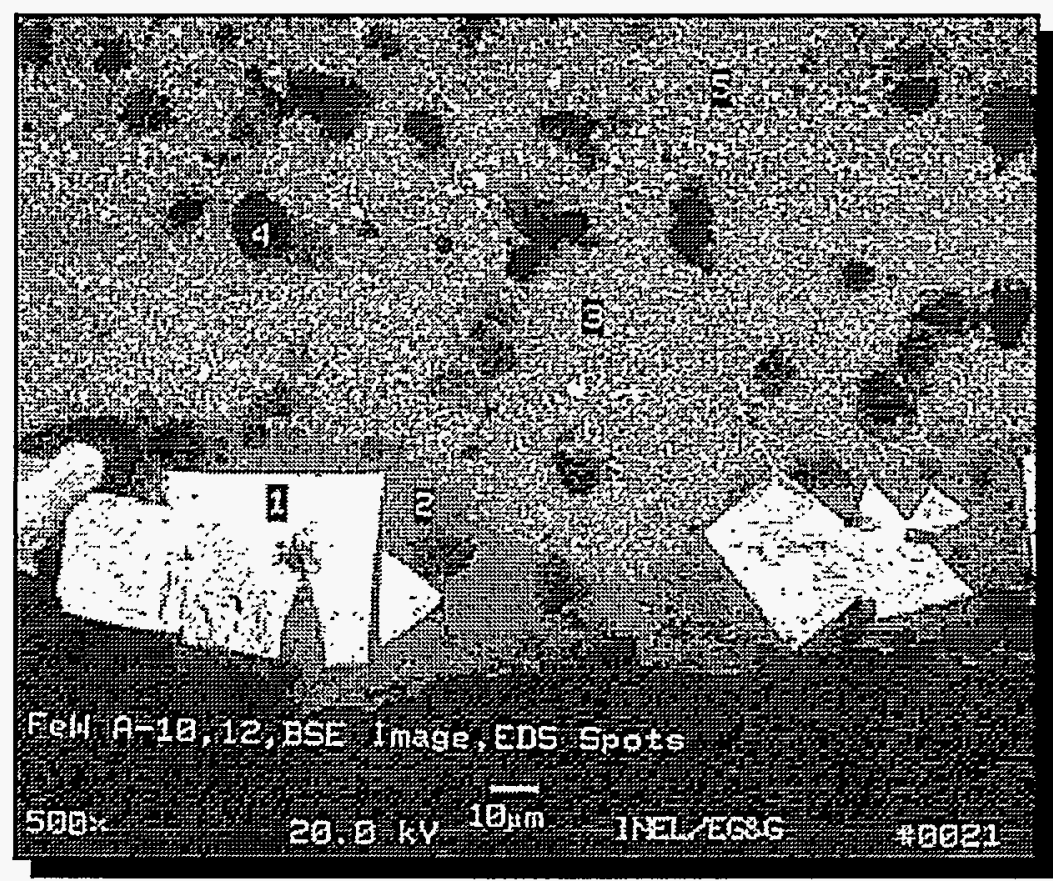

Figure 40. Spray Trial 8, Substrate Interface, BSE Image, EDS Spots, 500x. 


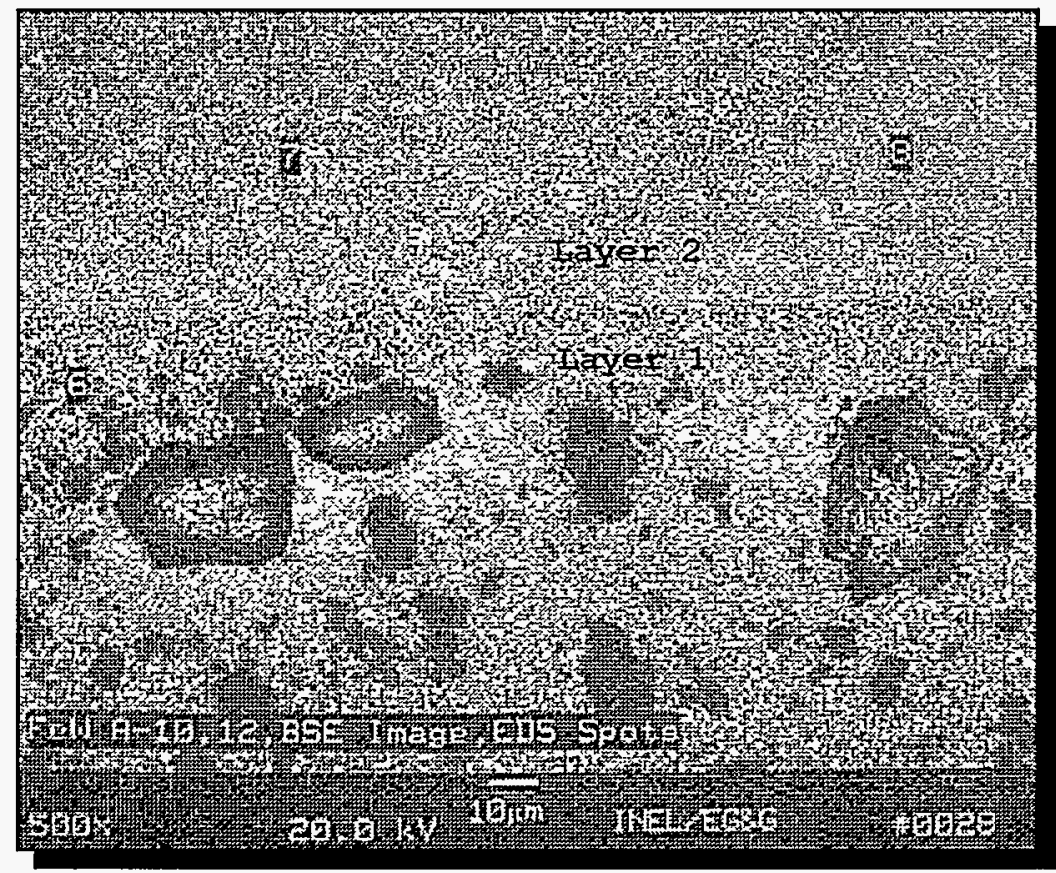

Figure 41. Spray Trial 8, Layer 1-2 Interface, 500x. 
Since there is oxygen and chlorine at this interface, it is not clear why these elements were absent in the first layer. The oxygen is available from the 1 to 2 percent oxygen contained in the chamber atmosphere. The chlorine could come from binders in the graphite or nozzle ceramics. Additional chemical analyses may explain this observation.

The remaining 0.2 in. of the sample, adjacent to the thin, light colored layer, displayed a uniform metallurgical appearance. one location was selected from this area and two area raster analyses were performed in close proximity. These areas had a diameter of $27 \mu \mathrm{m}$; the chemical analysis information identified the areas as $9 G 1$ and 9G2. Two spot analyses were then performed within area $9 \mathrm{Gl}$ at locations distinguished as $9 \mathrm{~A}$ and $9 \mathrm{~B}$ in Figure 42 . Two spot analyses were also performed in the second area, 9G2; these spot locations are identified as $9 \mathrm{C}$ and $9 \mathrm{D}$ in Figure 43 . The weight percents are summarized as follows:

\section{WEIGHT PERCENT COMPARISONS}

Area Raster Diameter $(27 \mu \mathrm{m})$ - Spot Diameter $(2 \mu \mathrm{m})$

$\begin{array}{lrrrrrr} & 9 G 1 & 9 A & 9 B & 9 G 2 & 9 C & 9 D \\ \text { Chlorine } & & 0.4 & & & & \\ \text { Iron } & 31.6 & 83.3 & 23.5 & 42.2 & 80.6 & 23.0 \\ \text { Tungsten } & 68.4 & 16.3 & 76.5 & 57.8 & 19.4 & 77.0\end{array}$

In reviewing the results from this examination, it is found an area raster of $27 \mu \mathrm{m}$ produces a composition closer to the expected composition of the alloy. An extension to this analysis would be to increase the diameter of the area raster analysis until multiple analyses, at the larger diameter, would produce the same result. This would then be the area over which the sample could be referenced as uniform or homogeneous.

Additional photomicrographs from other areas of this sample are included in Appendix C.

If the required homogeneity of the end product is known, a spray forming system could be tailored to produce the product using this technique of analysis on the as-sprayed sample. 


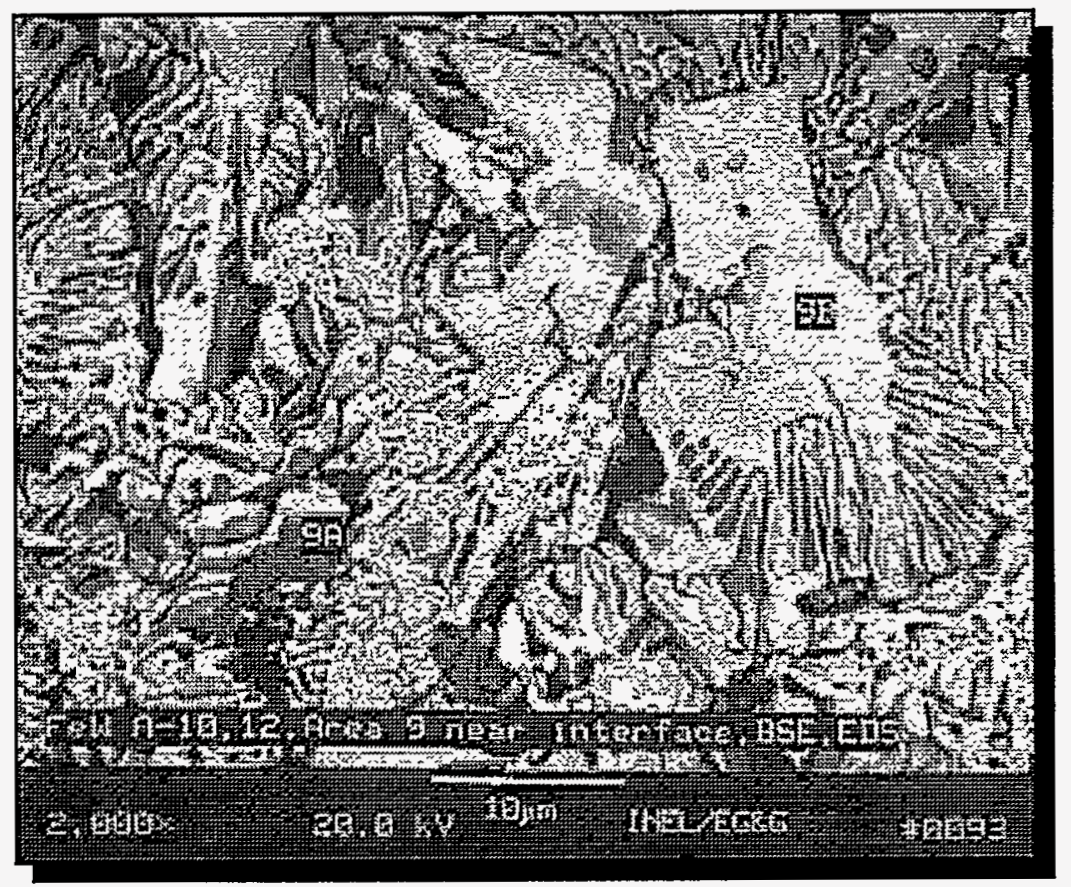

Figure 42. Spray Trial 8, Area Raster 1, 2,000X.

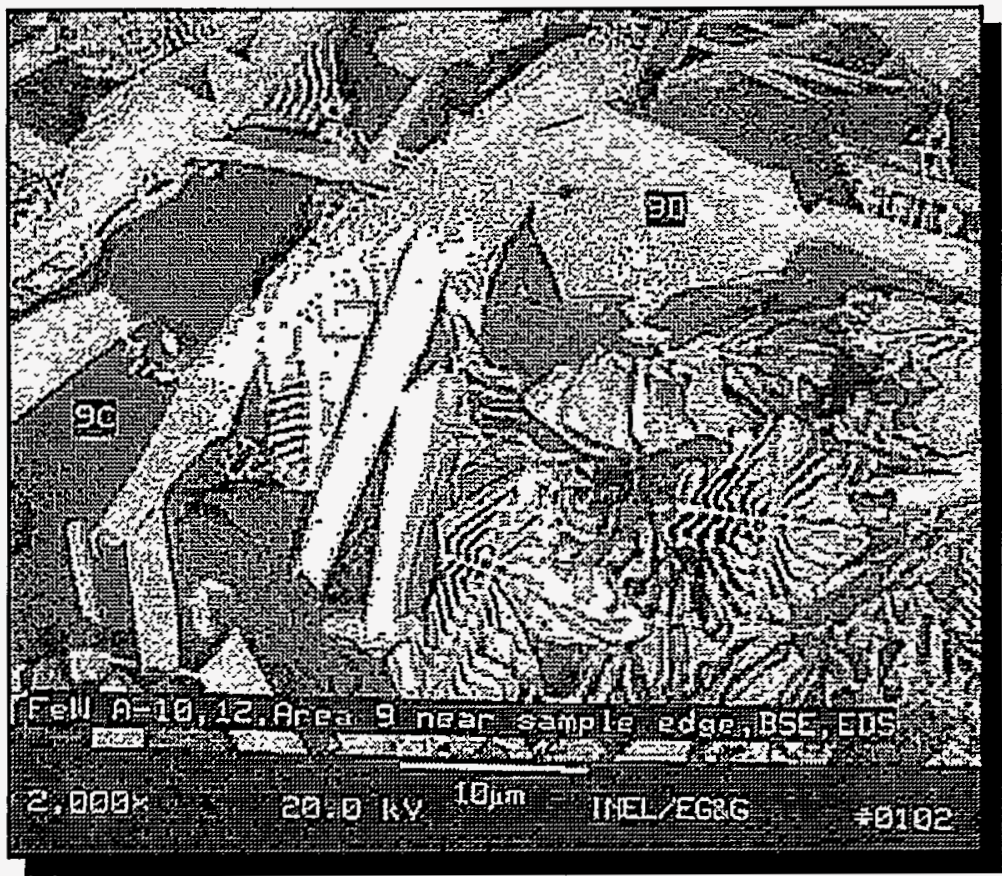

Eigure 43. Spray Trial 8, Area Raster 2, 2,000X. 


\section{FINDINGS AND CONCLUSIONS}

\subsection{POWDER ANALYSES}

\subsubsection{Overspray Powders}

Four spray trials were used to determine an average amount of overspray that could be collected from the chamber floor. The amount of overspray averaged less than $10 \%$ of the total powder sprayed during the spray trial. This is the amount of overspray observed without additional tailoring of the nozzle design to improve performance.

Ceramic particles and fibers were visible in the powder recovered from the floor of the chamber. The mass contribution from these elements was concluded to be insignificant.

At 10,000X magnification, discrete particles measuring as small as $0.2 \mu \mathrm{m}$ diameter could be identified. One method of providing a more comprehensive analysis of the overspray powder size distribution would be to have forward scattered electron beam images as well as back scattered electron beam images taken on a selection of samples from the overspray collections. Such analysis would distinguish which of the tiny particles are dense metal and which might be ceramic compositions. Analysis of this nature would also reveal what quantities exist and would enable estimations to be made relative to how these quantities might accumulate to form a hazard.

The paramount finding is that tiny particles are within the larger overspray groupings. If these particles are metallic, then the group of large overspray powders that accumulate on the chamber floor could present a pyrophoric hazard.

The powders collected during the Extended surrogate Alloy Experiments have been archived and are available for further analyses.

\subsubsection{Airborne Particulate}

To establish spray forming as a low emissions process, it is important to minimize the occurrence of the particles which can be carried away in the discharge gases. These particles are also the size range which can attach themselves to surfaces within the spray chamber and accumulate in sufficient amounts to later become a pyrophoric danger.

Instrumentation used by health physicists in Air Quality Control was utilized to collect the particles from the gases being 
deflected from the substrate surface (see sect. 4.3). Photomicrographs confirmed the existence of particles ranging from 0.07 to $3 \mu \mathrm{m}$ in diameter.

Examination of the photomicrographs revealed a combination of nonmetal and metal particles. The particles of most interest were those displaying a composition ratio of equal parts iron and tungsten.

The significant observation is the large overlap in the size range of the particles recovered from the overspray on the chamber floor and the particle size range observed in the photomicrographs from the airborne particle collections. Based on this examination, there is confidence that all particles being produced by the sprayforming process can be identified. It was important during the course of this Program to determine if this identification of particles could be confirmed.

\subsubsection{Plume Collections}

Particles from the spray plume collections were compared to the particles collected from the chamber floor. It was determined the overspray collections were also a good representation of the particle distribution of the spray plume if the overspray powder was separated with a $75 \mu \mathrm{m}$ sieve.

\subsection{COMPONENT CERAMICS}

Excessive ceramic wear and component failure were noted during these spray trials (see introduction of sect. 4). If it is desirable to spray the surrogate alloy in quantities of $300 \mathrm{~g}$ or more, extensive improvements will be required for the component ceramics.

\subsection{SPRAY NOZZLE PERFORMANCE}

The nozzles with three liquid orifices produced a more homogeneous appearing spray plume at operating pressures near 23 psia. It is postulated that lower gas-to-metal mass ratios can be attained in a tailored spray system configured to operate with three liquid orifices than in a spray system utilizing a single liquid orifice nozzle. This assumes that both nozzles have the same gas-orifice-area to liquid-orifice-area ratio.

Samples were produced for analysis using nozzle supply pressures from 18 to 41 psia. In general, the lower operating pressures produced a better consolidated product. The primary reason for poor consolidation and higher porosity at the higher operating pressures was attributed to the lower argon supply 
temperature. Spray plumes at the higher operating pressures were uniform and appeared to have finer particles.

In the third spray trial (discussed in sect. 5.3), the heat capacity was sufficient to melt through the $0.02-i n$. thick carbon steel tube when the nozzle was operating at 22 psia. When the argon supply was increased to 29 psia, the 0.02-in. thickness was no longer subject to melt-through. This provides confirmation of the on-line flexibility of the spray forming process. By adjusting supply pressure, the heat content of the spray plume can be regulated to compensate for varying substrate conditions. In addition to demonstrating on-line flexibility achieved by adjusting the argon supply pressure to increase gas cooling, this experiment also confirmed coatings can be applied with a metallurgical bond.

As-sprayed products were produced with large areas displaying grain sizes of $10 \mu \mathrm{m}$ diameter and less. For the first time during this Program, this has been accomplished at gas-to-metal mass ratios of less than 1.0. A sample of the spray plume was also collected under identical spray conditions. Preliminary analysis of this collection reveals the majority of particles range in size from 35 to $70 \mu \mathrm{m}$ in diameter.

\subsection{AS-SPRAYED PRODUCT PROPERTIES}

\subsubsection{First Grit Blasted Carbon Steel Tube}

Three samples were prepared for analysis. The average hardness depicted by each of these samples did not confirm a difference in the homogeneity (see Table 3 ).

The EDS spot analysis for two of these samples indicated there was no compositional differences within the limits of the analysis (approximately 4w/o). The third sample did show evidence of tungsten enriched locations (see Table 2).

\subsubsection{Second Grit Blasted Carbon Steel Tube}

When the substrate is a major component providing solidification of the spray plume, high porosity is observed in the as-sprayed product. Having applied a thin layer of as-sprayed material to the substrate, a subsequent, thicker layer can be applied over this layer with minimal porosity at the interface between the two layers. Microstructure in this thick layer will display grain sizes in the $8 \mu \mathrm{m}$ diameter range. A thin layer can be applied over a thick, hot, previously applied layer with minimal porosity at the interface. This thin layer will maintain low porosity and fine metallurgical structure at $400 \mathrm{X}$ (see Figure 31). 


\subsubsection{Consolidation on Coated and Uncoated Graphite}

Molybdenum and zirconium oxide coatings on the machined graphite plate withstood the spray consolidation process with minor deterioration. The as-sprayed product readily separated from the coated surfaces. After spraying across the boron nitride surface, minor deterioration was visible. The spray did not adhere to this surface. The yttrium oxide coating released from the graphite surface and mixed with the as-sprayed product during consolidation of the spray. Observations during Spray Trial 8 concluded that the machined graphite provided a surface where the consolidation of the spray plume was more uniform. Following this spray trial, the assprayed material separated with ease from the graphite surface. Machining marks could be detected in the as-sprayed product where the material had consolidated on the graphite. Graphite would be a desirable mold material for exhibiting detail in a net-formed product sprayed from the surrogate alloy.

\subsubsection{Thin Deposit on Machined Graphite}

Seven randomly selected EDS spot analyses across the thickness of two specimens reflected the same compositional analysis for the two samples within the limits of detection.

When one of the samples was observed at 2,000X magnification, two different anomalies occurred in the $10 \mu \mathrm{m}$ diameter range. When a $2 \mu \mathrm{m}$ diameter EDS spot analysis was performed on each of the 10 $\mu \mathrm{m}$ diameter anomalies, high segregation was observed.

These results revealed the as-sprayed product may appear homogeneous over a broad area and still have segregation on a small scale.

\subsubsection{Thick Deposit On Machined Graphite}

A thick deposit (0.217 in.) was consolidated at an argon supply pressure of $18 \mathrm{psia}$. The upper 0.2 in. of this deposit displayed low porosity (i.e., rough calculations of less than 2\%). At 100X magnification, the sample displayed uniform characteristics. At 500X magnification, the porosity was still low, however, some discolorations were visible.

A location was randomly chosen which was generally representative of the sample. Magnification at 2,000x revealed light and dark anamolies. By using a general area raster technique, the average composition was determined for two areas having a diameter of $27 \mu \mathrm{m}$ each. The chemical analyses from these areas indicated segregation when compared to the given analysis of the surrogate alloy. Preferentially selecting each $10 \mu \mathrm{m}$ diameter anomaly and 
performing a spot analysis of $2 \mu \mathrm{m}$ in diameter indicated even stronger segregation.

The composition of the surrogate alloy was given as $49.6 \mathrm{w} / \mathrm{o}$ iron, $49.6 \mathrm{w} / 0$ tungsten, and $0.8 \mathrm{w} / 0$ carbon. Reviewing all the chemical analyses results raises concerns that should be addressed prior to drawing conclusions.

The chemical composition of the as-sprayed product can appear to be homogeneous with a selection of small diameter (2 $\mu \mathrm{m}$ diameter) spot analyses. If magnification is increased, it may become apparent that the product is not homogeneous. This segregation can occur on an area larger than the spot diameter. This is possible since the spot would likely overlap the boundaries of the small segregated areas.

If the magnification is increased and the spot analysis is preferentially directed to minimize overlapping the segregated boundaries, then enriched areas of the two prime constituents can be identified.

\subsubsection{Summary status}

Safety and design information concerning particulate size and quantity for a prototype production spray forming facility has been obtained and characterization data for the spray plume under one set of conditions documented. Possible mold materials and mold coatings for a prototype production facility have also been identified. The possibility of spray forming thick deposits using the surrogate alloy has been demonstrated. The excessive ceramic wear and spray system component failures exhibited during the spray trials may be due to the choice of the surrogate alloy. In conjunction with designing a prototype system, the reaction of system ceramics with the metal to be sprayed will need to be evaluated. While the spray forming process has not been optimized for the surrogate alloy, test results to date indicate the desirability for MMES to continue with a conceptual design of a prototype production spray forming facility.

\subsection{EXCHANGE OF TECHNICAL INEORMATION/TECHNOLOGY TRANSFER}

To complement Program efforts, technical exchange meetings, spray trial demonstrations, and presentations with Program participants were conducted throughout the Extended Surrogate Alloy Experiments. This exchange of information enabled dynamic review and comparison of Program accomplishments as they occurred, thereby alleviating potential redundancy of activities. Equipment efficiency was augmented through continued use of the U.S. Air Force induction power supply unit. 
The Government's technology transfer approach has captured the interest of the private sector. Shared communications and cooperative agreements between the National Laboratories and private enterprises will optimize the transition of state-of-theart technology and real-time application of spray forming. Spray forming applications specific to commercial and industrial criteria continue to be explored and requirements assessed with emphasis on the mutual benefits of dual use endeavors. Custom Spray Technologies, Inc., remains committed to technology transfer efforts that demonstrate the potential of spray forming technology to the private sector. 


\section{REFERENCES}

1. I.D. Watson et al., "Spray Forming as a New Processing Technique," presented at The First Annual International Workshop on Solvent Substitution, Phoenix, AZ, December 1990.

2. S.A. Ploger and L.D. Watson, "Net-Shape Spray Forming of Amorphous/Microcrystalline Metal Alloys and Recycled Metal Alloys and Articles Produced Thereby," U.S. Patent Application/Serial No.: 07,779,543, Filing Date: October 18, 1991.

3. I.D. Watson et al., "Nozzle-Aspirated Metal Forming," presented at the Metallurgical Society's International Symposium on Casting of Near Net Shape Products, Honolulu, HI, November 1988 .

4. L.D. Watson et al., "Aerosol Production of Molten Metals," presented at the 4th Miami International Symposium on MultiPhase Transport and Particulate Phenomena, Miami Beach, FL, December 1986.

5. I.D. Watson et al., "A Process of Spraying Controlled Porosity Metal Structures Against a Substrate and Articles Produced Thereby," U.S. Patent Application/Serial No. 07,623,851, Filing Date: December 7, 1990, Foreign Filing License Granted: December 26, 1990.

6. J.I. Alvarez and I.D. Watson, "Apparatus and Method for Spraying Iiquid Materials," U.S. Patent No. 4,919,853, April 24,1990 .

7. S.A. Ploger and L.D. Watson, "A Low Temperature Process of Applying High Strength Metal Coatings to a substrate and Article Produced Thereby," U.S. Patent Application/Serial No. 07,599,773, Filing Date: October 18, 1990, Foreign Filing License Granted: November 1, 1990.

8. J.L. Alvarez and I.D. Watson, "Device and Technique for InProcess Sampling and Analysis of Molten Metals and other Liquid Presenting Harsh Sampling Conditions," U.S. Patent No. $4,806,150$, February 21, 1989. 
APPENDIX A: EXPERIMENTAL PIAN 


\section{APPENDIX A \\ EXPERIMENTAL PLAN \\ SPRAY FORMING HEAVY METALS \\ $76 Y-\operatorname{GSK} 39$}

\section{INTRODUCTION}

The objective of the Program effort, "Spray Forming Heavy Metals," 76Y-GSK39, is to provide sufficient information for determining the feasibility of building a system to spray depleted uranium and its alloys. Throughout performance of this Experimental Plan, it is essential to show that sufficient support for supplying spray components (i.e., spray nozzles, gas heaters, substrate materials, etc.) is viable for implementing this technology at the Y-12 Plant managed by Martin Marietta Energy Systems, Inc. (MMES) in Oak Ridge, Tennessee.

\section{SYSTEM CONFIGURATION AND MODIFICATION}

\section{Objectives:}

Configure spray system to be convenient for conducting multiple spray runs. Configurations must allow for a variety of substrate geometries which can accommodate different substrate materials. Port modifications will be necessary to allow sampling experiments of chamber atmosphere and areas near and within the spray plume.

\section{Activities:}

During this Program, the spray forming effort will focus on an iron-tungsten-carbon alloy (composition: $49.6 \% \mathrm{Fe}-49.6 \% \mathrm{~W}-.8 \% \mathrm{C}$ ) . Temperatures required for the various spray components of the system will be in excess of $1800^{\circ} \mathrm{C}$. Type $\mathrm{C}$ thermocouples will be fabricated for component, melt and gas temperatures. Type $S$ thermocouples will be fabricated and should be adequate for monitoring substrate and plume parameters.

Modifications will be effected that will allow for spraying a large variety of substrate textures and materials. In order to monitor temperatures of the substrate materials and spray plume, additional temperature monitors will be required in the existing system. There are sufficient capabilities to adapt the outputs from these monitors into the Data Acquisition System (DAS). A system will be configured that will allow manipulation of the substrate material stock (i.e., plate, bar, tube, etc.) over a container. This will enable most of the overspray to be collected while allowing the nebulizing gas to escape providing worst case overspray estimates for chamber accumulations while spraying small irregular items. Port entries will be constructed that will enable particle monitoring of the chamber environment, as well as particle monitoring of the area near the spray plume. 
APPENDIX A

SYSTEM CONFIGURATION AND MODIFICATION/Activities (Cont'd)

Design and construct a modular spray assembly that will enable the system components to be assembled and checked on the lab bench prior to installation in the chamber.

\section{SPRAY TRIAIS WITH SURROGATE ALLOY}

\section{Objectives:}

Determine substrate candidates and surface textures that would be adequate for implementing depleted uranium as feedstock. Recommend a component assembly for use in early, depleted uranium spray trials. Analyze samples to determine homogeneity, density and contamination. Monitor chamber exhaust to determine emission potential. Examine chamber atmosphere to determine particle deposition that may collect on the chamber walls, etc. Collect large particle overspray and monitor spray plume properties.

\section{Activities:}

The temperatures necessary to spray the surrogate alloy will create high wear on the ceramic parts. This will necessitate the fabrication and assembly of multiple spray components. Spray efforts will commence with the nozzle design used at the conclusion of the Addendum I effort. Multiple spray runs will allow measurements to identify the spray rate capabilities of this design and to determine the major wear areas.

While accumulating nozzle output data, the as-sprayed samples will be evaluated and determinations made relative to the value of further analyses. The substrate thickness will be varied and temperatures monitored to allow first order calculations of plume heat capacities. The surface texture of these different thicknesses will also be varied and visual assessment of adherence to the substrate will be documented. The primary substrate material will be carbon steel. If time and funding allow, it will be useful to spray aluminum, copper or stainless steel to confirm heat capacity calculations.

Depending on the earlier results, nozzle geometries may be varied to improve nozzle performance for the second set of spray trials. The first priority will be to consistently produce the same product with an identical set of spray parameters. At this point, the geometries can be slightly altered to provide differences in the as-sprayed products. Samples from these spray trials will be evaluated and a selection of samples sent for further metallurgical 


\section{APPENDIX A \\ SPRAY TRIALS WITH SURROGATE ALLOY/ACtivities (COnt'd)}

and composition studies. Results from these analyses will indicate how the spray parameters or to what extent the nozzle geometries should be further modified to produce the desired as-sprayed results. It may be necessary to alter material to achieve different heat capacities in the substrate.

The surrogate alloy has been chosen for its irregular phase properties and for having melting points near that of depleted uranium and uranium alloys. The high reactivity of tungsten will provide useful contamination studies. With a density over 13 grams per cubic centimeter, this will also simulate gas to metal flow rates which will be likely for proper nozzle performance in the uranium alloys. Chemical analyses can confirm the as-sprayed product preserves a homogeneous structure. Photomicrographs can show grain structure and metallurgical properties which may be preserved through spray forming that are difficult or impossible to achieve using conventional processing techniques.

With results from the earlier spray trials and the sample analyses, determinations can be made relative to the effect of substrate parameters. If funding and time permit, it may be beneficial to preheat thicker substrates and compare those results with results from the earlier spray trials where thinner substrates were not preheated.

\section{PLUME AND PRODUCT ANALYSES BY POWDER COLLECTION FROM NOZZLES}

\section{Objectives:}

Provide data for confirmation that the spray forming process will provide as-sprayed uranium products within acceptable, EPA emission standards. Provide estimates of general chamber maintenance that would be required if the spray system was employed to spray depleted uranium and its alloys.

\section{Activities:}

To assess the viability of spray forming technology for depleted uranium products, there are two crucial areas of concern: (1) Emissions to the atmosphere from the process, and (2) Buildup within the spray chamber itself.

Periodic measurements made in previous Programs indicate that emissions from the chamber exhaust to the atmosphere can be eliminated. Chamber exhaust contaminants will be checked throughout this Program. 


\section{APPENDIX A \\ PLUME AND PRODUCT ANALYSES BY POWDER COLLECTION FROM NOZZLES Activities (Cont'd)}

The second area of concern is buildup within the spray chamber itself. Measurements will be made within the chamber area to determine particle size and quantity that may contribute to a gradual residue accumulation within the chamber. Of additional concern is the larger particles that may become overspray in the area of consolidation. A container will be used to collect this overspray while allowing the nebulizing gas to escape. The container can be weighed and emptied following each spray trial. This data will contribute to general spray system maintenance requirements that would be necessary in a pilot scale activity to spray depleted uranium.

To the extent that time and funding allow, sampling will be conducted near and within the plume itself to determine if nozzle performance can be verified with a sampling system. This would lend itself to on-line analyses in a pilot scale operation. The information obtained would enable evaluation of component operation and would indirectly monitor component wear and product properties.

\section{EXCHANGE OF TECHNICAL INFORMATION}

Results from spray trials and determinations specific to substrate material will be documented with MMES. Review and consensus of progress will serve to facilitate integration of achievements into comparable Programs. To the extent that exchange of technical information is contained within the statement of Work, CST may effect direct exchange of information and work with other Programs at MMES request.

\section{TECHNOLOGY TRANSFER}

As Program results evidence a potential for commercialization, participation of the private sector will be solicited. MMES will be informed prior to any spray forming demonstration involving potential Commercial interests. Programs will be sought between MMES, CST and Commercial participants.

\section{FINAL REPORT}

Results and recommendations will be documented in a Final Report. A Draft Final Report will be transmitted to MMES on or before August 26, 1994. Comments or suggestions may be incorporated into the Final Report if received prior to September 1, 1994. The Final Report will be issued to MMES September 5, 1994.

To ensure that the Final Report deadline is met, timely receipt of sample analyses results is required. 
APPENDIX A (Cont'd)

\section{PROJECTED SCHEDULE - SPRAY FORMING HEAVY METALS 76Y-GSK39}

PROGRAM MONTH

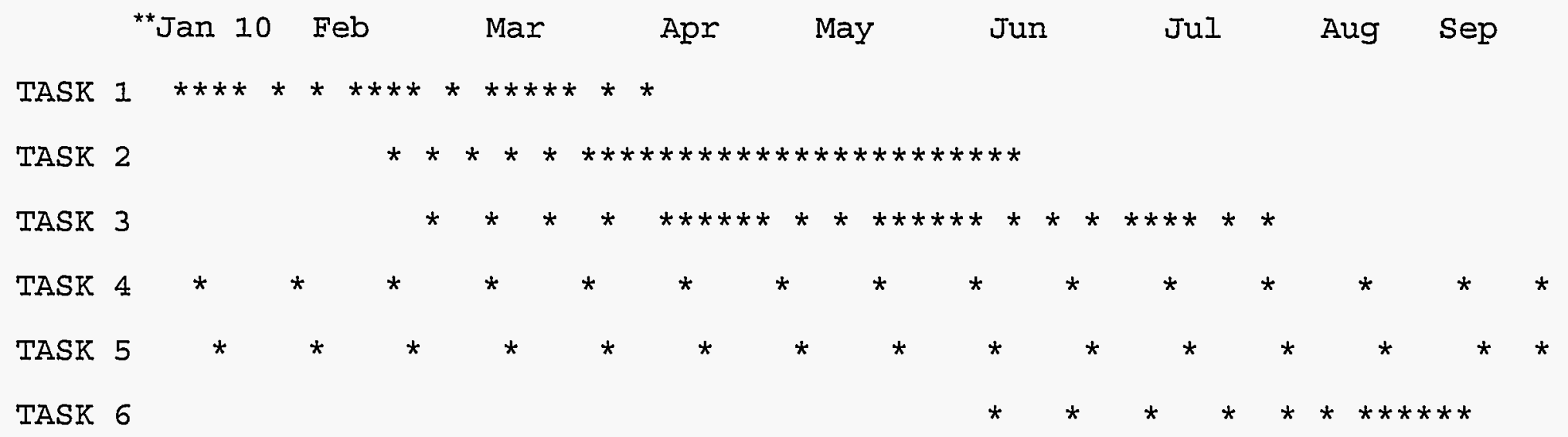

\section{DELIVERABLES :}

A. Weekly reports from CST to MMES Thursday of each Program week.

B. Monthly reports for TASK 4 and TASK 5 from CST to MMES the first working day of the following month.

C. Submit Experimental Plan for Spray Trials with Surrogate Alloy (February 7 , 1994).

D. System Checkout Complete (March 11, 1994).

E. Complete Spray Trials with Surrogate Alloy (June 6, 1994).

** Spacing proportional to number of Program weeks occurring in each month. 
PROJECTED SCHEDULE - SPRAY FORMING HEAVY METALS 76 Y -GSK3 9

PROGRAM MONTH

**an 10 Feb Mar Apr May Jun Jul Aug Sep

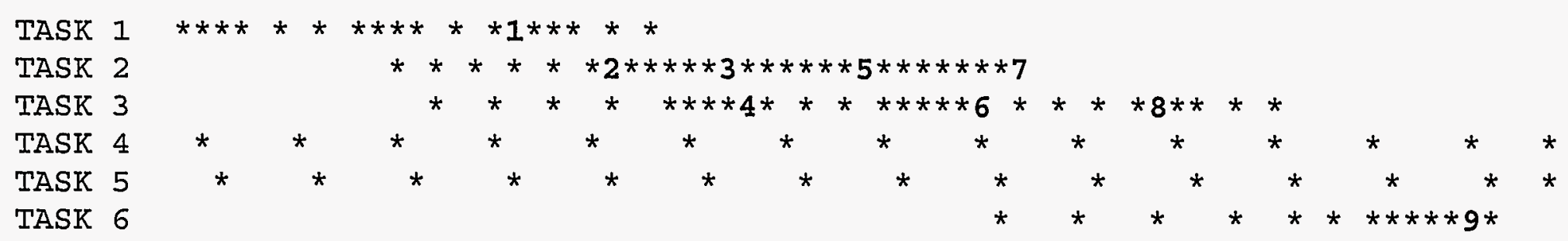

\section{DELIVERABLES :}

A. Weekly reports from CST to MMES Thursday of each Program week.

B. Monthly reports for TASK 4 and TASK 5 from CST to MMES the first working day of the following month.

C. Submit Experimental Plan for Spray Trials with Surirogate Alloy (February 7, 1994).

D. System Checkout Complete (March 11, 1994).

E. Complete Spray Trials with Surrogate Alloy (June 6, 1994).

\section{PROGRAM CHECKPOINTS:}

1. Perform a system heat-up to provide an operational check.

2. Commence spray trials with initial nozzle design.

3. Complete spray trials with initial nozzle design.

4. Collect samples from chamber atmosphere using Cascade Impactors.

5. Commence spray trials with tailored nozzle design.

6. Remit samples to EG\&G Idaho, Inc. from Cascade Impactor collections.

7. Remit samples to EG\&G Idaho, Inc. from tailored spray trials.

8. Spray trials to collect particles near and within spray plume.

9. Remit Final Report (Draft Report will be issued late August for Customer review and approval).

** Spacing proportional to number of Program weeks occurring in each month.

\section{LW03 84JT . MMES - R1}


APPENDIX B: CASCADE IMPACTOR DATA 


\section{APPENDIX B CASCADE IMPACTOR DATA}

There were no particles present in FeWA-11, Stage 1 for metallurgical analysis.

Explanatory information specific to the Cascade Impactor Table data is presented in the template below. These footnotes are consistent throughout Appendix B.

\section{Based on Standardless EDS Analysis}

\begin{tabular}{llllll}
\hline \multirow{2}{*}{ Element } & Line & $\begin{array}{l}\text { Weight } \\
\text { percent }\end{array}$ & $\begin{array}{l}\text { Atomic } \\
\text { percent }^{b}\end{array}$ & $\begin{array}{l}\text { Precision } \\
2-S i g m a\end{array}$ & K-ratioc \\
\hline
\end{tabular}

\footnotetext{
astandardless EDS Analysis (ZAF Corrections via Magic V) Accelerating voltage $20.0 \mathrm{KeV}$ Beam - sample incidence angle $90.0 \mathrm{deg}$. $\mathrm{X}$-ray emergence angle $\mathrm{x}$-ray - window incidence angle 35.0 deg. 0.0 deg.
}

${ }^{b}$ Atomic percent is normalized to 100; normalization factor: 1.000

${ }^{c} K$-ratio $=K$-ratio $\times R$; where $R=$ reference (standard)/reference (sample) 
Table 5. Cascade Impactor, Particle Analysis, FeWA-11, Stage 2-1 Back Scattered Electron Image

Based on Standardless EDS Analysis ${ }^{a}$

\begin{tabular}{|c|c|c|c|c|c|}
\hline Element & Line & $\begin{array}{l}\text { Weight } \\
\text { percent }\end{array}$ & $\begin{array}{l}\text { Atomic } \\
\text { percent }\end{array}$ & $\begin{array}{l}\text { Precision } \\
\text { 2-Sigma }\end{array}$ & K-ratio ${ }^{c}$ \\
\hline $\mathrm{Cr}$ & $\mathrm{KA}$ & 2.19 & 3.45 & 0.15 & 0.0233 \\
\hline $\mathrm{Fe}$ & $\mathrm{KA}$ & 51.39 & 75.45 & 0.59 & 0.5421 \\
\hline $\mathrm{Ni}$ & $\mathrm{KA}$ & 0.42 & 0.59 & 0.13 & 0.0044 \\
\hline$W$ & LA & 46.01 & 20.52 & 1.18 & 0.3880 \\
\hline Total & & 100.01 & & & \\
\hline Iterations & & 5 & & & \\
\hline
\end{tabular}

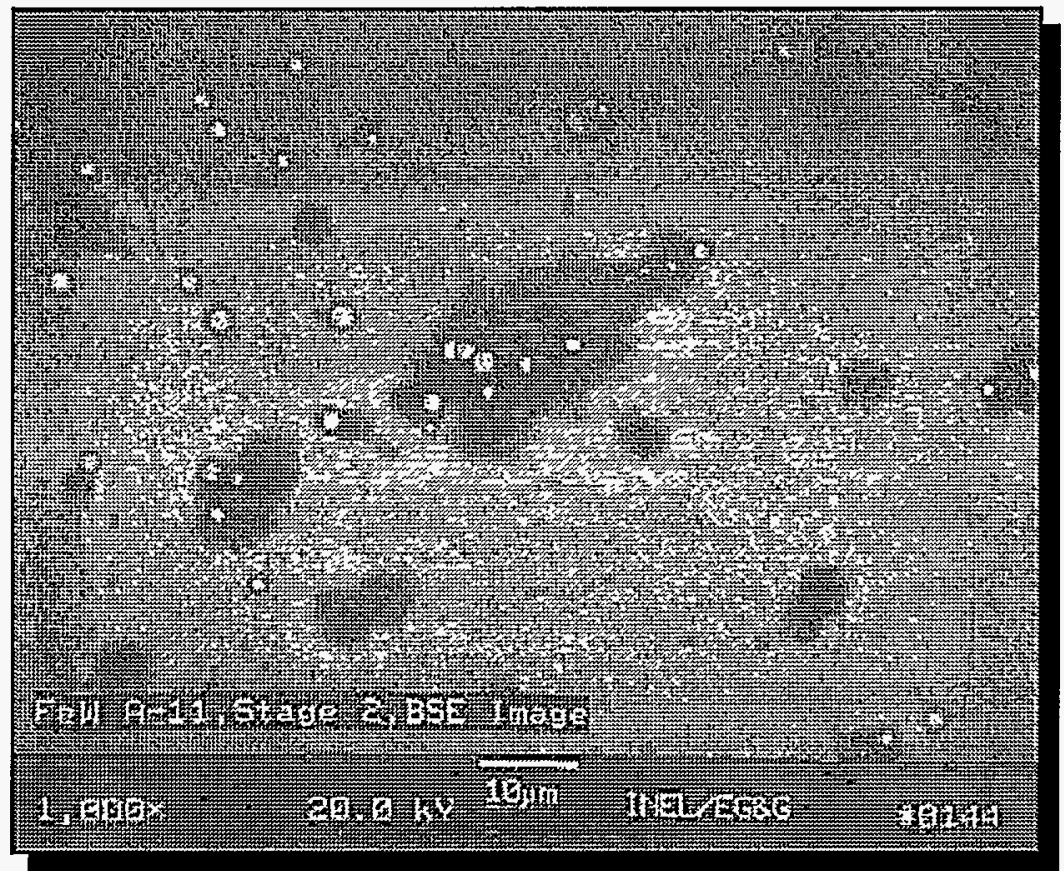

Figure 44. Magnification of Collection Plate Depicting Surrogate Alloy Particulate. 
Table 6. Cascade Impactor, Particle Analysis, FeWA-11, Stage 2-2 Foreward Scattered Electron Image

Based on Standardless EDS Analysis ${ }^{a}$

\begin{tabular}{|c|c|c|c|c|c|}
\hline Element & Line & $\begin{array}{l}\text { Weight } \\
\text { percent }\end{array}$ & $\begin{array}{l}\text { Atomic } \\
\text { percent }\end{array}$ & $\begin{array}{l}\text { Precision } \\
\text { 2-sigma }\end{array}$ & K-ratioc \\
\hline 0 & $\mathrm{KA}$ & 45.97 & 57.81 & 1.83 & 0.1796 \\
\hline $\mathrm{E}$ & $\mathrm{KA}$ & 12.04 & 12.75 & 1.67 & 0.0198 \\
\hline $\mathrm{Na}$ & $\mathrm{KA}$ & 10.47 & 9.16 & 0.22 & 0.0360 \\
\hline Al & $\mathrm{KA}$ & 7.17 & 5.35 & 0.12 & 0.0387 \\
\hline $\mathrm{Si}$ & $\mathrm{KA}$ & 14.72 & 10.54 & 0.15 & 0.0909 \\
\hline $\mathrm{Ca}$ & $\mathrm{KA}$ & 6.39 & 3.21 & 0.09 & 0.0583 \\
\hline $\mathrm{Cr}$ & $\mathrm{KA}$ & 0.81 & 0.31 & 0.05 & 0.0071 \\
\hline $\mathrm{Fe}$ & $\mathrm{KA}$ & 2.32 & 0.83 & 0.09 & 0.0204 \\
\hline $\mathrm{Ni}$ & $\mathrm{KA}$ & 0.12 & 0.04 & 0.03 & 0.0011 \\
\hline Total & & 100.01 & & & \\
\hline Iterations & & 12 & & & \\
\hline
\end{tabular}

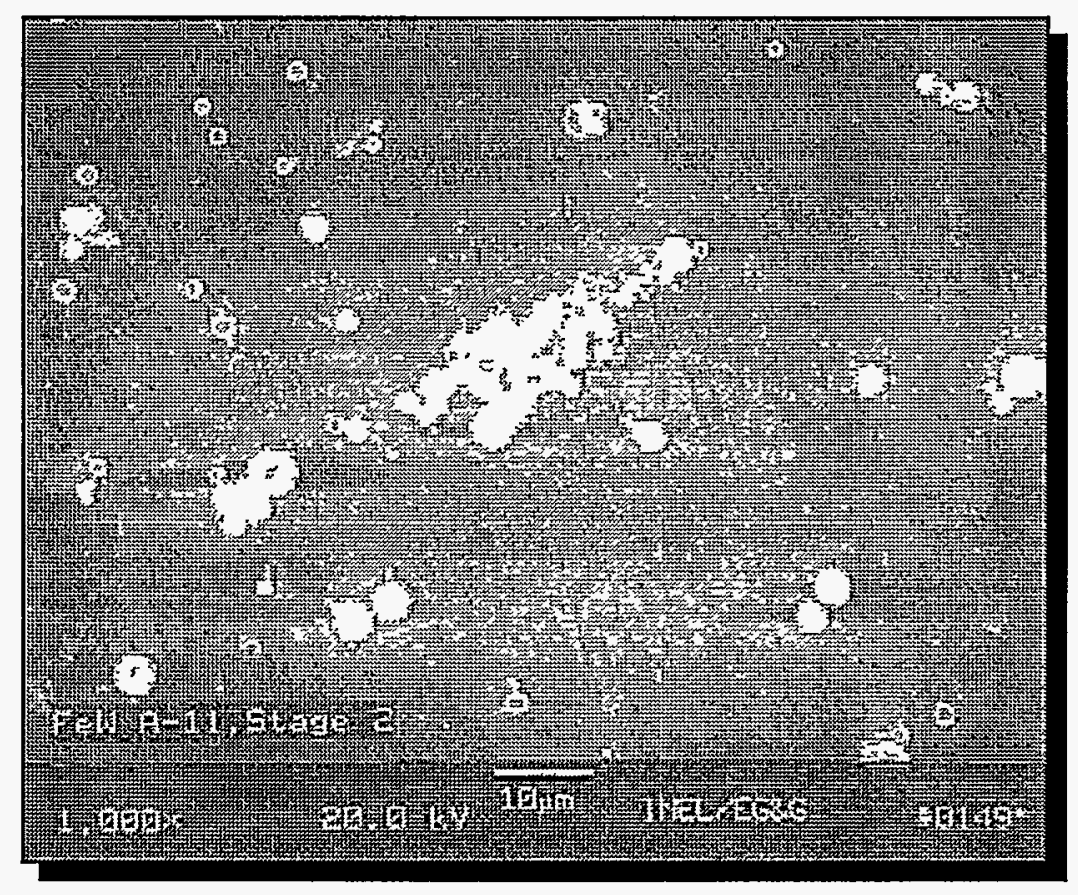

Figure 45. Magnification of Collection Plate Depicting Nonmetal Particulate. 
Table 7. Cascade Impactor, Particle Analysis, FeWA-11, Stage 3-1 Back Scattered Electron Image

\section{Based on Standardless EDS Analysis ${ }^{a}$}

\begin{tabular}{lccccc}
\hline Element & Line & $\begin{array}{l}\text { Weight } \\
\text { percent }\end{array}$ & $\begin{array}{l}\text { Atomic } \\
\text { percent }\end{array}$ & $\begin{array}{l}\text { Precision } \\
\text { 2-Sigma }\end{array}$ & K-ratio \\
\hline D & $\mathrm{KA}$ & 2.80 & 12.50 & 0.35 & 0.0103 \\
$\mathrm{Na}$ & $\mathrm{KA}$ & 0.12 & 0.38 & 0.06 & 0.0004 \\
$\mathrm{Al}$ & $\mathrm{KA}$ & 0.36 & 0.96 & 0.08 & 0.0019 \\
$\mathrm{Ca}$ & $\mathrm{KA}$ & 2.36 & 4.21 & 0.10 & 0.0210 \\
$\mathrm{Cr}$ & $\mathrm{KA}$ & 2.14 & 2.95 & 0.11 & 0.0224 \\
$\mathrm{Fe}$ & $\mathrm{KA}$ & 48.29 & 61.89 & 0.44 & 0.5019 \\
$\mathrm{~W}$ & $\mathrm{LA}$ & $\underline{43.92}$ & 17.10 & 0.89 & 0.3660 \\
Total & & 99.99 & & & \\
Iterations & & & & & \\
\end{tabular}

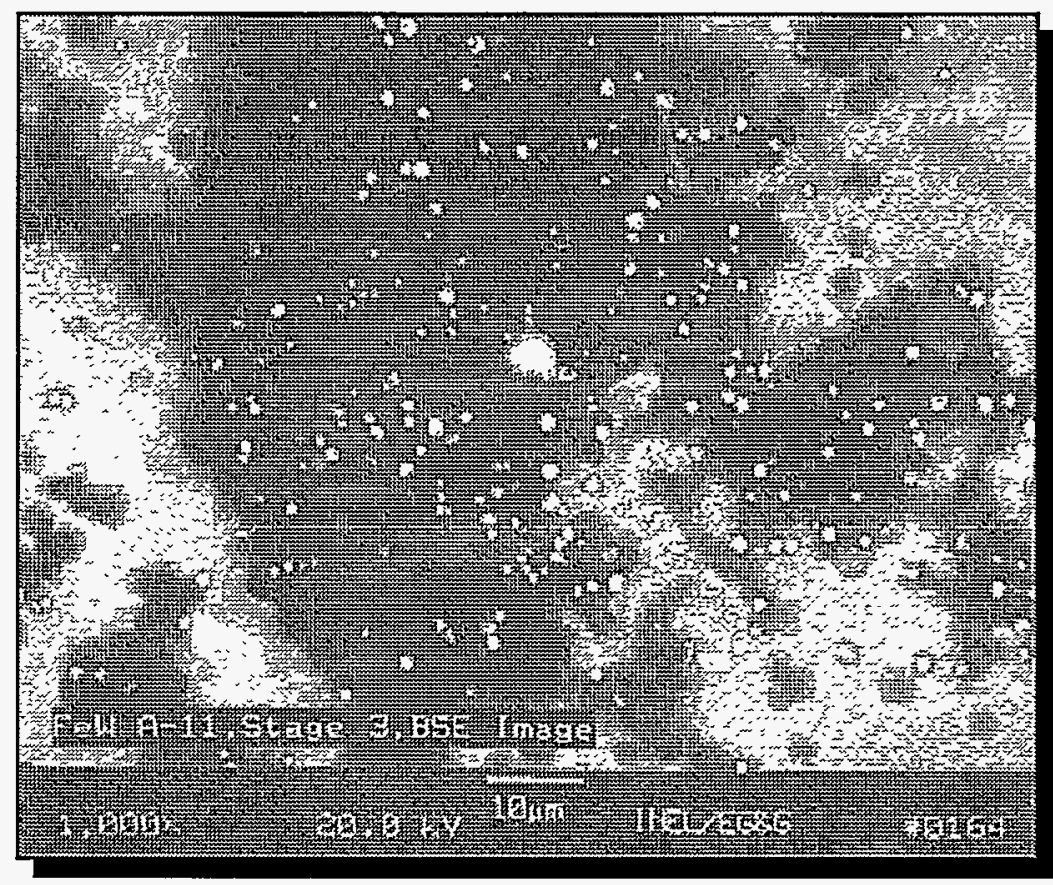

Figure 46. Magnification of Collection Plate Depicting Surrogate Alloy Particulate. 
Table 8. Cascade Impactor, Particle Analysis, EewA-11, Stage 3-2 Foreward Scattered Electron Image

\section{Based on Standardless EDS Analysis}

\begin{tabular}{lccccc}
\hline Element & Line & $\begin{array}{l}\text { Weight } \\
\text { percent }\end{array}$ & $\begin{array}{l}\text { Atomic } \\
\text { percent }\end{array}$ & $\begin{array}{l}\text { Precision } \\
\text { 2-Sigma }\end{array}$ & K-ratioc \\
\hline $\mathrm{O}$ & $\mathrm{KA}$ & 41.87 & 52.80 & 1.77 & 0.1506 \\
$\mathrm{~F}$ & $\mathrm{KA}$ & 20.14 & 21.39 & 1.58 & 0.0351 \\
$\mathrm{Na}$ & $\mathrm{KA}$ & 12.75 & 11.19 & 0.25 & 0.0412 \\
$\mathrm{Al}$ & $\mathrm{KA}$ & 5.23 & 3.91 & 0.11 & 0.0265 \\
$\mathrm{Si}$ & $\mathrm{KA}$ & 5.87 & 4.22 & 0.10 & 0.0356 \\
$\mathrm{~K}$ & $\mathrm{KA}$ & 0.14 & 0.07 & 0.02 & 0.0013 \\
$\mathrm{Ca}$ & $\mathrm{KA}$ & 10.76 & 5.41 & 0.11 & 0.1001 \\
$\mathrm{Cr}$ & $\mathrm{KA}$ & 0.37 & 0.14 & 0.04 & 0.0033 \\
$\mathrm{Fe}$ & $\mathrm{KA}$ & 1.61 & 0.58 & 0.08 & 0.0141 \\
$\mathrm{Ni}$ & $\mathrm{KA}$ & 0.05 & 0.02 & 0.02 & 0.0004 \\
$\mathrm{Zr}$ & $\mathrm{LA}$ & 1.21 & 0.27 & 0.07 & 0.0085 \\
Total & & 100.00 & & & \\
Iterations & & & & & \\
& & & & & \\
\hline
\end{tabular}

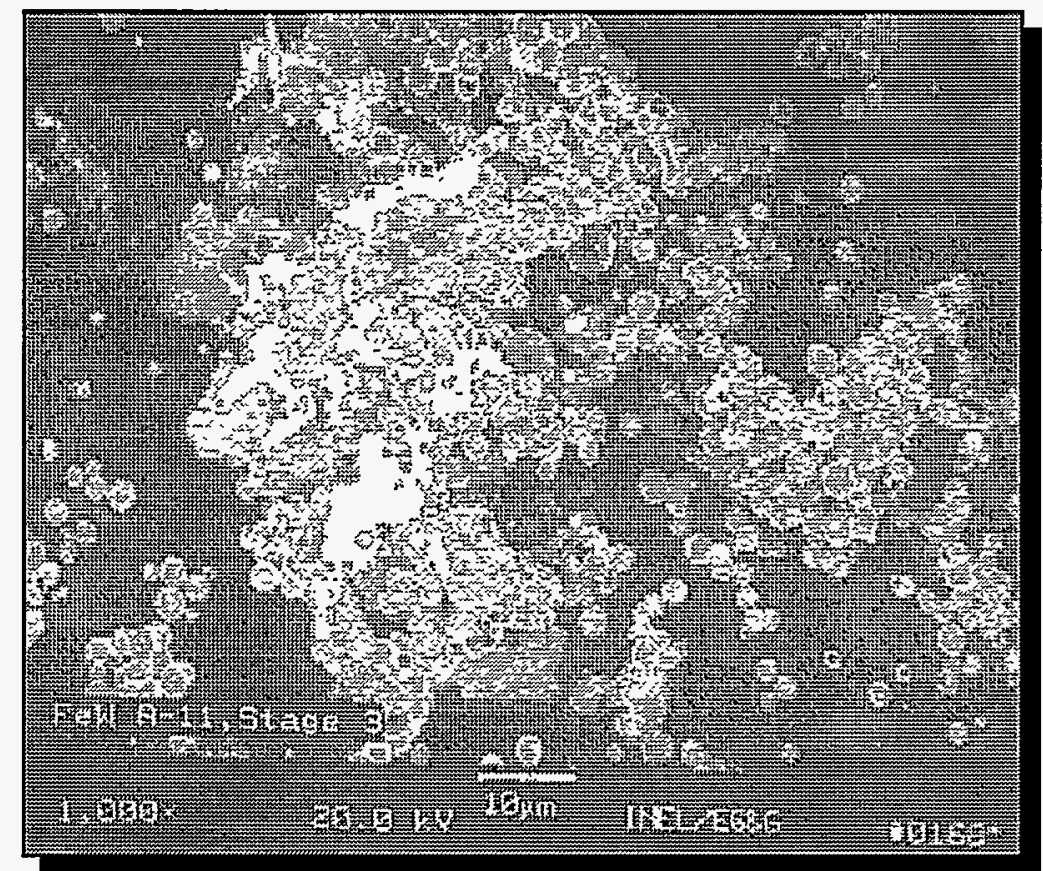

Figure 47. Magnification of Collection Plate Depicting Nonmetal Particulate. 
Table 9. Cascade Impactor, Particle Analysis, FeWA-11, Stage 4-1 Back Scattered Electron Image

Based on Standardless EDS Analysis

\begin{tabular}{|c|c|c|c|c|c|}
\hline Element & Iine & $\begin{array}{l}\text { Weight } \\
\text { percent }\end{array}$ & $\begin{array}{l}\text { Atomic } \\
\text { percent }\end{array}$ & $\begin{array}{l}\text { Precision } \\
2 \text {-Sigma }\end{array}$ & K-ratio ${ }^{c}$ \\
\hline $\mathrm{Na}$ & $\mathrm{KA}$ & 3.08 & 10.27 & 0.19 & 0.0095 \\
\hline $\mathrm{Ca}$ & $\mathrm{KA}$ & 0.45 & 0.86 & 0.07 & 0.0040 \\
\hline $\mathrm{Cr}$ & $\mathrm{KA}$ & 1.80 & 2.65 & 0.11 & 0.0190 \\
\hline $\mathrm{Fe}$ & $\mathrm{KA}$ & 48.96 & 67.17 & 0.45 & 0.5142 \\
\hline$W$ & LA & 45.72 & 19.05 & 0.90 & 0.3845 \\
\hline Total & & 100.01 & & & \\
\hline Iterations & & 6 & & & \\
\hline
\end{tabular}

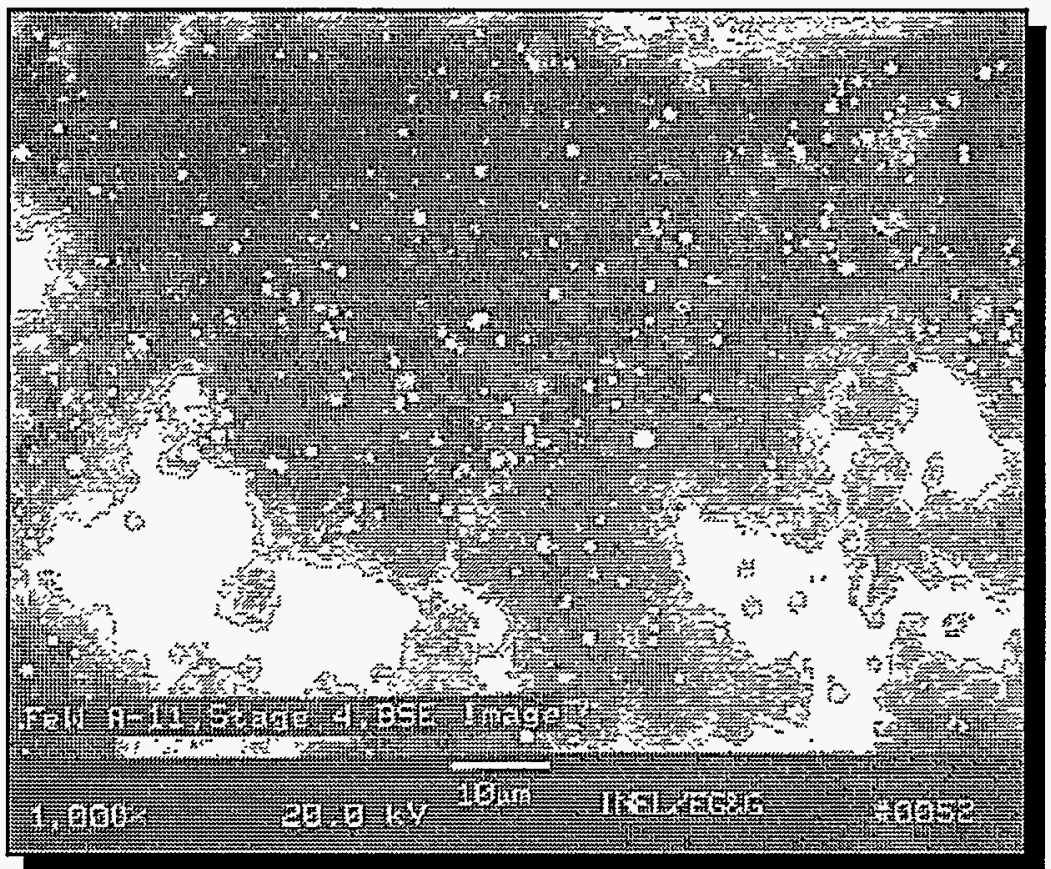

Figure 48. Magnification of Collection Plate Depicting Surrogate Alloy Particulate. 
Table 10. Cascade Impactor, Particle Analysis, FeWA-11, Stage 4-2 Foreward Scattered Electron Image

Based on Standardless EDS Analysis ${ }^{a}$

\begin{tabular}{|c|c|c|c|c|c|}
\hline Element & Line & $\begin{array}{l}\text { Weight } \\
\text { percent }\end{array}$ & $\begin{array}{l}\text { Atomic } \\
\text { percent }\end{array}$ & $\begin{array}{l}\text { Precision } \\
2 \text {-Sigma }\end{array}$ & K-ratioc \\
\hline 0 & $\mathrm{KA}$ & 48.17 & 60.78 & 1.47 & 0.1798 \\
\hline $\mathrm{F}$ & $\mathrm{KA}$ & 9.53 & 10.13 & 1.33 & 0.0150 \\
\hline $\mathrm{Na}$ & $\mathrm{KA}$ & 11.61 & 10.20 & 0.21 & 0.0401 \\
\hline Al & $\mathrm{KA}$ & 6.63 & 4.96 & 0.11 & 0.0353 \\
\hline $\mathrm{Si}$ & $\mathrm{KA}$ & 12.23 & 8.79 & 0.13 & 0.0753 \\
\hline $\mathrm{K}$ & $\mathrm{KA}$ & 0.19 & 0.10 & 0.02 & 0.0016 \\
\hline $\mathrm{Ca}$ & $\mathrm{KA}$ & 7.33 & 3.69 & 0.09 & 0.0668 \\
\hline $\mathrm{Cr}$ & $\mathrm{KA}$ & 0.43 & 0.17 & 0.04 & 0.0037 \\
\hline $\mathrm{Fe}$ & $\mathrm{KA}$ & 2.16 & 0.78 & 0.08 & 0.0190 \\
\hline $\mathrm{Zn}$ & $K A$ & 0.33 & 0.10 & 0.06 & 0.0028 \\
\hline $\mathrm{Zr}$ & LA & 1.40 & 0.31 & 0.04 & 0.0092 \\
\hline Total & & 100.01 & & & \\
\hline Iterations & & 13 & & & \\
\hline
\end{tabular}

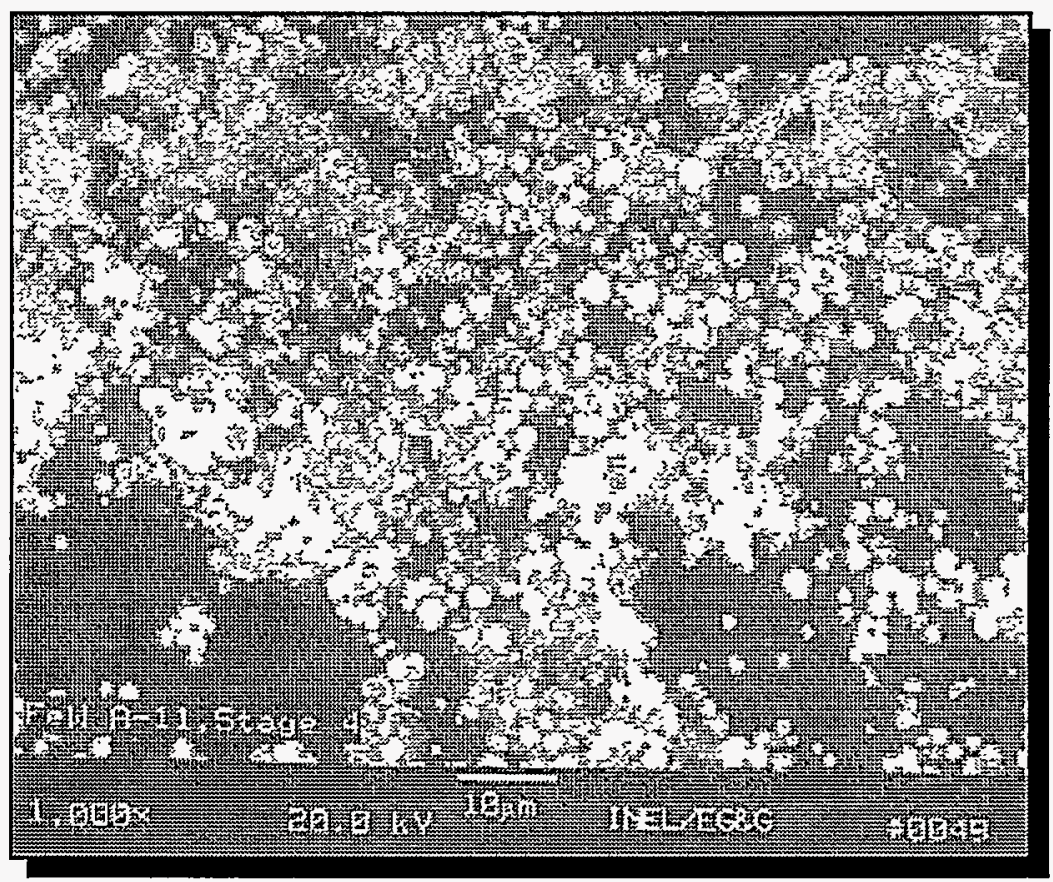

Figure 49. Magnification of Collection Plate Depicting Nonmetal Particulate. 
Table 11. Cascade Impactor, Particle Analysis, FeWA-11, Stage 5-1 Back Scattered Electron Image

Based on Standardless EDS Analysis

\begin{tabular}{|c|c|c|c|c|c|}
\hline Element & Line & $\begin{array}{l}\text { Weight } \\
\text { percent }\end{array}$ & $\begin{array}{l}\text { Atomic } \\
\text { percent }^{b}\end{array}$ & $\begin{array}{l}\text { Precision } \\
\text { 2-Sigma }\end{array}$ & K-ratioc \\
\hline 0 & $\mathrm{KA}$ & 8.80 & 31.14 & 0.56 & 0.0336 \\
\hline ma & $\mathrm{KA}$ & 2.22 & 5.47 & 0.19 & 0.0068 \\
\hline Al & $\mathrm{KA}$ & 1.68 & 3.52 & 0.11 & 0.0089 \\
\hline $\mathrm{Ca}$ & $\mathrm{KA}$ & 0.67 & 0.94 & 0.07 & 0.0059 \\
\hline $\mathrm{Cr}$ & $\mathrm{KA}$ & 0.96 & 1.05 & 0.09 & 0.0099 \\
\hline $\mathrm{Fe}$ & $\mathrm{KA}$ & 43.88 & 44.47 & 0.40 & 0.4495 \\
\hline Zr & LA & 1.78 & 1.10 & 0.07 & 0.0101 \\
\hline$W$ & L.A & 40.01 & 12.31 & 0.80 & 0.3276 \\
\hline Total & & 100.00 & & & \\
\hline Iterations & & 6 & & & \\
\hline
\end{tabular}

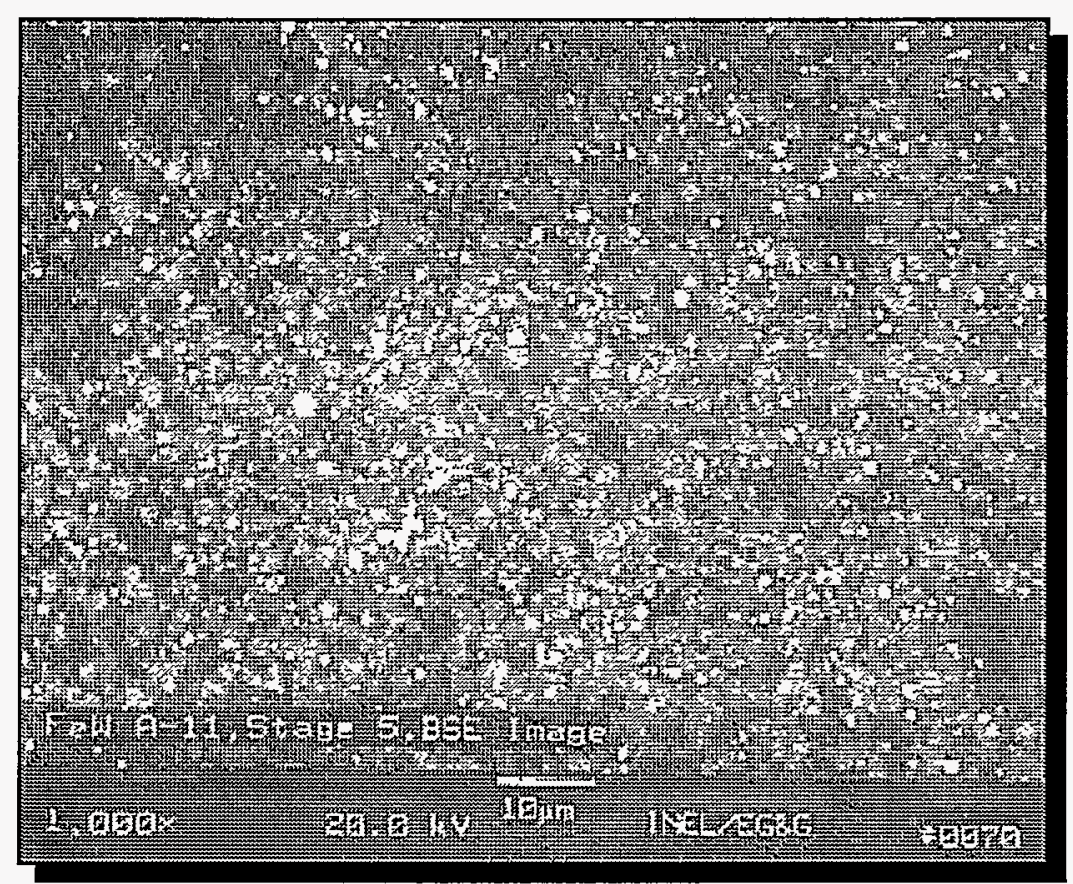

Figure 50. Magnification of Collection Plate Depicting Surrogate Alloy Particulate. 
Table 12. Cascade Impactor, Particle Analysis, FeWA-11, Stage 5-2 Foreward Scattered Electron Image

Based on Standardless EDS Analysis

\begin{tabular}{lccccc}
\hline Element & Line & $\begin{array}{l}\text { Weight } \\
\text { percent }\end{array}$ & $\begin{array}{l}\text { Atomic } \\
\text { percent }\end{array}$ & $\begin{array}{l}\text { Precision } \\
\text { 2-Sigma }\end{array}$ & K-ratioc \\
\hline $\mathrm{O}$ & $\mathrm{KA}$ & 44.74 & 55.96 & 1.64 & 0.1649 \\
$\mathrm{~F}$ & $\mathrm{KA}$ & 16.89 & 17.79 & 1.34 & 0.0282 \\
$\mathrm{Na}$ & $\mathrm{KA}$ & 11.66 & 10.15 & 0.21 & 0.0387 \\
$\mathrm{Al}$ & $\mathrm{KA}$ & 9.29 & 6.89 & 0.12 & 0.0483 \\
$\mathrm{Si}$ & $\mathrm{KA}$ & 5.02 & 3.57 & 0.08 & 0.0295 \\
$\mathrm{~K}$ & $\mathrm{KA}$ & 0.14 & 0.07 & 0.02 & 0.0013 \\
$\mathrm{Ca}$ & $\mathrm{KA}$ & 9.56 & 4.77 & 0.10 & 0.0885 \\
$\mathrm{Cr}$ & $\mathrm{KA}$ & 0.17 & 0.07 & 0.03 & 0.0015 \\
$\mathrm{Fe}$ & $\mathrm{KA}$ & 1.12 & 0.40 & 0.06 & 0.0098 \\
$\mathrm{Zn}$ & $\mathrm{KA}$ & 0.18 & 0.05 & 0.04 & 0.0015 \\
$\mathrm{Zr}$ & $\mathrm{IA}$ & 1.23 & 0.27 & 0.04 & 0.0085 \\
Total & & 100.00 & & & \\
Iterations & & & & & \\
& & & & & \\
\hline
\end{tabular}

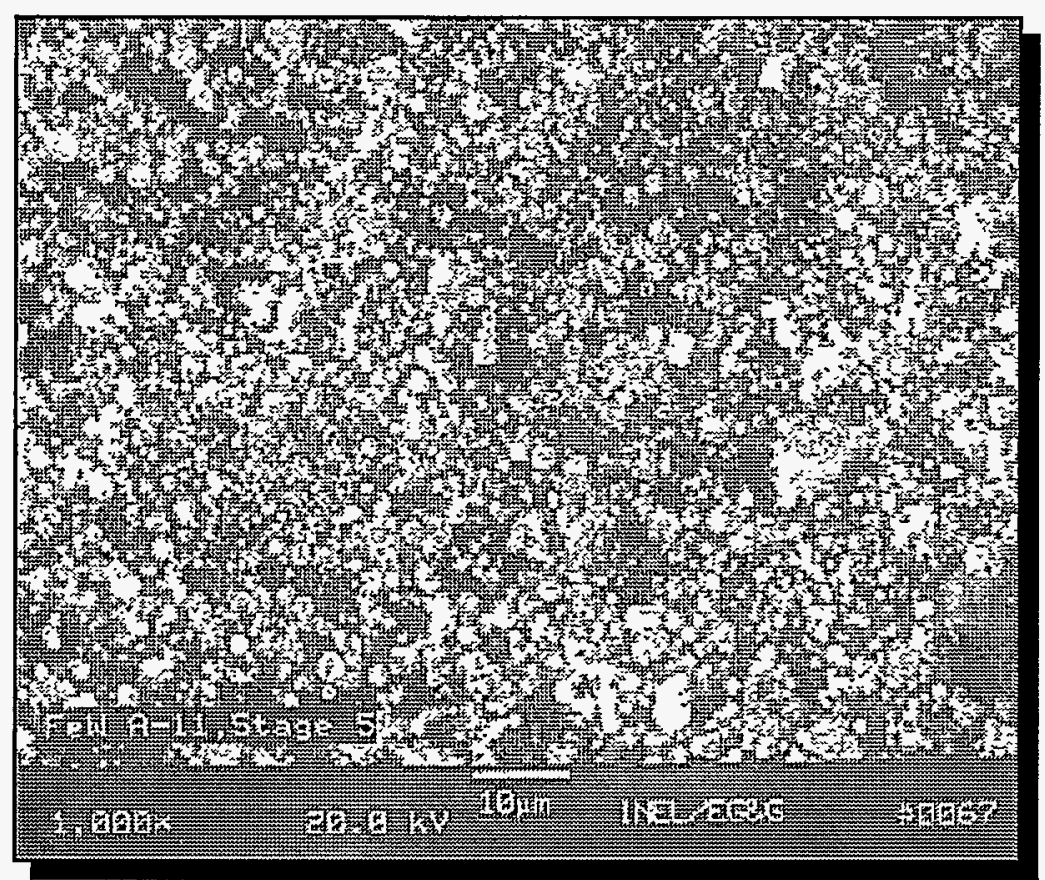

Figure 51. Magnification of Collection Plate Depicting Nonmetal Particulate. 
Table 13. Cascade Impactor, Particle Analysis, FeWA-11, Stage 6-1 Back Scattered Electron Image

Based on Standardless EDS Analysis ${ }^{a}$

\begin{tabular}{|c|c|c|c|c|c|}
\hline Element & Line & $\begin{array}{l}\text { Weight } \\
\text { percent }\end{array}$ & $\begin{array}{l}\text { Atomic } \\
\text { percent }\end{array}$ & $\begin{array}{l}\text { Precision } \\
\text { 2-Sigma }\end{array}$ & K-ratioc \\
\hline 0 & $\mathrm{KA}$ & 31.14 & 59.00 & 0.95 & 0.1296 \\
\hline $\mathrm{F}$ & $\mathrm{KA}$ & 3.13 & 5.00 & 1.29 & 0.0081 \\
\hline $\mathrm{Na}$ & $\mathrm{KA}$ & 7.75 & 10.22 & 0.65 & 0.0247 \\
\hline Al & $\mathrm{KA}$ & 5.14 & 5.78 & 0.16 & 0.0262 \\
\hline $\mathrm{Ca}$ & $\mathrm{KA}$ & 2.73 & 2.06 & 0.10 & 0.0242 \\
\hline $\mathrm{Cr}$ & $\mathrm{KA}$ & 0.42 & 0.25 & 0.07 & 0.0041 \\
\hline $\mathrm{Fe}$ & $\mathrm{KA}$ & 21.75 & 11.80 & 0.32 & 0.2090 \\
\hline $\mathrm{Zn}$ & $\mathrm{KA}$ & 4.28 & 1.99 & 0.26 & 0.0390 \\
\hline$W$ & LA & $\underline{23.64}$ & 3.90 & 0.71 & 0.1807 \\
\hline Total & & 99.98 & & & \\
\hline Iterations & & 9 & & & \\
\hline
\end{tabular}

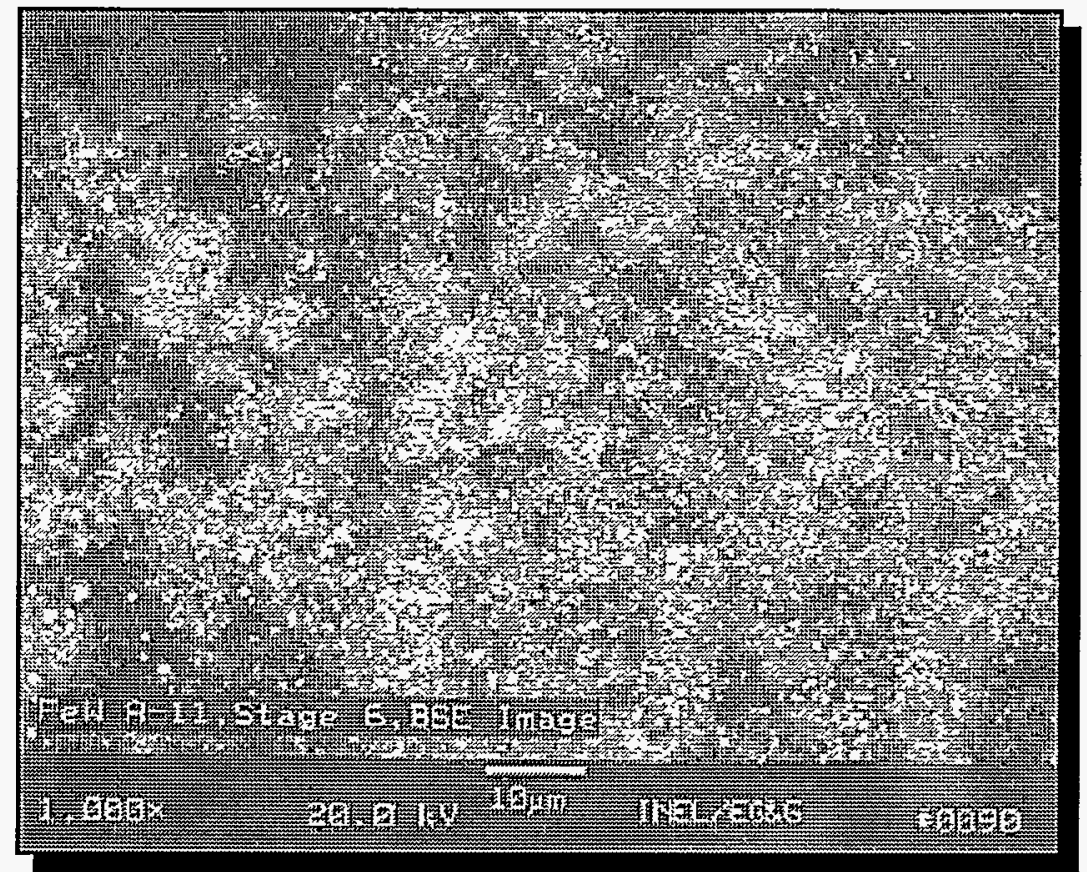

Figure 52. Magnification of Collection Plate Depicting Surrogate Alloy Particulate. 
Table 14. Cascade Impactor, Particle Analysis, FeWA-11, Stage 6-2 Foreward Scattered Electron Image

Based on Standardless EDS Analysis ${ }^{a}$

\begin{tabular}{|c|c|c|c|c|c|}
\hline Element & Line & $\begin{array}{l}\text { Weight } \\
\text { percent }\end{array}$ & $\begin{array}{l}\text { Atomic } \\
\text { percent }\end{array}$ & $\begin{array}{l}\text { Precision } \\
2 \text {-Sigma }\end{array}$ & $\mathrm{K}$-ratioc \\
\hline 0 & $\mathrm{KA}$ & 41.55 & 56.97 & 0.85 & 0.1433 \\
\hline $\mathrm{F}$ & $\mathrm{KA}$ & 14.05 & 16.22 & 0.49 & 0.0255 \\
\hline $\mathrm{Na}$ & $\mathrm{KA}$ & 9.87 & 9.42 & 0.23 & 0.0320 \\
\hline Al & $\mathrm{KA}$ & 5.71 & 4.65 & 0.12 & 0.0293 \\
\hline $\mathrm{Si}$ & $\mathrm{KA}$ & 5.16 & 4.03 & 0.10 & 0.0315 \\
\hline $\mathrm{K}$ & $\mathrm{KA}$ & 0.32 & 0.18 & 0.04 & 0.0027 \\
\hline $\mathrm{Ca}$ & $\mathrm{KA}$ & 6.65 & 3.64 & 0.10 & 0.0600 \\
\hline $\mathrm{Cr}$ & $\mathrm{KA}$ & 0.32 & 0.14 & 0.05 & 0.0029 \\
\hline $\mathrm{Mn}$ & $\mathrm{KA}$ & 0.03 & 0.01 & 0.02 & 0.0003 \\
\hline $\mathrm{Fe}$ & $\mathrm{KA}$ & 3.14 & 1.24 & 0.11 & 0.0282 \\
\hline $\mathrm{Zn}$ & $\mathrm{KA}$ & 3.54 & 1.19 & 0.17 & 0.0307 \\
\hline Zr & LA & 9.65 & 2.32 & 0.05 & 0.0686 \\
\hline Total & & 99.99 & & & \\
\hline Iterations & & 13 & & & \\
\hline
\end{tabular}

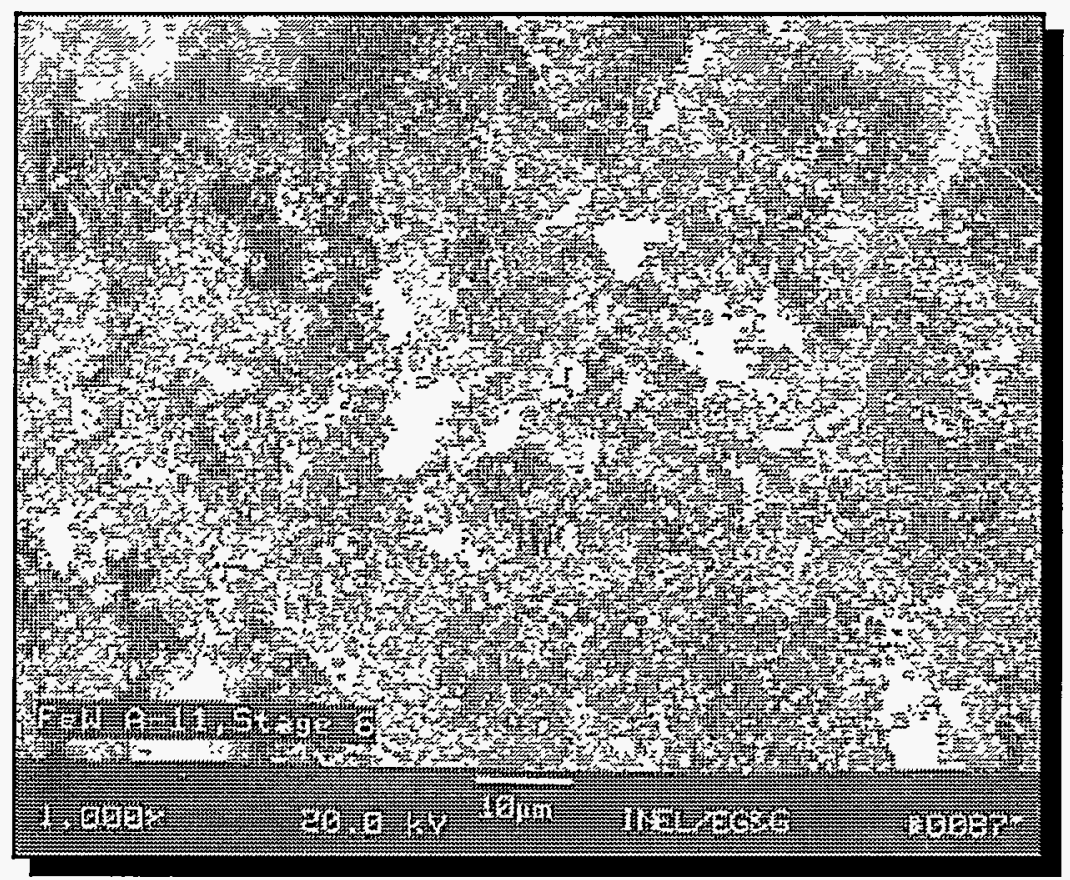

Figure 53. Magnification of Collection Plate Depicting Nonmetal Particulate. 
Table 15. Cascade Impactor, Particle Analysis, FeWA-11, Stage 7-1 Back Scattered Electron Image

Based on Standardless EDS Analysis ${ }^{a}$

\begin{tabular}{|c|c|c|c|c|c|}
\hline Element & Line & $\begin{array}{l}\text { Weight } \\
\text { percent }\end{array}$ & $\begin{array}{l}\text { Atomic } \\
\text { percent }\end{array}$ & $\begin{array}{l}\text { Precision } \\
\text { 2-Sigma }\end{array}$ & K-ratioc \\
\hline 0 & $\mathrm{KA}$ & 31.23 & 57.21 & 0.77 & 0.1370 \\
\hline $\mathbf{E}$ & $\mathrm{KA}$ & 3.19 & 4.92 & 1.18 & 0.0084 \\
\hline $\mathrm{Na}$ & $\mathrm{KA}$ & 12.02 & 15.32 & 0.61 & 0.0389 \\
\hline AI & $\mathrm{KA}$ & 4.39 & 4.77 & 0.12 & 0.0217 \\
\hline $\mathrm{Ca}$ & $\mathrm{KA}$ & 1.14 & 0.83 & 0.06 & 0.0101 \\
\hline $\mathrm{Cr}$ & $\mathrm{KA}$ & 0.62 & 0.35 & 0.06 & 0.0059 \\
\hline $\mathrm{Fe}$ & $\mathrm{KA}$ & 20.33 & 10.67 & 0.25 & 0.1952 \\
\hline $\mathrm{Zn}$ & $\mathrm{KA}$ & 4.92 & 2.20 & 0.22 & 0.0446 \\
\hline Zr & I.A & 1.18 & 0.38 & 0.07 & 0.0072 \\
\hline$W$ & I.A & 20.98 & 3.34 & 0.52 & 0.1598 \\
\hline Total & & 100.00 & & & \\
\hline Iterations & & 9 & & & \\
\hline
\end{tabular}

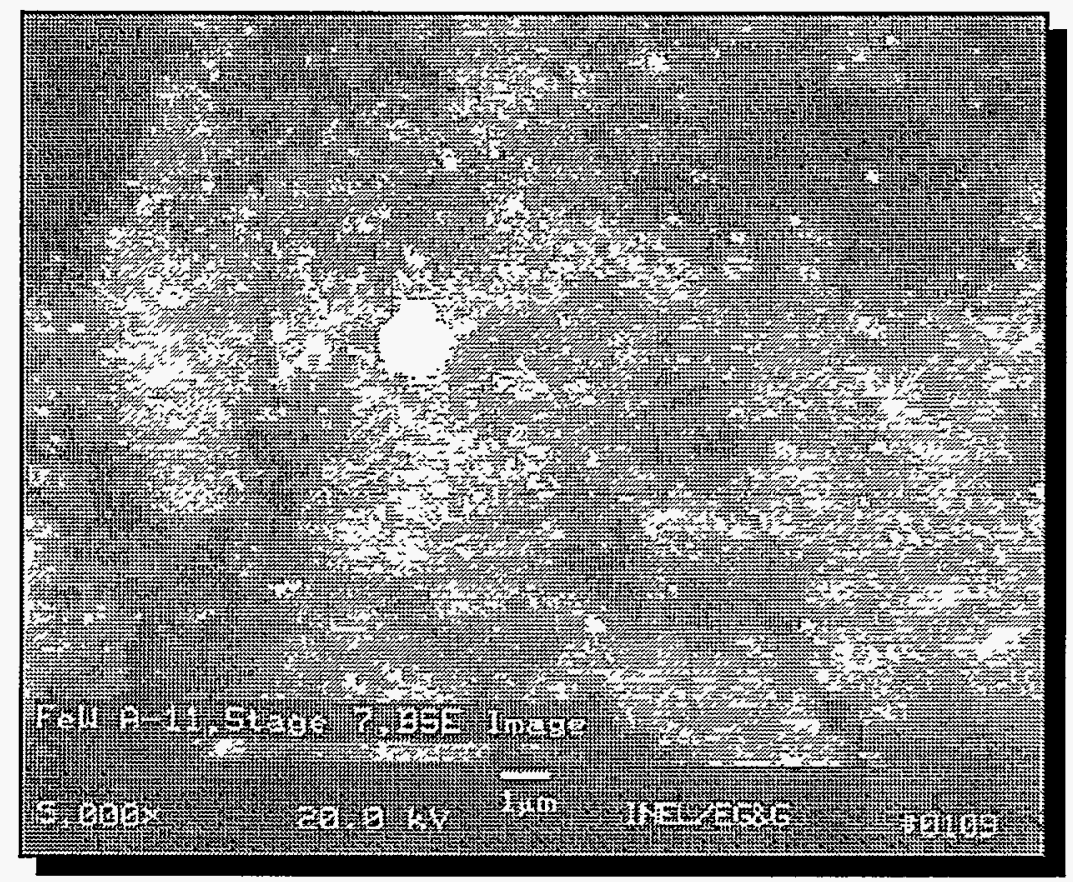

Figure 54. Magnification of Collection Plate Depicting Surrogate Alloy Particulate. 
Table 16. Cascade Impactor, Particle Analysis, FeWA-11, Stage 7-2 Foreward Scattered Electron Image

Based on Standardless EDS Analysis

\begin{tabular}{|c|c|c|c|c|c|}
\hline Element & Line & $\begin{array}{l}\text { Weight } \\
\text { percent }\end{array}$ & $\begin{array}{l}\text { Atomic } \\
\text { percent }^{b}\end{array}$ & $\begin{array}{l}\text { Precision } \\
\text { 2-Sigma }\end{array}$ & K-ratioc \\
\hline 0 & $\mathrm{KA}$ & 41.20 & 53.49 & 0.59 & 0.2114 \\
\hline $\mathrm{F}$ & $\mathrm{KA}$ & 15.01 & 16.41 & 1.18 & 0.0313 \\
\hline $\mathrm{Na}$ & $\mathrm{KA}$ & 18.22 & 16.47 & 0.49 & 0.0576 \\
\hline Al & KA & 6.30 & 4.85 & 0.11 & 0.0281 \\
\hline $\mathrm{Si}$ & $\mathrm{KA}$ & 4.81 & 3.56 & 0.08 & 0.0261 \\
\hline K & $\mathrm{KA}$ & 0.24 & 0.13 & 0.03 & 0.0021 \\
\hline $\mathrm{Ca}$ & $\mathrm{KA}$ & 2.05 & 1.06 & 0.05 & 0.0190 \\
\hline $\mathrm{Cr}$ & $\mathrm{KA}$ & 0.22 & 0.09 & 0.03 & 0.0020 \\
\hline $\mathrm{Fe}$ & $\mathrm{KA}$ & 2.78 & 1.03 & 0.08 & 0.0256 \\
\hline $\mathrm{Zn}$ & $\mathrm{KA}$ & 9.18 & 2.92 & 0.20 & 0.0794 \\
\hline Total & & 100.01 & & & \\
\hline Iterations & & 12 & & & \\
\hline
\end{tabular}

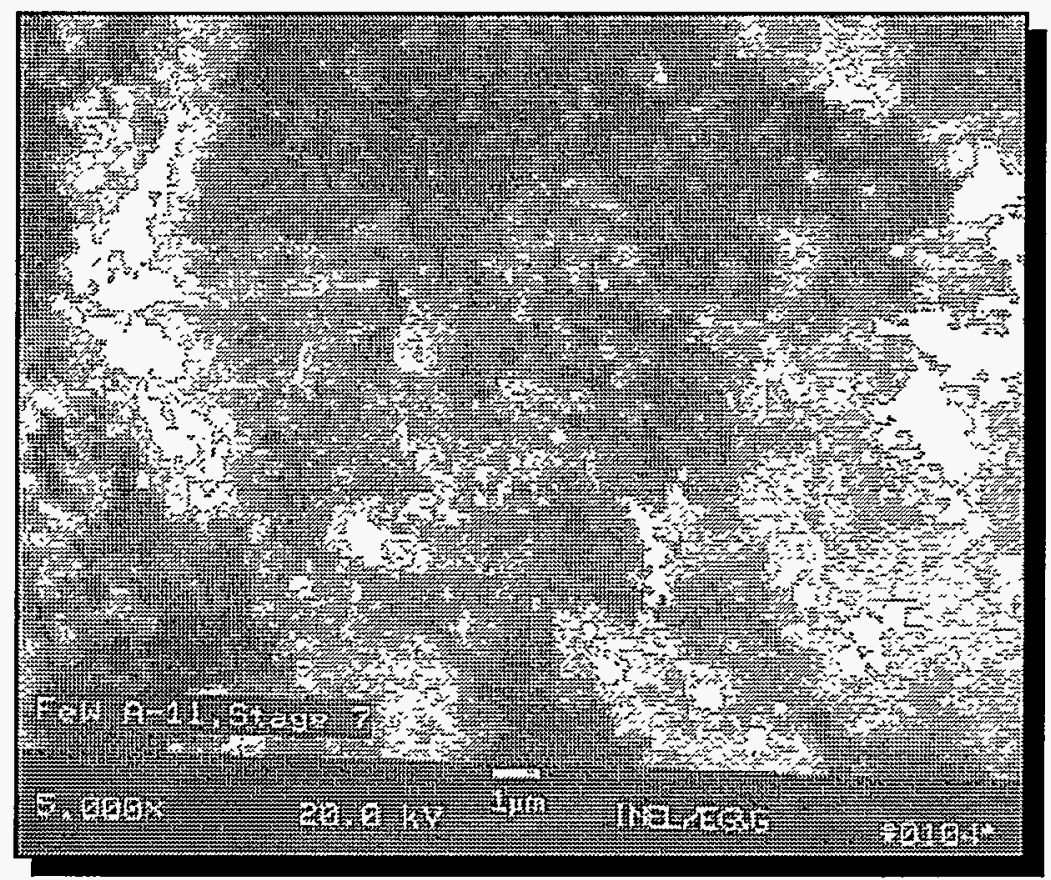

Figure 55. Magnification of Collection Plate Depicting Nonmetal Particulate. 
Table 17. Cascade Impactor, Particle Analysis, FeWA-11, Filter-1 Back Scattered Electron Image

Based on Standardless EDS Analysis ${ }^{a}$

\begin{tabular}{lcrccc}
\hline Element & Iine & $\begin{array}{l}\text { Weight } \\
\text { percent }\end{array}$ & $\begin{array}{l}\text { Atomic } \\
\text { percent }\end{array}$ & $\begin{array}{l}\text { Precision } \\
\text { 2-Sigma }\end{array}$ & K-ratioc \\
\hline $\mathrm{O}$ & $\mathrm{KA}$ & 37.88 & 57.04 & 1.80 & 0.1645 \\
$\mathrm{~F}$ & $\mathrm{KA}$ & 10.70 & 13.56 & 1.51 & 0.0242 \\
$\mathrm{Na}$ & $\mathrm{KA}$ & 8.73 & 9.15 & 0.57 & 0.0277 \\
$\mathrm{Al}$ & $\mathrm{KA}$ & 5.32 & 4.75 & 0.14 & 0.0266 \\
$\mathrm{Si}$ & $\mathrm{KA}$ & 6.09 & 5.23 & 0.26 & 0.0365 \\
$\mathrm{~K}$ & $\mathrm{KA}$ & 0.46 & 0.28 & 0.05 & 0.0038 \\
$\mathrm{Ca}$ & $\mathrm{KA}$ & 2.82 & 1.70 & 0.08 & 0.0253 \\
$\mathrm{Cr}$ & $\mathrm{KA}$ & 0.00 & 0.00 & 0.00 & 0.0000 \\
$\mathrm{Fe}$ & $\mathrm{KA}$ & 10.16 & 4.38 & 0.19 & 0.0946 \\
$\mathrm{Zn}$ & $\mathrm{KA}$ & 6.66 & 2.46 & 0.25 & 0.0589 \\
$\mathrm{~W}$ & $\mathrm{IA}$ & 9.65 & 1.26 & 0.44 & 0.0715 \\
$\mathrm{~Pb}$ & $\mathrm{MA}$ & 1.53 & 0.18 & 0.49 & 0.0105 \\
Total & & 100.00 & & & \\
Iterations & & 12 & & & \\
& & & & & \\
\hline
\end{tabular}

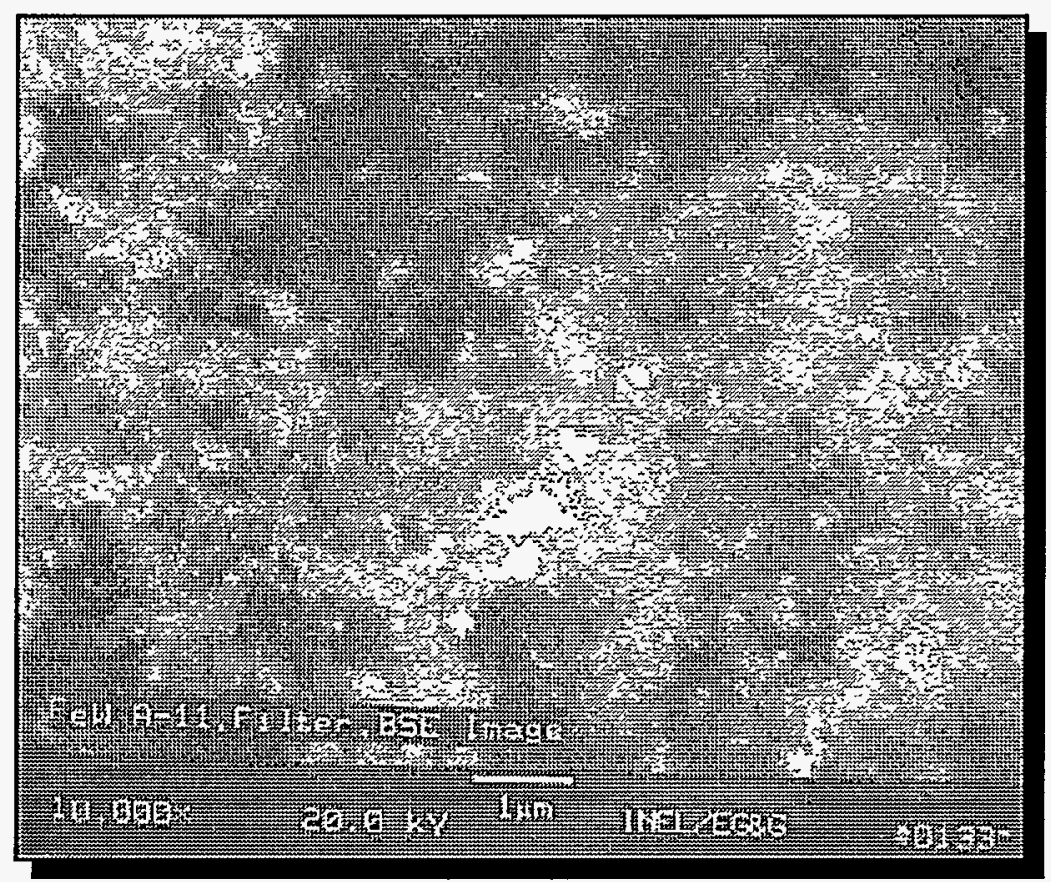

Figure 56. Magnification of Collection Plate Depicting Surrogate Alloy Particulate. 
Table 18. Cascade Impactor, Particle Analysis, FeWA-11, Filter-2 Foreward Scattered Electron Image

Based on Standardless EDS Analysis

\begin{tabular}{|c|c|c|c|c|c|}
\hline Element & Line & $\begin{array}{l}\text { Weight } \\
\text { percent }\end{array}$ & $\begin{array}{l}\text { Atomic } \\
\text { percent }\end{array}$ & $\begin{array}{l}\text { Precision } \\
\text { 2-Sigma }\end{array}$ & K-ratioc \\
\hline 0 & $\mathrm{KA}$ & 38.56 & 51.07 & 2.20 & 0.1675 \\
\hline $\mathrm{F}$ & $\mathrm{KA}$ & 16.82 & 18.76 & 1.23 & 0.0352 \\
\hline $\mathrm{Na}$ & $\mathrm{KA}$ & 12.43 & 11.46 & 0.42 & 0.0398 \\
\hline A.1 & $\mathrm{KA}$ & 5.96 & 4.68 & 0.12 & 0.0287 \\
\hline $\mathrm{Si}$ & $\mathrm{KA}$ & 11.04 & 8.33 & 0.14 & 0.0638 \\
\hline $\mathrm{K}$ & $\mathrm{KA}$ & 0.62 & 0.34 & 0.04 & 0.0053 \\
\hline $\mathrm{Ca}$ & $\mathrm{KA}$ & 3.48 & 1.84 & 0.07 & 0.0317 \\
\hline $\mathrm{Cr}$ & $\mathrm{KA}$ & 0.04 & 0.02 & 0.02 & 0.0004 \\
\hline $\mathrm{Fe}$ & $\mathrm{KA}$ & 2.45 & 0.93 & 0.09 & 0.0223 \\
\hline $\mathrm{Zn}$ & $\mathrm{KA}$ & 7.67 & 2.49 & 0.22 & 0.0665 \\
\hline $\mathrm{Pb}$ & $\mathrm{MA}$ & 0.94 & 0.10 & 0.10 & 0.0066 \\
\hline Total & & 100.01 & & & \\
\hline Iterations & & 12 & & & \\
\hline
\end{tabular}

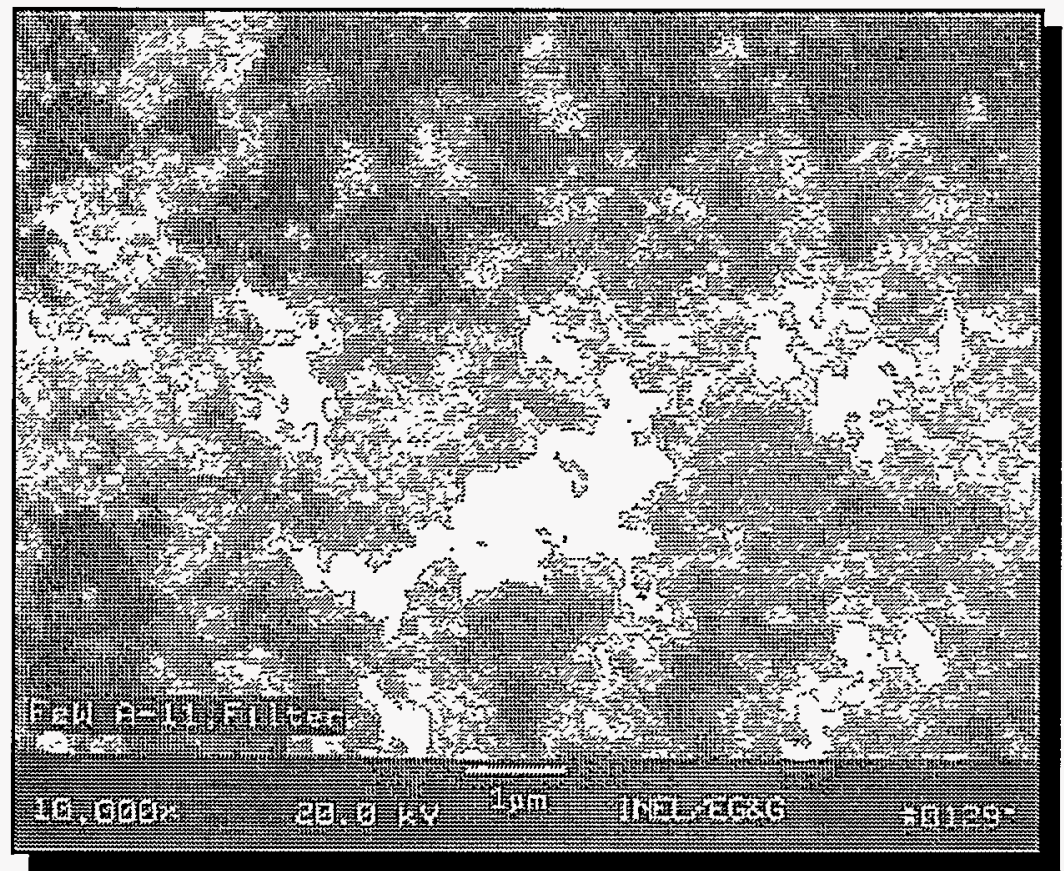

Figure 57. Magnification of Collection Plate Depicting Nonmetal Particulate. 
APPENDIX C: SPRAY TRIAL DATA 


\section{APPENDIX C SPRAY TRIAL DATA}

Metallurgical data and photomicrographs representative of the spray trials conducted during the Extended Surrogate Alloy Experiments are presented in Appendix C.

Tables 19 and 20 display summary information specific to the spray parameters for each spray trial. Figures 58 through 67 illustrate the microstructure identified in other areas examined in the thick deposit produced during Spray Trial 8.

Source: Photomicrographs represented in Appendix C Figures reprinted with permission from EG\&G Idaho, Inc. 
Table 19. Parametric Summary - Spray Trials 1-6

Based on Extended Surrogate Alloy Experiments

\begin{tabular}{lcccc}
\hline Spray & Argon & Argon & Furnace & Substrate \\
Period & (psia) & $\left({ }^{\circ} \mathrm{C}\right)$ & $\left({ }^{\circ} \mathrm{C}\right)$ & $\left({ }^{\circ} \mathrm{C}\right)$ \\
\hline
\end{tabular}

Spray Trial 1

\begin{tabular}{|c|c|c|c|c|c|}
\hline 1 & 18 & 1400 & 1705 & & 350 \\
\hline 2 & 22 & 1372 & 1705 & & 500 \\
\hline 3 & 28 & 1304 & 1705 & & 600 \\
\hline \multicolumn{6}{|c|}{ Spray Trial 2} \\
\hline 1 & 36 & 1239 & 1750 & 396 & -954 \\
\hline \multicolumn{6}{|c|}{ Spray Trial 3} \\
\hline 1 & 17.5 & 1433 & 1717 & & 365 \\
\hline 2 & 22 & 1362 & 1782 & & 420 \\
\hline 3 & 27 & 1315 & 1809 & & 653 \\
\hline 4 & 29 & 1275 & 1823 & & 687 \\
\hline 5 & 31 & 1249 & 1865 & & 842 \\
\hline 6 & 39 & 1172 & 1893 & & 364 \\
\hline \multicolumn{6}{|c|}{ Spray Trial 4} \\
\hline 1 & 46 & 1181 & 1735 & 552 & -856 \\
\hline 2 & 40 & 1140 & 1800 & & 392 \\
\hline
\end{tabular}

Spray Trial 5

\begin{tabular}{|c|c|c|c|c|}
\hline 1 & $16-24$ & 1250 & 1750 & NA \\
\hline 2 & $16-24$ & 1250 & 1750 & $N A$ \\
\hline 3 & $16-24$ & 1250 & 1750 & NA \\
\hline 4 & $16-24$ & 1250 & 1750 & $\mathrm{NA}$ \\
\hline 5 & $16-24$ & 1250 & 1750 & NA \\
\hline \multicolumn{5}{|c|}{ Spray Trial 6} \\
\hline 1 & $22-30$ & 1260 & 1748 & NA \\
\hline 2 & $19-25$ & 1199 & 1748 & $N A$ \\
\hline
\end{tabular}


T20APPC.CST

Table 20. Parametric Summary - Spray Trials 7-10

Based on Extended Surrogate Alloy Experiments

\begin{tabular}{lcccc}
\hline $\begin{array}{l}\text { Spray } \\
\text { Period }\end{array}$ & Argon & Argon & Furnace & Substrate \\
& $($ psia) & $\left({ }^{\circ} \mathrm{C}\right)$ & $\left({ }^{\circ} \mathrm{C}\right)$ & $\left({ }^{\circ} \mathrm{C}\right)$ \\
\hline
\end{tabular}

\section{Spray Trial 7}

Data for Spray Trial 7 Not Reduced

Spray Trial 8

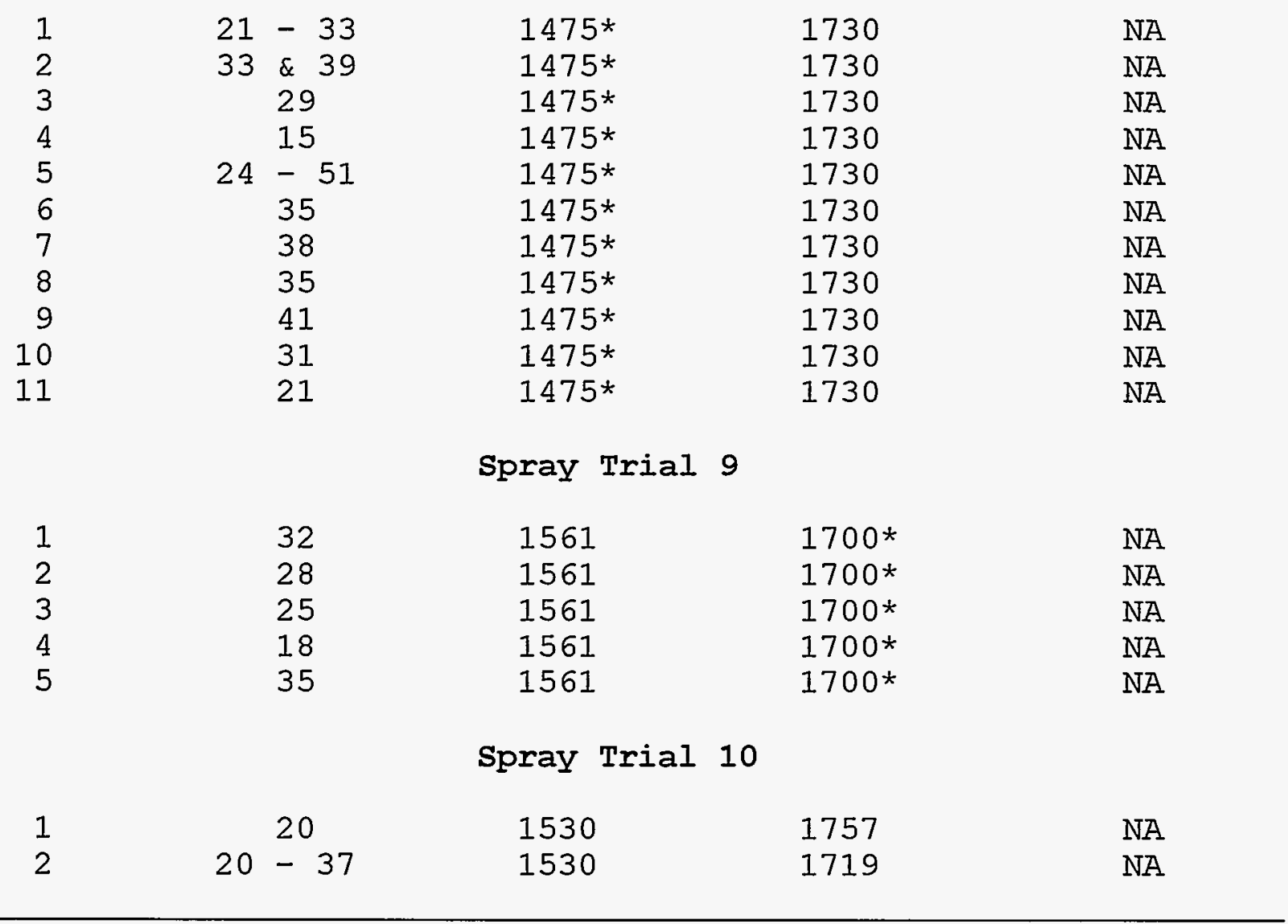

*Asterisk denotes estimated temperature. 


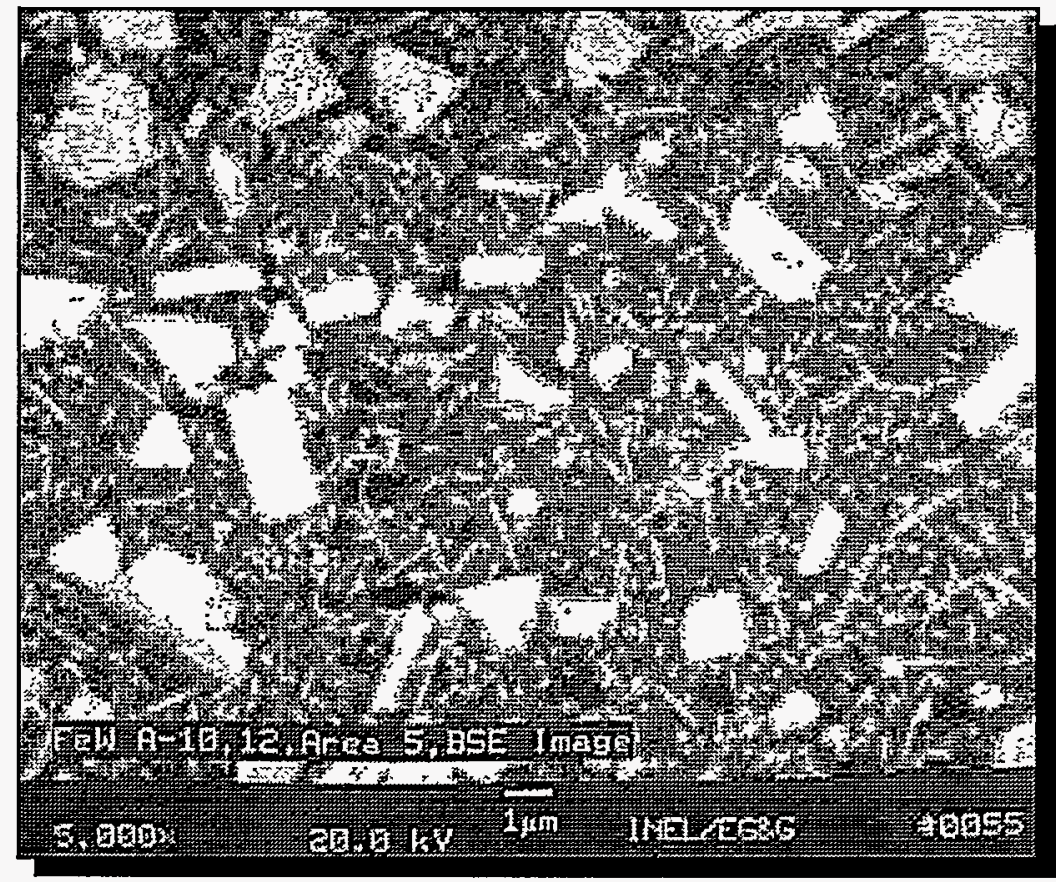

Figure 58. Spray Trial 8, Period 11, Area 5 (Sect. 5.5.3).

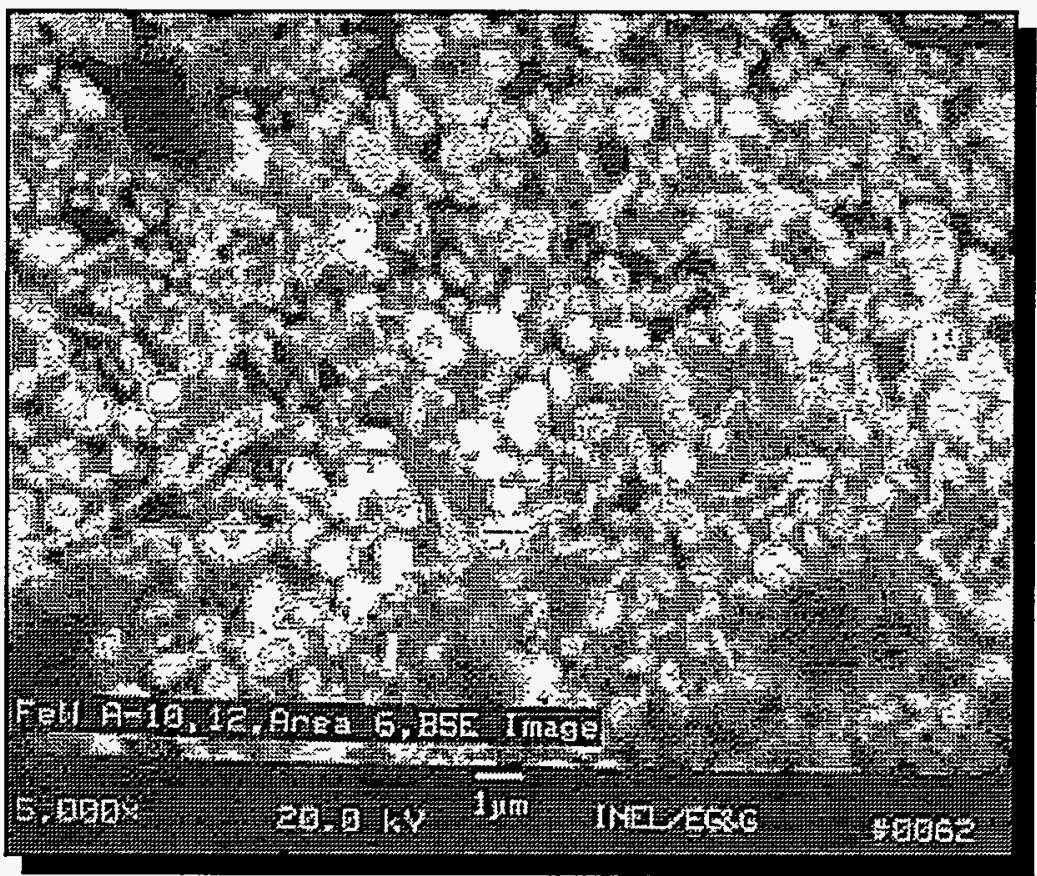

Figure 59. Spray Trial 8, Period 11, Area 6 (Sect. 5.5.3). 


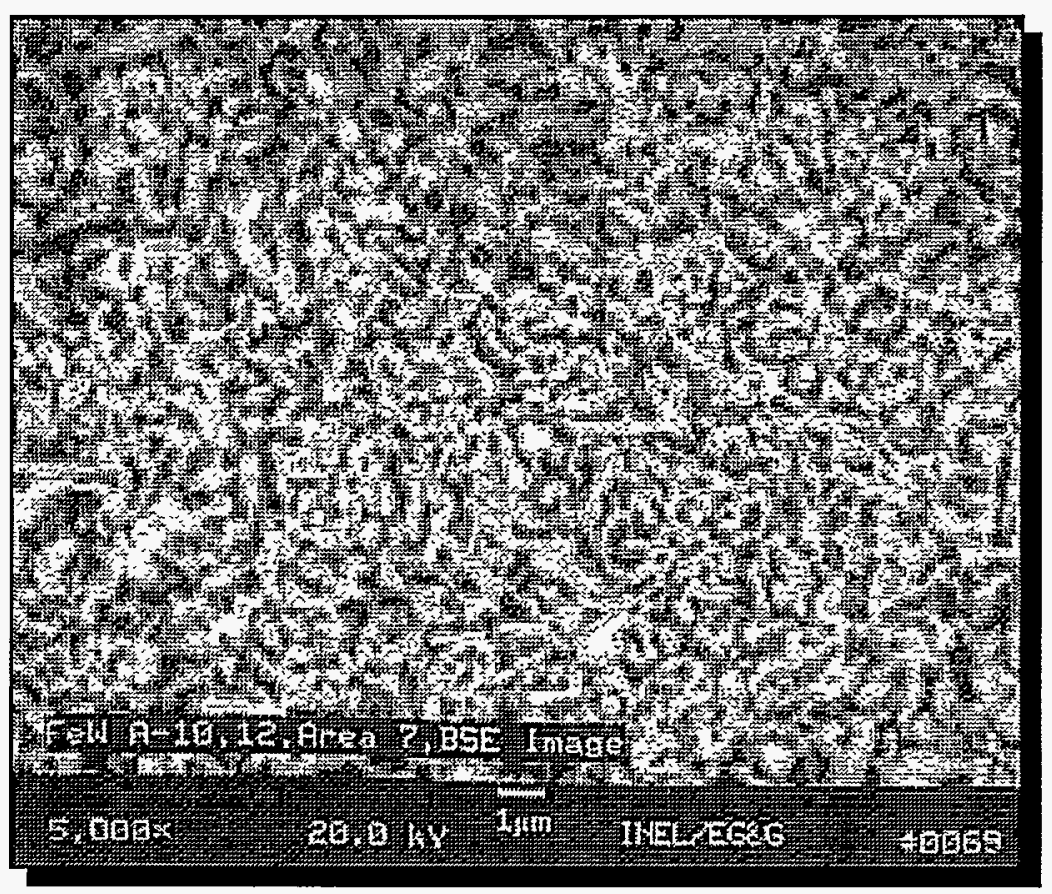

Figure 60. Spray Trial 8, Period 11, Area 7 (Sect. 5.5.3).

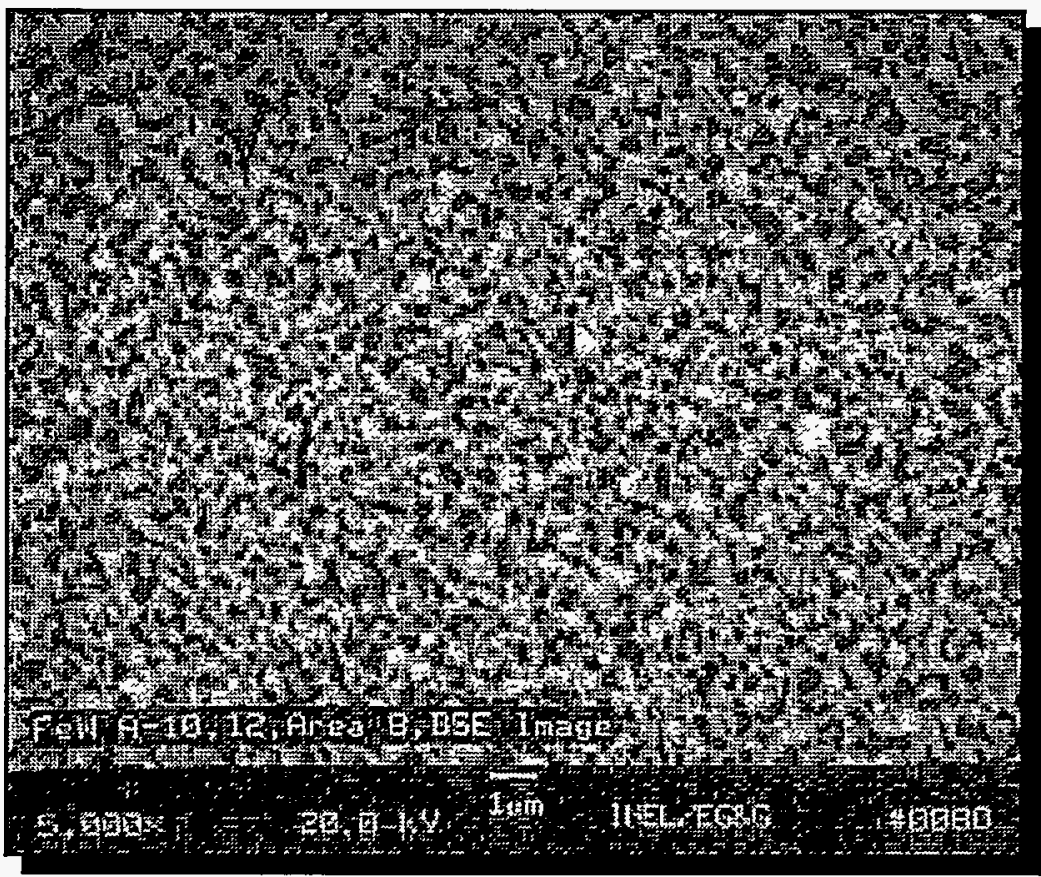

Figure 61. Spray Trial 8, Period 11, Area 8 (Sect. 5.5.3). 


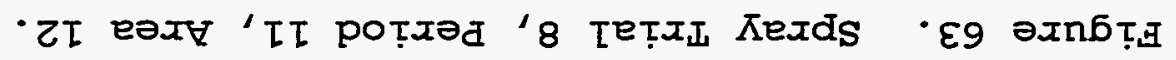

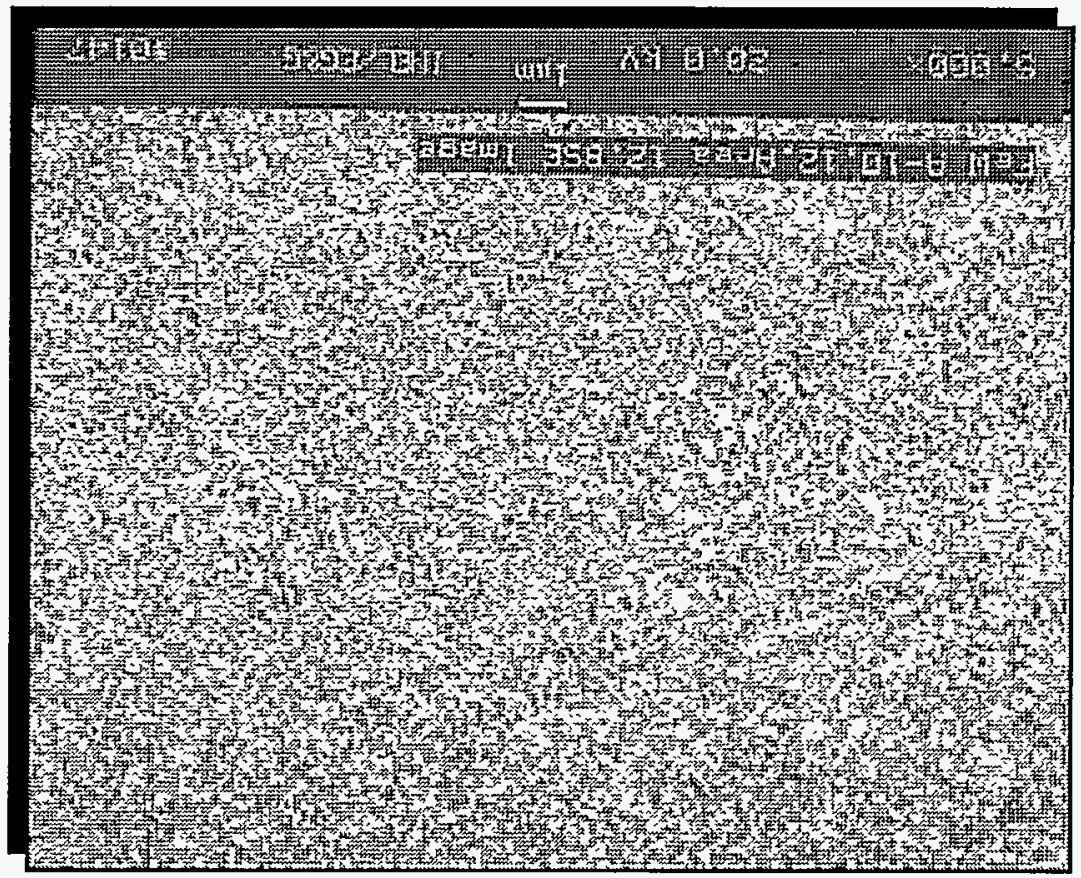

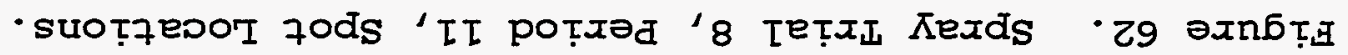

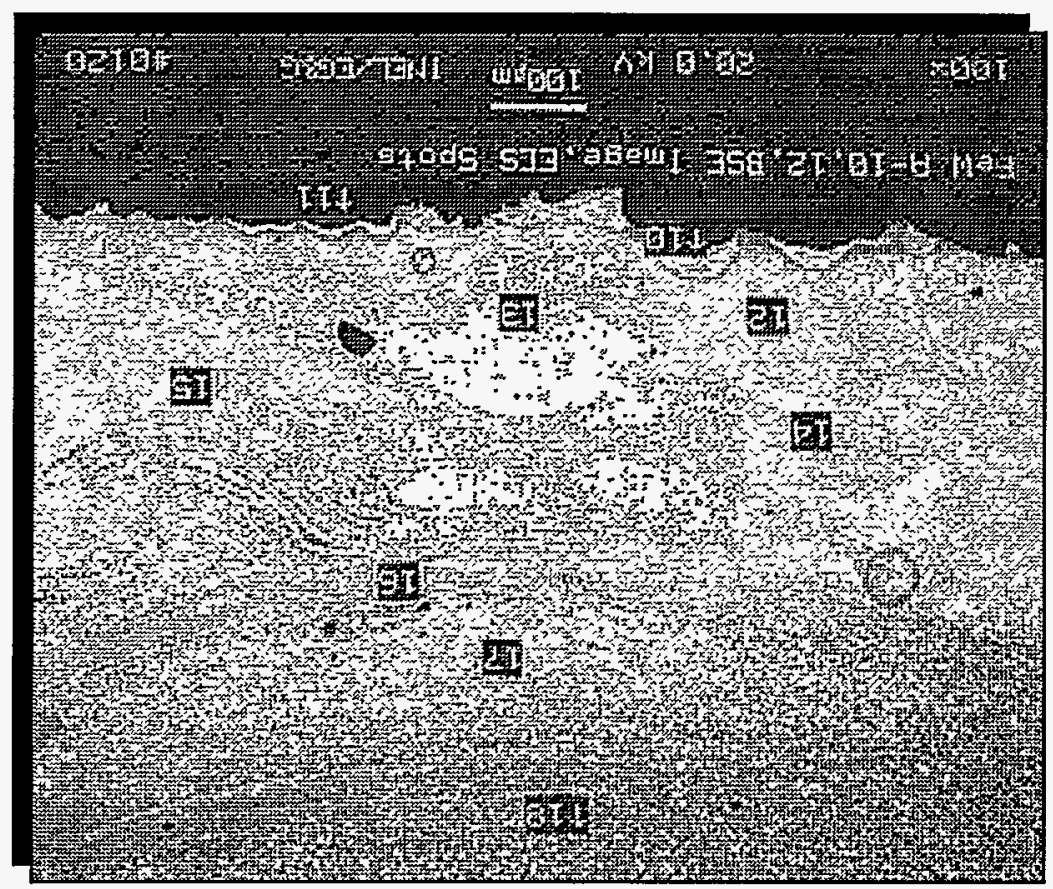




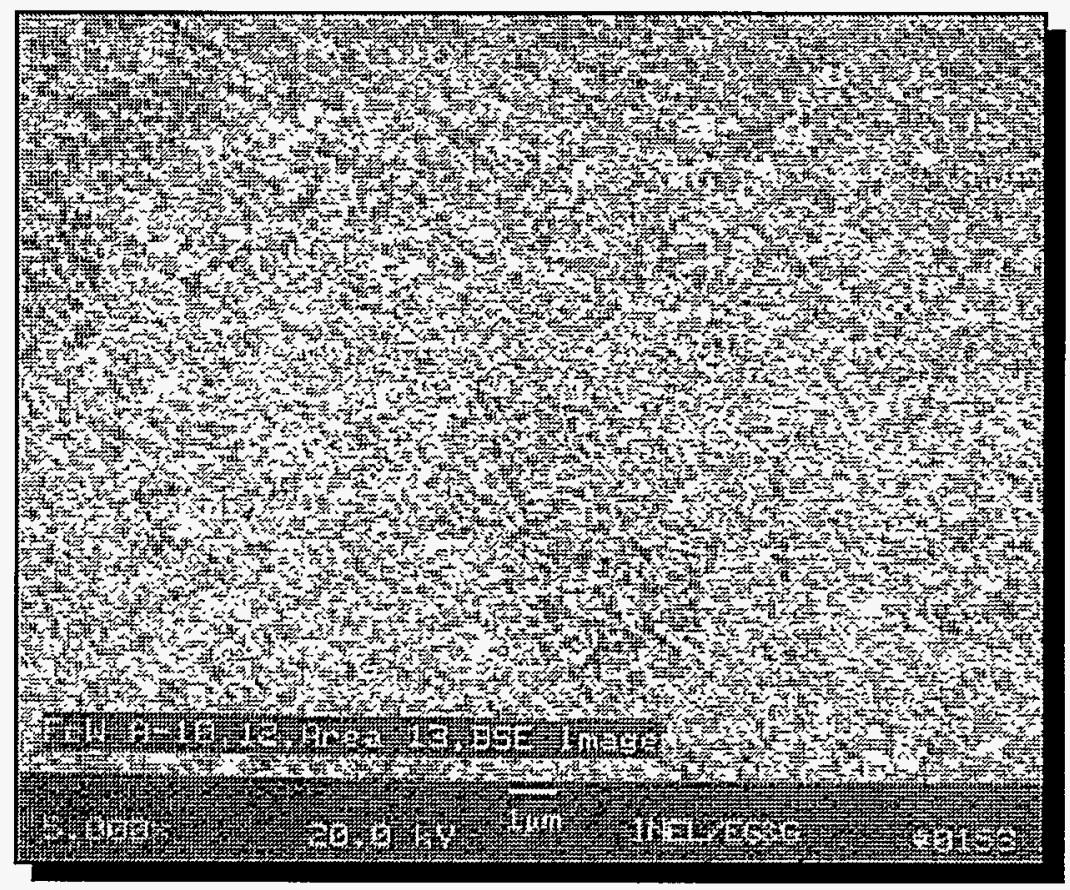

Figure 64. Spray Trial 8, Period 11, Area 13.

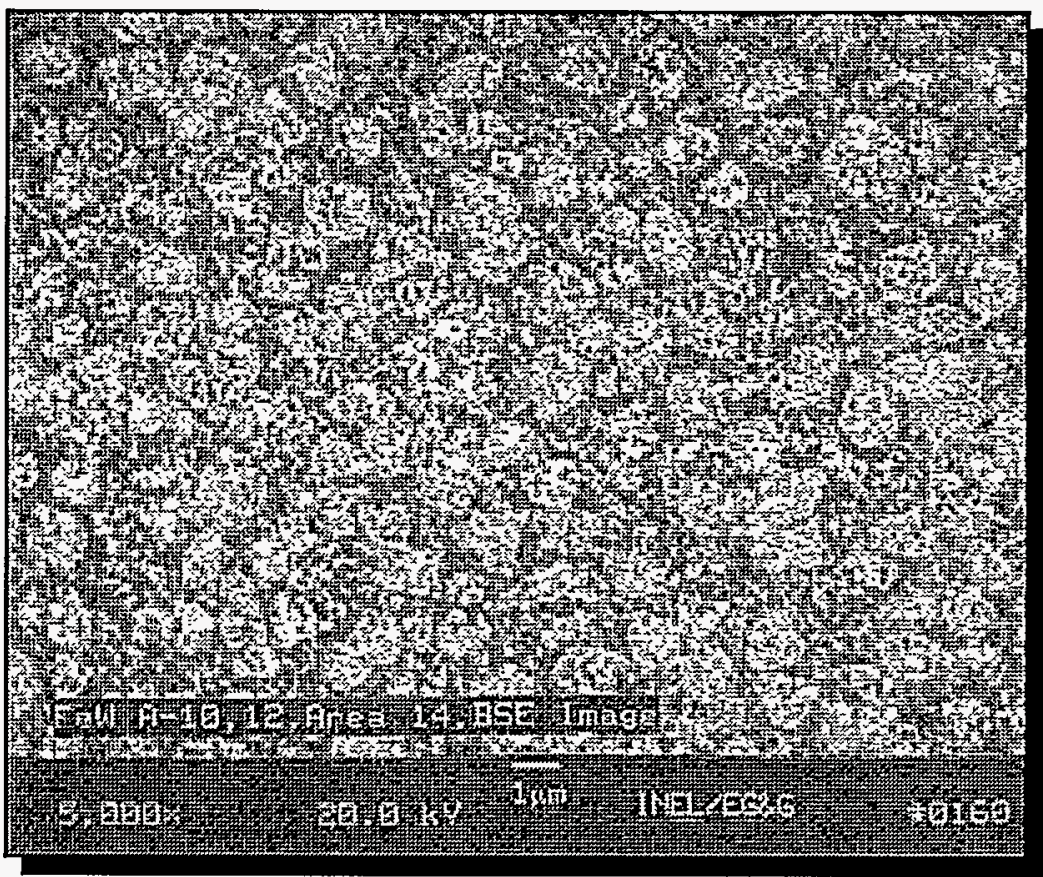

Figure 65. Spray Trial 8, Period 11, Area 14. 


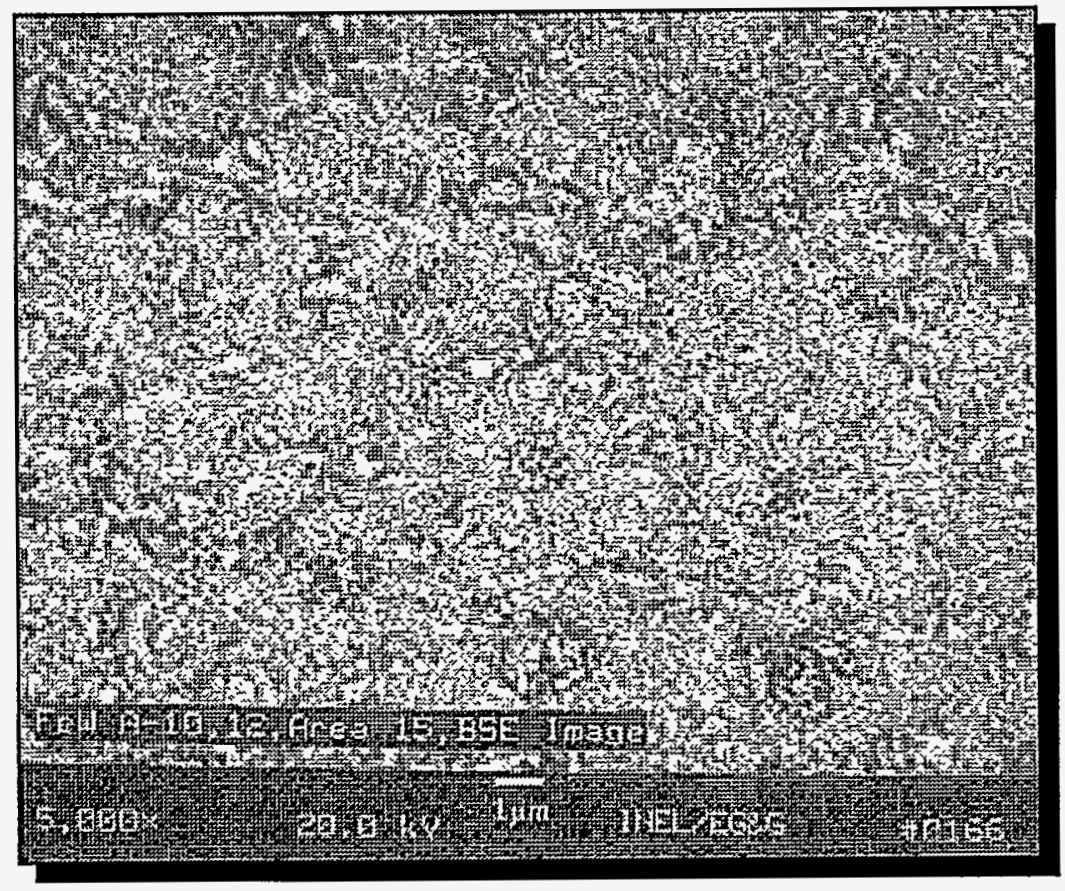

Figure 66. Spray Trial 8, Period 11, Area 15.



Figure 67. Spray Trial 8, Period 11, Area 16. 


\section{DISTRIBUTION}

P. B. Blacker, IITCO

S. R. Churnetski, MMES (4)

R. J. Glovan, MSE (2)

J. I. Harness, DOE-ORO

A. B. Johnson, DOE-HQ (2)

R. D. Korynta, DOE-ORO

A. P. Malinauskas, MMES

D. V. Miley, LITCO

J. O. Moore, DOE-ORO

R. G. Neal, MMES

J. L. Sharp, MMES

J. E. Thompson, MMES (4)

P. R. Trudel, DOE-ID

L. D. Watson, CST (MF)

A. K. Lee, DOE OSTI (2)

Y-12 Central Files (RC) 